$$
\begin{aligned}
& \text { UNIVERSIDADE DE SÃO PAULO } \\
& \text { INSTITUTO DE GEOCIÊNCIAS }
\end{aligned}
$$

\title{
CARACTERIZAÇÃO TAFONÔMICA E ESTRATIGRÁFICA DE Cloudina lucianoi (BEURLEN \& SOMMER, 1957) ZAINE \& FAIRCHILD, 1985, NO GRUPO CORUMBÁ, EDIACARANO DO SUDOESTE DO BRASIL
}

\section{Felipe van Enck Meira}

Orientador: Prof. Dr. Thomas Rich Fairchild

$$
\text { DISSERTAÇÃO DE MESTRADO }
$$

Programa de Pós-graduação em Geoquímica e Geotectônica

São Paulo 


\title{
UNIVERSIDADE DE SÃO PAULO \\ INSTITUTO DE GEOCIÊNCIAS
}

\section{CARACTERIZAÇÃO TAFONÔMICA E ESTRATIGRÁFICA DE Cloudina lucianoi (BEURLEN \& SOMMER, 1957) ZAINE \& FAIRCHILD, 1985, NO GRUPO CORUMBÁ, EDIACARANO DO SUDOESTE DO BRASIL}

\section{Felipe van Enck Meira}

\author{
Dissertação apresentada ao Programa \\ de Pós-Graduação em Geoquímica e \\ Geotectônica do Instituto de Geociências \\ da Universidade de São Paulo, como \\ parte dos requisitos para a obtenção do \\ título de mestre.
}

Orientador: Prof. Dr. Thomas Rich Fairchild

\section{DISSERTAÇÃO DE MESTRADO}

Programa de Pós-graduação em Geoquímica e Geotectônica

São Paulo 
Ficha catalográfica preparada pelo Serviço de Biblioteca e Documentação do Instituto de Geociências da Universidade de São Paulo

Meira, Felipe van Enck

Caracterização tafonômica e estratigráfica de Cloudina lucianoi (Beurlen \& Sommer, 1957) Zaine \& Fairchild, 1985, no Grupo Corumbá, Ediacarano do sudoeste do Brasil / Felipe van Enck Meira. - São Paulo, 2011

103 p.: il + 3 anexos

Dissertação (Mestrado) : IGc/USP

Orient.: Fairchild, Thomas Rich

1. Mato Grosso do sul: Tafonomia 2. Brasil: Cloudina 3. Grupo Corumbá I. Título 
"Uma mudança deixa sempre patamares para uma nova mudança." Niccolo Maquiavel A todos aqueles que, desde o princípio, torceram e acreditaram em mim. 


\section{Agradecimentos}

Em primeiro lugar, gostaria de agradecer à experiência que vivi nestes três anos de Mestrado, que apesar das dificuldades, me proporcionaram muito amadurecimento, profissional quanto pessoal. Não há palavras para traduzir a importância dessa experiência em minha vida, e que pretendo carregar para sempre.

Ao Prof. Dr. Thomas Rich Fairchild pela orientação, especialmente nas etapas finais da dissertação. Agradeço a ele também por todos os ensinamentos passados nestes quase 15 anos de contato.

À minha família, especialmente meus pais, José Carlos e Sylvia, e minha irmã, Patrícia, pelo carinho, compreensão e apoio durante este processo.

À Evelyn Aparecida Mecenero Sanchez Bizan e Guilherme Raffaeli Romero, pela ajuda e apoio de extrema importância, sem os quais não conseguiria finalizar este trabalho.

À Erika Paula Machado Peixoto, com quem tive o prazer de compartilhar muitos momentos importantes de minha vida.

Aos inestimáveis amigos que fiz ao longo destes três anos, em meio às correrias, sucessos e frustrações do dia-a-dia: Mírian Liza Alves Forancelli Pacheco, Wilson Soares Júnior, Cléber Pereira Calça, Giselle Utida, Paula Sucerquia Rendón, Rejane Rocha, Johanna Mendez Duque, Angela Meira Faleiros, José Eduardo Sartori, John Rico Bautista, Luis Gustavo Viegas, Geane Carolina Cavalcante, Nívea Magalhães, Antonio Paranhos Filho, Silas Gubitoso, Andreia Teodoro, Aline Ghilardi, Luana Soares, Victor Soficier Badaró, Alexandra Aguja, Carlos Mario, Oscar Romero, Emiliano Oliveira, Gabriela Fontaneta, Lucas Warren e Fernanda Quaglio.

Aos amigos que fiz durante a graduação, principalmente Paulo Gustavo Rossi, Fernanda Navarro Sonim, Maithê Wanzo Hohl e Daniel Tadeu Espinha.

Aos professores doutores José Maurício Piliackas, Maria da Graça Salomão, Paulo César Boggiani, Juliana de Moraes Leme, Marcos Egydio da 
Silva, Edilson Pissato, Wânia Duleba, Setembrino Petri, Antônio Carlos RochaCampos e Oswaldo Siga Júnior, que por meio de conversas, reflexões e aulas, contribuíram à minha formação profissional e pessoal.

Ao Sr. Ulrich Schwair, pelas conversas esclarecedoras, e pela ajuda na tradução de artigos em alemão, necessários para este trabalho.

A todos os funcionários do IGc-USP que, de algum modo, colaboraram para este trabalho, em especial à Zefinha, Ivone Cardoso, Isaac Jamil Sayeg, Tadeu, Magali Poli e Ana Paula Cabanal.

Ao CNPq (processo número 135500/2008-7), pela concessão de bolsa de estudos junto ao Programa de Pós-graduação em Geoquímica e Geotectônica do IGc-USP. Também agradeço ao Prof. Dr. Paulo César Boggiani, por me incluir em seu projeto "Isótopos estáveis (C,O e Sr) do Grupo Itapucumi e correlações com o Grupo Corumbá (Ediacarano)", financiado pela FAPESP (processo número 2010-02677-0), o permitiu a realização de atividades ligadas ao estudo.

Por último, mas não menos importante agradeço a Raphael Cangelli Filho, Maria Elizabeth Mendonça Alves, Jorge Gonçalves de Macedo, Fábio Salzano, Carolina Fonseca, Viviane Martins e Daniela Leal, por suas contribuições em diferentes fases de minha vida sendo, sem dúvida, responsáveis por quem sou hoje.

Obrigado! 


\section{RESUMO}

Estudos do fóssil-índice Cloudina Germs 1972, do Neo-ediacarano, representado no Brasil por Cloudina lucianoi (Beurlen \& Sommer) Zaine \& Fairchild 1985, foram realizados nos calcários da Formação Tamengo, Grupo Corumbá, SW Brasil, nas pedreiras de Saladeiro, Corcal e Laginha na região de Corumbá, MS. Cloudina foi encontrada em cinco fácies, previamente definidas por outros autores, na Formação Tamengo: grainstones oolíticos, calcários cristalinos maciços, packstones bioclasticos, ritmitos de mudstone calcífero/ folhelhos, e mudstones com Cloudina. Estas fácies foram depositadas numa variedade de contextos deposicionais numa rampa carbonática marcada por depósitos frequentes provocados por tempestades (representados pelos calcários cristalinos maciços e packstones bioclasticos) e caracterizada por bancos e baixios de ooides, que, em direção ao continente, protegiam um habitat calmo não apenas para Cloudina e esteiras microbianas e trombólitos associados, mas possivelmente para o outro metazoário na formação, Corumbella, também. Dentre as descobertas paleontológicas desta pesquisa, destacam-se duas: 1) Uma espécie nova de Cloudina, C. latilabrum nov. sp., caracterizada por seu diâmetro estreito e extensas abas finas partindo da borda distal dos segmentos sucessivos que constituem a concha; 2) A coexistência de fragmentos de colônias de cianobactérias e intraclastos tromboíticos com conchas de Cloudina, uma ocorrência coerente com a bem conhecida associação Cloudina-trombólitos, presente em Namíbia, Canadá e Omã. Fósseis de Cloudina são fragmentos em sua grande maioria, em razão dos processos de transporte, mas espécimes da nova espécie, aparentemente inteiros, e possivelmente autóctones, foram observados na fácies de mudstones com Cloudina, e espécimes quase completos constitutem um tempestito na forma de coquinito (packstone bioclástico). A contribuição estratigráfica mais importante desta pesquisa foi a descoberta de Cloudina na Formação Guaicurus, acima da Formação Tamengo, descoberta esta que estende a biozona de Cloudina até quase o topo do Grupo Corumbá.

Palavras-chave: Cloudina - Grupo Corumbá - Mato Grosso do Sul Tafonomia - Brasil 


\section{ABSTRACT}

New studies of the late Ediacaran index fossil Cloudina Germs 1972, as represented in Brazil by Cloudina lucianoi (Beurlen \& Sommer) Zaine \& Fairchild 1985, were carried out in the limestones of the Tamengo Formation, Corumbá Group, SW Brazil, in the Saladeiro, Corcal and Laginha quarries near Corumbá, MS. Cloudina was found in five facies of this formation previously defined for this region: ooid grainstones, massive crystalline limestone, bioclastic packstones, calciferous mudstone / shale rhythmites, and mudstones with Cloudina. These facies were deposited in a variety of depositional settings on a carbonate ramp marked by frequent storm deposits (represented by the massive crystalline limestone and bioclastic packstone facies) and characterized by banks and shoals of ooid grainstones that landward provided a calm protected habitat not only for Cloudina and associated microbial mats and thrombolites, but also possibly for Corumbella as well. Paleontological discoveries of this research include: 1 ) a new species of Cloudina, C. latilabrum nov. sp., characterized by narrow diameter and flanges flaring outward from the distal borders of successive segments of the shell; 2) fragments of cyanobacterial colonies and thrombolitic intraclasts together with shells of Cloudina, an occurrence consistent with the well-known Cloudina-thrombolite association of Nambia, Canada, and Oman. Fossils of Cloudina are mostly fragmented as the result of transport, but apparently whole, possibly autochthonous specimens of the new species were observed in the mudstone facies, and nearly complete specimens comprise a coquinite storm deposit (bioclastic packstones). The most important stratigraphic contribution of the present research is the discovery of Cloudina in the Guaicurus Formation overlying the Tamengo Formation, thereby extending the Cloudina biozone almost to the top of the Corumbá Group.

Key-words: Cloudina - Corumbá Group - Mato Grosso do Sul - Taphonomy Brazil 


\section{LISTA DE FIGURAS}

Figura 1. A) Eletromicrografia de concha silicificada de Cloudina hartmannae, da

Formação Dengying, China, na qual se pode notar o encaixe de sucessivos segmentos formando a estrutura, e a porção basal oclusa, típicas do gênero. Escala representa $280 \mu \mathrm{m}$. Extraído de Chen et al. (2008). B) Reconstituição da concha em corte longitudinal. B) Reconstituição da concha em corte longitudinal. Os septos internos transversais, presentes na imagem original, extraída de Seilacher (1999), foram retirados aqui, uma vez que esta concepção foi refutada por Hua et al. (2005) em análise de fósseis fosfatizados da Formação Dengying, China.

Figura 2.1.1. Principais eventos que marcaram o final do Neoproterozoico. Modificado de Walter \& Heys (1985), Narbonne (2005) e Marshall (2006).

Figura 2.1.2. Fósseis ediacaranos. A) Eletromicrografia de embrião de metazoário permineralizado por fosfato, com 16 células. Formação Doushantuo, China (extraído de Hagadorn et al. 2006); B) Eletromicrografia de Ramitubus increscens Liu et al., 2008, possível cnidário da Formação Doushantuo, China (extraído de Liu et al. 2008); C) Rangeomorfo da Formação Trepassey, Inglaterra (extraído de Narbonne 2004); D) Kimberella quadrata Wade, 1968, possível molusco da Formação Ust Pinega, Rússia (extraído de Fedonkin \& Waggoner 1997); E) Archaeonassa, icnito da Formação Ust Pinega, Rússia (extraído de Jensen 2003); F) O metazoário conchífero Namacalathus hermanastes Grotzinger et al., 2000, Subgrupo Kuibis, Namíbia (extraído de Grotzinger et al. 2000). Escalas representam $200 \mu \mathrm{m}$ em A e B; $2,5 \mathrm{~mm}$ em C; e $1 \mathrm{~cm}$ em D, E e F.

Figura 2.2.1. Diagramas das principais influências no substrato marinho na transição Ediacarano-Cambriano, e após o Cambriano. Notar a gradual redução na influência microbiana, e progressiva participação de metazoários. Extraído de Bottjier et al. (2000).

Figura 2.2.2. Conchas de Cloudina hartmannae e com perfurações, indicadas pelas setas, interpretadas como resultado de predação. Notar brotamento em B. Escalas representam $250 \mu \mathrm{m}$ em A, $150 \mu \mathrm{m}$ em B e $350 \mu \mathrm{m}$ em C. Modificado de Hua et al. (2003).

Figura 3.1.1. Distribuição do gênero Cloudina no mundo. 
Figura 3.1.2. Estratigrafia das sub-bacias Zaris e Witputs, Grupo Nama, Namíbia, mostrando a distribuição dos metazoários conchíferos, incluindo Cloudina, juntamente com as datações em tufos vulcânicos e a ocorrência do icnogênero Treptichnus pedum. Extraído de Grotzinger et al. (2000). O posicionamento de T.pedum foi baseado em dados de Grotzinger et al. (1995).

Figura 3.2.1. Reconstituição esquemática de Cloudina proposta por Germs (1972) e Glaessner (1976). Notar as corrugações na superfície externa da concha, e a parede interna lisa. Extraído de Glaessner (1976).

Figura 3.2.2. Deformação dúctil (A) em Cloudina hartmannae do Grupo Ara, Omã; e deformação rúptil (B) em Cloudina riemkeae do Grupo Nama, na Namíbia. Escala representa $700 \mu \mathrm{m}$ em (A) e $180 \mu \mathrm{m}$ em (B). Extraído de Conway Morris (1990) (A) e Grant (1990) (B).

Figura 3.2.3. Esquema de sucessivos cortes oblíquos em Cloudina (A) que poderiam dar a impressão de se tratarem de aparentes septos transversais, como ilustrado em (B) por Grant (1990). Extraído de Hua et al. (2005) (A) e de Grant (1990) (B).

Figura 3.2.4. Evidência de brotamento em Cloudina hartmannae, Formação Dengying, China. Escala: 400 m. Extraído de Hua et al. (2005).

Figura 4.1.1. Mapa geológico da Faixa Paraguai (A), e da área de estudo (B). Em $B$, os círculos amarelos correspondem às pedreiras enfocadas no presente trabalho: $\mathrm{S}$ Pedreira Saladeiro; C - Pedreira Corcal; L - Pedreira Laginha. (A) Adaptado de Alvarenga et al. (2000) e Boggiani et al. (2010). (B) Adaptado de Oliveira (2010).

Figura 6. Colunas estratigráficas das pedreiras estudadas. Extraídas de Boggiani et al. (2010). A estratigrafia da Pedreira Corcal foi baseada em T.R. Fairchild (com. pess.).

Figura 6.1. Frequência de diâmetros de Cloudina lucianoi na amostra 6219, da fácies packstone bioclástico, Pedreira Saladeiro. $\mathrm{N}=105$; amplitude de classes $=0,4 \mathrm{~mm}$.

Figura 6.2. Frequência de diâmetros de Cloudina lucianoi nas lâminas petrográficas GP/L1E-10 a GP/L1E-20, da fácies packstone bioclástico, Pedreira Corcal. N = 157; amplitude de classes $=0,3 \mathrm{~mm}$. 


\section{LISTA DE TABELAS}

Tabela 1. Principais organismos associados à biozona de Cloudina, segundo Zaine \& Fairchild (1987), Zaine (1991), Grotzinger et al. (1995, 2000), Amthor et al. (2003), Gaucher et al. (2003), Hua et al. (2007) e o presente trabalho. Vale ressaltar que, embora o microfóssil Bavlinella faveolata também ocorra em depósitos paleozoicos (Vidal 1976), sua presença como principal componente em assembleias microfossilíferas caracteriza o final do Ediacarano (Germs et al. 1986; Palacios 1989).

Tabela 2. Resumo esquemático da estratigrafia do Grupo Corumbá e Formação Puga no Estado do Mato Grosso do Sul, Brasil. Segundo Almeida (1965), Boggiani (1998), Gaucher et al. (2003), e o presente trabalho.

Tabela 3. Esquema das fáceis e associações de fáceis da Formação Tamengo aflorantes na região de Corumbá. Extraído de Oliveira (2010).

Tabela 4. Fácies das formações Tamengo e Guaicurus contendo Cloudina na região de Corumbá, MS. Nome das fácies segundo Oliveira (2010), exceto packstones bioclásticos e mudstones com Cloudina, criadas no presente trabalho.

Tabela 5: Diâmetros de Cloudina lucianoi em amostras da fácies ritmitos mudstones / 44 folhelhos da Formação Tamengo. Frente oeste de lavra da Pedreira Laginha.

Tabela 6: Dimensões de Cloudina provenientes de amostra de calcilutito, Formação 50 Guaicurus, Pedreira Corcal. 


\section{LISTA DE PRANCHAS}

Prancha 1. Estruturas de origem sedimentar e fósseis da fácies ritmitos mudstones calcíferos / folhelhos, fotografadas em microscópio petrográfico (Nicóis paralelos). Pedreira Laginha, Formação Tamengo. A) Ooide normal (GP/L1E - 119), proveniente da frente oeste de lavra. Escala $=100 \mu \mathrm{m}$; B) Ooide bentônico (GP/L1E - 111), frente leste de lavra. Escala $=50 \mu \mathrm{m} ; C)$ Microfitólitos (GP/L1E - 108), frente leste de lavra. Notar bioclasto (Cloudina?) no canto superior direito da figura. Escala $=300 \mu \mathrm{m} ; \mathrm{D}$ ) Possível trombólito (GP/L1E - 115), frente leste de lavra. Escala $=200 \mu \mathrm{m} ; \mathrm{E}$ ) Agregado de células cocoidais (GP/L1E - 111), frente leste de lavra. Notar ooide bentônico no canto inferior esquerdo da figura. Escala $=50 \mu \mathrm{m}$; F) Cloudina com múltiplas fragmentações (GP/L1E - 111), frente leste de lavra. Escala $=200 \mu \mathrm{m} ; \mathrm{G}$ ) Bioclasto corrugado (GP/L1E - 110), frente leste de lavra. Escala $=200 \mu \mathrm{m} ; \mathrm{H}$ ) Detalhe da figura anterior. Escala $=50 \mu \mathrm{m}$; I) Seções transversais de Cloudina (GP/L1E - 109), frente leste de lavra. Notar preenchimento espático em fexemplar à esquerda da figura, e deformação rúptil em fóssil à direita. Escala $=200 \mu \mathrm{m} ; \mathrm{J}$ ) Seção transversal a oblíqua de Cloudina, exibindo abas evidentes (GP/L1E - 113), frente leste de lavra. Escala $=200 \mu \mathrm{m}$.

Prancha 2. Metazoários preservados na superfície de amostras de mão da fácies ritmitos mudstones calcíferos / folhelhos, frente oeste de lavra da Pedreira Laginha. Formação Tamengo. A) Seção transversal de Cloudina lucianoi (GP/1T-108). Escala $=1 \mathrm{~cm}$; B) Cloudina lucianoi e Corumbella werneri $(\mathrm{GP} / 1 \mathrm{~T}-109)$. Escala $=1 \mathrm{~cm} ; \mathrm{C})$ Detalhe de C. lucianoi da amostra anterior, exibindo espessamento em parte da parede da concha. Escala $=1 \mathrm{~mm}$; D) Detalhe de $C$. lucianoi de amostra ilustrada em A. Notar a ocorrência de dois anéis concêntricos, sendo o mais externo parcialmente visível. Escala $=1 \mathrm{~mm}$; E) Seção transversal incompleta de C. lucianoi $(\mathrm{GP} / 1 \mathrm{E}-6215)$. Escala $=1 \mathrm{~mm}$.

Prancha 3. Exemplares de Corumbella werneri em superfície de amostras de mão da fácies ritmitos mudstone calcífero / folhelho, frente oeste de lavra da Pedreira Laginha $(A-D)$, e em folhelhos da Pedreira Saladeiro (E e F). Formação Tamengo. Todas as escalas representam $1 \mathrm{~mm}$. A) GP/1E - 6213; B) GP/1E - 6212; C) GP /1E - 6211; D) GP/1E - 6214; E e F) GP/1E - 5760. 
Prancha 4. Fósseis e estruturas de origem sedimentar da fácies grainstones oolíticos.

Frente de oeste de lavra da Pedreira Laginha. Formação Tamengo. Lâminas petrográficas fotografadas em estereomicroscópio. Todas as escalas representam 1 $\mathrm{mm}$, exceto em A, que representa $5 \mathrm{~mm}$. A) Vista geral da lâmina GP/L1T - 1, evidenciando um exemplar de Cloudina com boa parte da extersão da concha preservada, além de bioclastos em meio a ooides, bem como servindo de nucleação para estes. B) Seção transversal de Cloudina, exibindo envelopamento (GP/L1E 26); C) Bioclasto com deformação dúctil, servindo de núcleo para ooide (GP/L1E 27); D) Bioclasto envelopado (GP/L1E - 32); E) Ooides com núcleo recristalizado (GP/L1E - 31).

Prancha 5. Cloudina em fácies de calcário maciço cristalino. Pedreira Saladeiro. Formação Tamengo. Lâminas petrográficas fotografadas em estereomicroscópio. Todas as escalas representam $1 \mathrm{~mm}$. A) Vista geral da lâmina GP/L1E - 21, onde se nota o empacotamento disperso a fraco dos bioclastos; Seções longitudinais (B) e transversal (C) em Cloudina (GP/L1E - 23).

Prancha 6. Packstones bioclásticos, provenientes da Pedreira Saladeiro. Formação Tamengo. As lâminas petrográficas (A - C; F) foram fotografadas em estereomicroscópio. A) Alternância entre níveis espáticos (claros), e níveis micríticos (escuros) na lâmina GP/L1E -45 . Escala $=1 \mathrm{~cm}$; B) Nível espático, exibindo fósseis com estrutura geopetal, e diferentes gerações de cimento (exemplar no canto superior) (GP/L1E - 8). Escala $=5 \mathrm{~mm}$; C) Seção transversal de Cloudina, apresentando delineamento poligonal. Notar estrutura geopetal neste fóssil, e fragmentos de concha no interior dos fósseis adjacentes (GP/L1E - 9). Escala $=1$ $\mathrm{mm}$. D) Superfície da amostra GP/1E - 6219, com conchas silicificadas, ressaltadas pelo intemperismo. Escala em centímetros; E) Superfície da amostra GP/1E - 3878, exibindo moldes internos de Cloudina. Escala $=1 \mathrm{~cm} ; \mathrm{F}$ ) Seção oblíqua a longitudinal de Cloudina latilabrum nov. sp. (GP/L1E - 24). Escala $=5 \mathrm{~mm}$.

Prancha 7. Cloudina formando packstones bioclásticos. Pedreira Corcal. Formação Tamengo. As lâminas petrográficas ( $B-D ; G$ e $H$ ) foram fotografadas em estereomicroscópio. A) Superfície da amostra GP/1E - 4143, exibindo fósseis preservados como moldes internos, densamente empacotados. Escala $=1 \mathrm{~cm} ; \mathrm{B}$ ) Seção longitudinal de Cloudina, com preenchimento espático, e deformação dúctil da concha (GP/L1E - 11). Escala = $1 \mathrm{~mm}$; C) Vista geral da lâmina GP/L1E - 17, evidenciando fósseis predominantemente paralelos ao acamamento, e estruturas geopetais, facilmente observáveis em exemplares no canto superior da figura. Escala = $5 \mathrm{~mm}$; D) Detalhe de seção transversal de Cloudina, com fragmento de concha no interior. Escala $=1 \mathrm{~mm}(\mathrm{GP} / \mathrm{L} 1 \mathrm{E}-17)$; E e F) Moldes internos na superfície da amostra GP/1E - 4119, apresentando diferentes gerações de cimento. 
Escala = $1 \mathrm{~mm}$; G) Seção transversal da lâmina GP/L1E - 14, com preservação reliquiar do segmento mais externo da concha. Escala $=1 \mathrm{~mm} ; \mathrm{H}$ ) Deformação dúctil em seção transversal (GP/L1E - 13). Escala $=1 \mathrm{~mm}$.

Prancha 8. Fácies de mudstones com Cloudina. Pedreira Corcal. Formação Guaicurus. Amostra GP/1E - 6216. Todas as escalas representam $1 \mathrm{~mm}$, exceto em $A$, que representa $1 \mathrm{~cm}$. A) Amostra de mão com fósseis em sua superfície; B) Detalhe de dois exemplares, com boa parte da extensão da concha preservada, em seção longitudinal; C) Cloudina exibindo inserção entre dois segmentos; D e E) Exemplares com abas visíveis.

Prancha 9. Fácies de mudstones com Cloudina. Arredores do Parque Marina Gattaz. Formação Tamengo. As lâminas petrográficas ilustradas em B e C foram fotografadas em estereomicroscópio. A) Superfície da amostra de mão GP/1E 6218, exibindo fósseis preferencialmente paralelos ao acamamento, mas sem direção preferencial em azimute. Escala em centímetros; B) Lâmina petrográfica (GP/L1E - 42) do perfil da amostra da figura anterior, exibindo contato erosivo entre mudstones na base e packstones, que por sua vez gradam para mudstones. Notar preenchimento espático dos fósseis. Escala $=1 \mathrm{~mm} ; \mathrm{C}$ ) Detalhe de tangencial a longitudinal de Cloudina latilabrum nov. sp. com preenchimento espático em seu interior, e nos espaços entre as abas (GP/L1E - 42). Escala $=1 \mathrm{~mm}$; D) C. latilabrum exibindo extensas abas (GP/1E - 6218). Escala $=1 \mathrm{~mm}$; E) Distribuição da frequência de diâmetros em $C$. latilabrum. Notar predomínio de indivíduos com dimensões entre 0,2 e $0,6 \mathrm{~mm}$; F) C. latilabrum paralela ao acamamento, ao lado de uma seção transversal de Cloudina lucianoi. Notar a diferença nos diâmetros entre os dois táxons (GP - 6218). Escala $=5 \mathrm{~mm}$.

Prancha 10. Cloudina latilabrum nov. sp. Holótipo $(A)$ e parátipos (B e C). Escala $=5 \mathrm{~mm}$;

D) Distribuição da frequência dos diâmetros; E e F) Superfície do material-tipo (GP/1E - 6218), com fósseis de C. latilabrum e Cloudina lucianoi. Notar o pequeno diâmetro da primeira espécie, em relação à segunda. Escala $=5 \mathrm{~mm}$; G) Seção transversal de C. latilabrum, exibindo escentricidade dos segmentos, e preenchimento espático. $O$ delineamento escuro da concha representa o arcabouço orgânico. Escala $=1 \mathrm{~mm} ; H)$ C. latilabrum em lâmina petrográfica $(G P / L 1 E-24)$ da fácies packstones bioclásticos, da Pedreira Saladeiro. Notar as extensas abas, diagnóstico para a espécie. Escala $=1 \mathrm{~mm}$. 


\section{ÍNDICE}

Capitulo 1- Introdução

Objetivos 4

Capítulo 2 - Introdução ao Período Ediacarano 5

2.1 Contexto Temporal 5

2.2 O cenário biológico e ambiental no limite Ediacarano-Cambriano 8

Capítulo 3- O estado atual do conhecimento do fóssil Cloudina 12

3.1 Cloudina como fóssil indice 12

3.2 Morfologia da concha e considerações filogenéticas 16

3.3 O modo de vida de Cloudina 20

Capítulo 4- Contexto Geológico 22

4.1 A Faixa Paraguai $\quad 22$

4.2 O Grupo Corumbá $\quad 24$

Capítulo 5- Material e Métodos 28

$\begin{array}{ll}\text { 5.1 Material Examinado } & 28\end{array}$

$\begin{array}{ll}5.2 \text { Atividades de Laboratório } & 28\end{array}$

$\begin{array}{ll}\text { 5.3 Atividades de Campo } & 30\end{array}$

Capítulo 6-Resultados 31

Capítulo 7- Discussão 53

7.1 A nova espécie de Cloudina 53

7.2 Caracterização tafonômica de Cloudina no Grupo Corumbá 55

7.3. Implicações estratigráficas $\quad 56$

Capítulo 8- Conclusões 58 
Referencias Bibliográficas

Anexos

74

Anexo 1- Paleontologia Sistemática

75

Anexo 2- Artigo

78

Anexo 3- Material analisado

90 


\section{CAPÍTULO 1}

Introdução

O período Ediacarano (635-542 Ma) é marcado pelo aparecimento dos primeiros macrorganismos morfologicamente complexos, denominados biota de Ediacara (vide Glaessner 1984; Narbonne 1998, 2005). O período também marca o surgimento dos mais antigos metazoários com evidência de biomineralização, circunscritos aos últimos $7 \mathrm{Ma}$ do período (Grotzinger et al. 1995; Amthor et al. 2003). Dentre estes, o gênero Cloudina (Germs 1972) tem recebido maior destaque, pois sua ampla distribuição geográfica (Conway Morris et al. 1990; Grant 1990), aliada a uma curta distribuição temporal (Grotzinger et al. 1995; Amthor et al. 2003), o torna um fóssil-índice para o fim do Ediacarano (Grant 1990). Sua importância também se deve ao fato de estes fósseis apresentarem as mais antigas marcas atribuídas à predação (Bengtson \& Yue 1992; Hua et al. 2003).

Cloudina consiste de uma concha calcária tubular reta, curva ou sinuosa, aberta em sua porção distal e oclusa na porção proximal, e composta por sucessivos segmentos em forma de tronco de cone (Fig. 1). (Germs 1972; Hahn \& Pflug 1985; Zaine \& Fairchild 1987; Grant 1990; Chen et al. 2008). O gênero foi cunhado por Germs (1972) em referência ao geólogo norteamericano Preston Cloud para fósseis em calcários do Grupo Nama, na Namíbia, onde duas espécies - Cloudina hartmannae e Cloudina riemkeae foram diferenciadas com base em tamanho (Germs 1972). Desde então, fósseis de diversas procedências no mundo têm sido atribuídos ao gênero (Fairchild 1978; Palacios 1989; Conway Morris et al. 1990; Gaucher \& Sprechmann 1999; Hagadorn \& Waggoner 2000; Hofmann \& Mountjoy 2001; Boggiani \& Gaucher 2004; Clausen \& Álvaro 2004; Gaucher et al. 2005; Kontorovich et al. 2008; Cortijo et al. 2010). No Brasil, a espécie Cloudina lucianoi (Beurlen \& Sommer 1957) Zaine \& Fairchild, 1985, ocorre em calcários da Formação Tamengo, próxima ao topo do Grupo Corumbá, na região de Corumbá, Mato Grosso do Sul. 

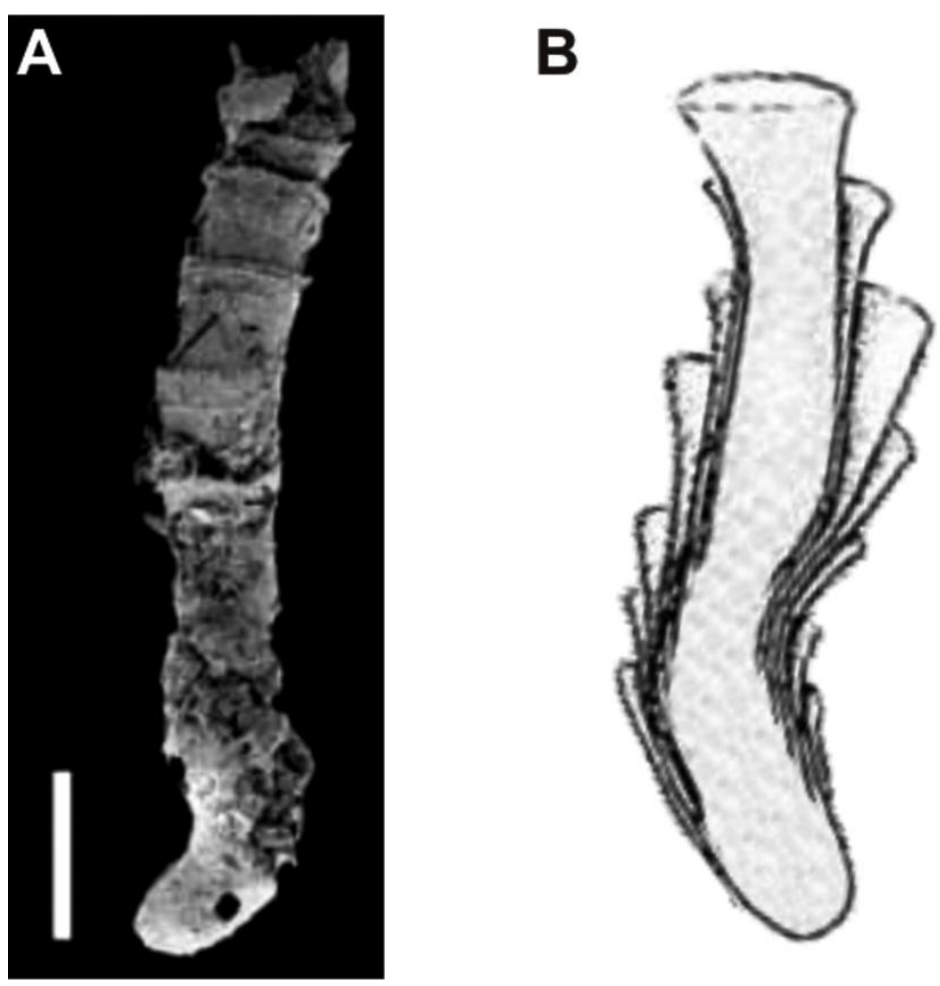

Figura 1: A) Eletromicrografia de concha silicificada de Cloudina hartmannae, da Formação Dengying, China, na qual se pode notar o encaixe de sucessivos segmentos formando a estrutura, e a porção basal oclusa, típicas do gênero. Escala representa $280 \mu \mathrm{m}$. Extraído de Chen et al. (2008). B) Reconstituição da concha em corte longitudinal. Os septos internos transversais, presentes na imagem original, extraída de Seilacher (1999), foram retirados aqui, uma vez que esta concepção foi refutada por Hua et al. (2005) em análise de fósseis fosfatizados da Formação Dengying, China.

Pesquisas nas últimas duas décadas têm revelado muito acerca de Cloudina e seu ambiente de vida. Dentre as descobertas, está sua associação a outros metazoários em depósitos da Namíbia (Grotzinger et al. 1995, 2000; Wood et al. 2002), EUA (Hagadorn \& Waggoner 2000), Canadá (Hofmann \& Mountjoy 2001), Omã (Amthor et al. 2003), China (Hua et al. 2003) e Rússia (Kontorovich et al. 2008). No Brasil, o fóssil Corumbella werneri (Hahn et al. 1982) é o único outro metazoário encontrado em conjunto com Cloudina (Zaine \& Fairchild 1987).

O caráter ainda incipiente do tratamento tafonômico de Cloudina contrasta com a grande quantidade de estudos já realizados com base em assembleias fanerozoicas (e.g., Brett \& Baird 1986; Speyer \& Brett 1986; Kidwell \& Holland 1991; Li \& Droser 1997). A análise detalhada realizada por 
Grant (1990) sobre os aspectos bioestratinômicos e diagenéticos de Cloudina de diversas localidades, com ênfase nos fósseis namíbios, consiste no principal estudo realizado até o momento. Também relevantes são as contribuições de Bengtson \& Yue (1992) e Hua et al. (2003) acerca das mais antigas marcas atribuídas à ação de predadores em exemplares de Cloudina hartmannae provenientes da Formação Dengying, na China.

Grande parte do que se conhece de Cloudina lucianoi provém das análises realizadas por Fairchild \& Zaine (1987) e Zaine (1991), em especial, do material-tipo descrito por Beurlen \& Sommer (1957), em tempestitos do topo da Pedreira Saladeiro, em Ladário, cidade vizinha à Corumbá. Zaine \& Fairchild (1985) e Hahn \& Pflug (1985) confirmaram, de modo independente, o posicionamento do fóssil brasileiro dentro do gênero Cloudina; os primeiros classificando-o como C. lucianoi, e os segundos, como C. waldei. Zaine \& Fairchild (1987) e Zaine (1991) argumentaram, no entanto, que o termo $C$. lucianoi tem prioridade sobre $C$. waldei, sendo este um sinônimo júnior, segundo o International Code of Zoological Nomenclature (1985).

No entanto, pouco ou nada foi escrito sobre a ocorrência deste fóssil em outros contextos deposicionais e estratigráficos nesta ou em outras pedreiras (Boggiani 1998), mesmo que tenham sido ilustrados (Zaine \& Fairchild 1987; Zaine 1991) ou mencionados em teses e dissertações (Boggiani 1998; Oliveira 2010). Logo, esta carência de informações sobre o primeiro metazoário conchífero de ampla distribuição no mundo motivou a análise mais aprofundada destas localidades apresentada nesta dissertação, com vistas ao entendimento deste singular fóssil no contexto de diferentes regimes energéticos e deposicionais. 


\section{Objetivos}

O presente trabalho foi realizado em afloramentos da Formação Tamengo, na região de Corumbá, já conhecidos na literatura - as pedreiras Saladeiro, Laginha e Corcal (Fairchild 1978; Hahn \& Pflug 1985; Zaine \& Fairchild 1985, 1987; Zaine 1991; Boggiani 1998; Gaucher et al. 2003; Boggiani et al. 2010).

Compuseram como cerne desta dissertação os seguintes objetivos:

1. Verificar se C. lucianoi consiste no único animal, além de Corumbella werneri, presente nos calcários, ou se existem outros metazoários previamente não reconhecidos;

2. Levantar as assinaturas bioestratinômicas e diagenéticas de C. lucianoi nos demais níveis onde este fóssil ocorre, além do topo da Pedreira Saladeiro;

3. Ampliar o conhecimento acerca da distribuição estratigráfica de $C$. lucianoi na região de Corumbá. 


\section{CAPÍTULO 2}

\section{Introdução ao período Ediacarano}

\subsection{Contexto temporal}

A Era Neoproterozoica é dividida em três períodos, segundo o International Comission on Stratigraphy (2008): Toniano (1000-850 Ma), Criogeniano (850-635 Ma) e Ediacarano (635-542 Ma). Esta era foi marcada por variações climáticas sem precedentes na história da Terra, das quais as mais importantes foram duas glaciações em nível global, a primeira há cerca de 710 Ma (Glaciação Sturtiana), e a segunda, há cerca de 635 Ma (Glaciação Marinoana), cada qual sucedida, em um curto período de tempo, por episódios de efeito estufa intenso (Kirschvink 1992; Hoffman et al. 1998; Hoffman \& Schrag 2002). A hipótese de um planeta coberto por geleiras, denominada Snowball Earth por Kirschvink (1992), e seu subsequente aquecimento, é embasada em observações tais como: 1) a presença de diamictitos supostamente glaciogênicos em regiões situadas em baixas paleolatitudes; 2) o abrupto contato destes com espessas "capas carbonáticas" sobrepostas, com cementstones de aragonita, indicando supersaturação dos oceanos em $\mathrm{CaCO}_{3}$; 3) reaparecimento de formações ferríferas, após um hiato de mais de 1 bilhão de anos, associadas aos diamictitos, e interpretadas como o resultado da anoxia dos oceanos em decorrência de seu confinamento sob as geleiras (Grotzinger \& Knoll 1995; Hoffman et al. 1998; Kennedy et al. 1998; Hoffman \& Schrag 2002; Halverson et al. 2005); 4) acentuadas excursões negativas de isótopos de carbono em rochas carbonáticas logo acima do contato com os diamictitos, como consequência, segundo Hoffman et al. (1998), da queda na biomassa durante as glaciações, ou do sequestro de matéria orgânica, devido às altas taxas de deposição de carbonatos (Fig. 2.1.1). 


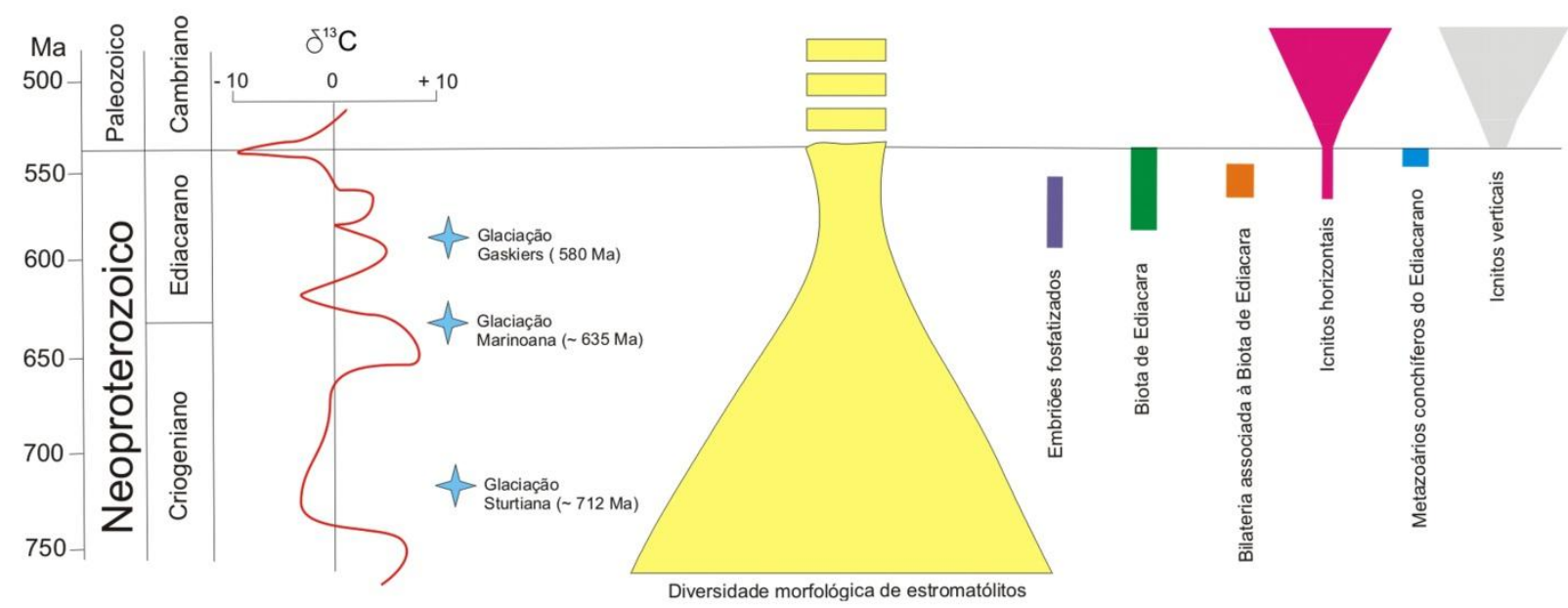

Figura 2.1.1: Principais eventos que marcaram o final do Neoproterozoico. Modificado de Walter \& Heys (1985), Narbonne (2005) e Marshall (2006).

Para Kirschvink (1992), os eventos de glaciação global foram condicionados, inicialmente, pela posição dos continentes na região equatorial do planeta, após a fragmentação do Rodínia, há 750 Ma (Li et al. 2008). Nesta configuração paleogeográfica e paleoclimática, ocorreu intenso intemperismo químico dos silicatos sobre uma grande área continental, o que consumiu tanto $\mathrm{CO}_{2}$ da atmosfera que o efeito estufa da época foi seriamente afetado, com subsequente queda abrupta na temperatura global. Consequentemente, mantos de gelo se formavam nos polos, se alastrando para as regiões de menor latitude, potencializando ainda mais a redução de temperatura pela reflexão dos raios solares (efeito albedo), o que resultou na invasão dos trópicos pelo gelo.

O período Ediacarano sucedeu a última glaciação global, Marinoana, e se estendeu até o limite com o período Cambriano. É marcado por uma glaciação, também, denominada Gaskiers, datada em $580 \mathrm{Ma}$ (Bowring et al. 2003), mas que diferentemente das glaciações anteriores, foi de abrangência mais restrita e sem o desenvolvimento de uma "capa carbonática" posterior (Halverson et al. 2005).

Mas o que mais marcou o Ediacarano foi o surgimento de vida animal macroscópica no planeta -- os metazoários. As mais antigas evidências dos 
Metazoa são microfósseis na forma de embriões, permineralizados por fosfato, na Formação Doushantuo, China (Xiao et al. 1998), com idade entre 580 e 551 $\mathrm{Ma}$ (Condon et al. 2005). Também são registradas nesta formação estruturas celulares e espículas de poríferos ( $\mathrm{Li}$ et al. 1998) e possíveis cnidários, estes já com dimensões de alguns milímetros (Xiao et al. 2000; Liu et al. 2008). Pouco depois, em rochas sedimentares depositadas entre 575 e $542 \mathrm{Ma}$, apareceu a biota de Ediacara, caracterizada por moldes e contramoldes de organismos de dimensões centimétricas desprovidos de carapaças ou conchas (Narbonne et al. 1997; Narbonne \& Gehling 2003). Estes fósseis foram inicialmente relacionados a filos de invertebrados que persistem até hoje (Glaessner 1959, 1984), mas em estudos subsequentes (e.g., Seilacher 1992; Seilacher et al. 2003) foram posicionados em categorias taxonômicas à parte dos Metazoa os vendobiontes (Seilacher 1992). Rochas siliciclásticas datadas entre 555 e $542 \mathrm{Ma}$ contêm icnofósseis horizontais e moldes atribuídos à Bilateria, filogeneticamente posicionada na base dos grupos biológicas que continuam até hoje (Fedonkin \& Waggoner 1997; Martin et al. 2000; Narbonne 2005). Por fim, restos esqueletais estão presentes em carbonatos do final do período (549 - 542 Ma, Grotzinger et al. 1995; Amthor et al. 2003) (Fig. 2.1.2). Este registro, contudo, é esparso, e ainda há lacunas que impedem compreensão plena do repentino aparecimento de grupos derivados na irradiação explosiva do Cambriano ("Explosão Cambriana").

Para Valentine (2007), a dificuldade em relacionar a biota de Ediacara a filos do Fanerozoico é porque ela inclui formas basais a vários clados que só se diversificaram no Cambriano. Tentativas de traçar a filogenia entre os clados de Metazoa têm tomado outro rumo, além do paleontológico, através do estudo de marcadores moleculares em organismos recentes (Valentine 2007). Por exemplo, os chamados genes Hox, responsáveis pela mediação nos padrões anteroposteriores em Bilateria (Valentine 2007), também foram constatados em Cnidaria (Finnerty \& Martindale 1999), o que sugere que estes genes estariam presentes no último ancestral comum a Cnidaria e Bilateria, provavelmente presente no Neoproterozoico. 


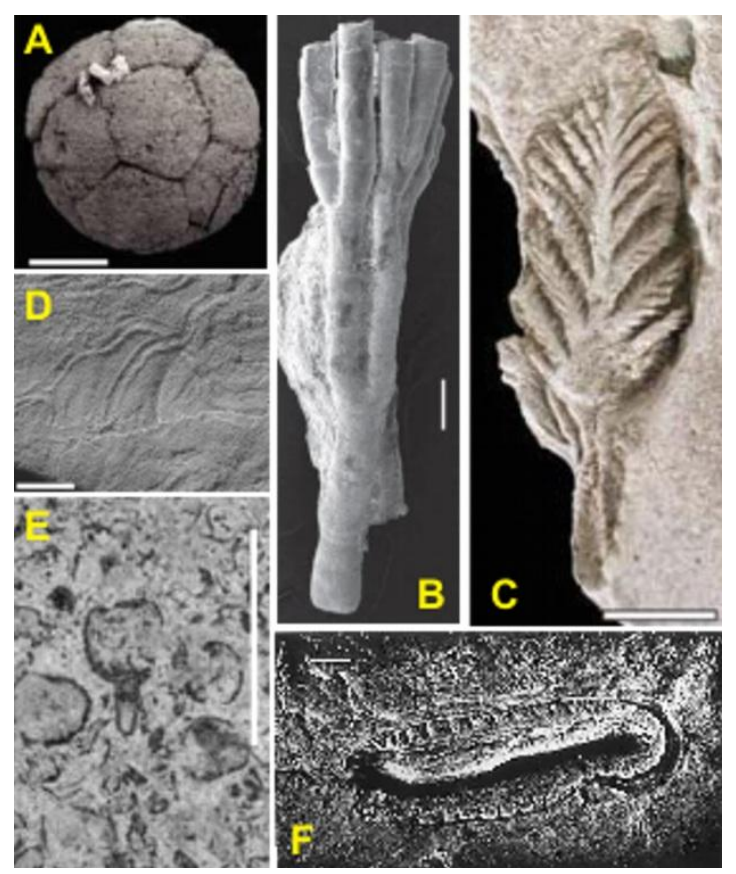

Figura 2.1.2: Fósseis ediacaranos. A) Eletromicrografia de embrião de metazoário permineralizado por fosfato, com 16 células. Formação Doushantuo, China (extraído de Hagadorn et al. 2006); B) Eletromicrografia de Ramitubus increscens Liu et al., 2008, possível cnidário da Formação Doushantuo, China (extraído de Liu et al. 2008); C) Rangeomorfo da Formação Trepassey, Inglaterra (extraído de Narbonne 2004); D) Kimberella quadrata Wade, 1968, possível molusco da Formação Ust Pinega, Rússia (extraído de Fedonkin \& Waggoner 1997); E) Archaeonassa, icnito da Formação Ust Pinega, Rússia (extraído de Jensen 2003); F) O metazoário conchífero Namacalathus hermanastes Grotzinger et al., 2000, Subgrupo Kuibis, Namíbia (extraído de Grotzinger et al. 2000). Escalas representam $200 \mu \mathrm{m}$ em A e B; 2,5 mm em C; e $1 \mathrm{~cm}$ em D, E e F.

\subsection{O cenário biológico e ambiental no limite Ediacarano - Cambriano}

O desaparecimento dos fósseis característicos do Ediacarano, como a biota de Ediacara, implica num importante evento de extinção ao final deste intervalo (Seilacher 1984). Com efeito, dados geoquímicos registram, para este limite, um acentuado desvio nos valores do $\delta^{13} \mathrm{C}$ em carbonatos marinhos para valores negativos, o que é interpretado como resultado da queda da biomassa da época, e subsequente enriquecimento dos oceanos (e dos carbonatos) no isótopo ${ }^{12} \mathrm{C}$, mais leve (Narbonne 2005) (Fig. 2.1.1). Kimura e Watanabe (2001) 
apontam como causa da extinção um extenso evento de anoxia em mares rasos. Além desta extinção, a transição entre o Ediacarano e o Cambriano é marcada, segundo Bottjier et al. (2000), por duas grandes inovações: o aparecimento de icnofósseis verticais, com ornamentação, e o surgimento de metazoários com conchas.

Icnitos horizontais e simples são registrados a partir de $560 \mathrm{Ma}$ em rochas siliciclásticas (Martin et al. 2000; Narbonne 2005). Feições sedimentológicas sinsedimentares que só poderiam se formar se os sedimentos arenosos envolvidos estivessem coesos, como estruturas "petee", sugerem que a interface sedimento-água em grandes áreas das plataformas rasas estaria ocupada e efetivamente selada por esteiras microbianas (Gehling 1999). Para Seilacher (1999), esta característica impediria que a água e o oxigênio circulassem livremente no substrato, restringindo, desta maneira, os habitats da biota de Ediacara à superfície recoberta por esteiras microbianas e aos níveis mais rasos do substrato. Rochas sedimentares do início do Cambriano, por outro lado, registram um aumento na quantidade e diversidade de icnofósseis, com icnitos ramificados, ornamentados e, mais importantemente, perpendiculares ao acamamento (Crimes 1987). Seilacher \& Pflüger (1994) apelidaram esta brusca transição ecológica de a "Revolução Agronômica" e atribuiram este processo ao surgimento de metazoários pastadores (como Kimberella). A eliminação das esteiras microbianas das plataformas rasas permitiu a livre circulação de água com oxigênio para as partes mais profundas do substrato e serviu de gatilho ecológico para a colonização destes estratos (Fig. 2.2.1). 


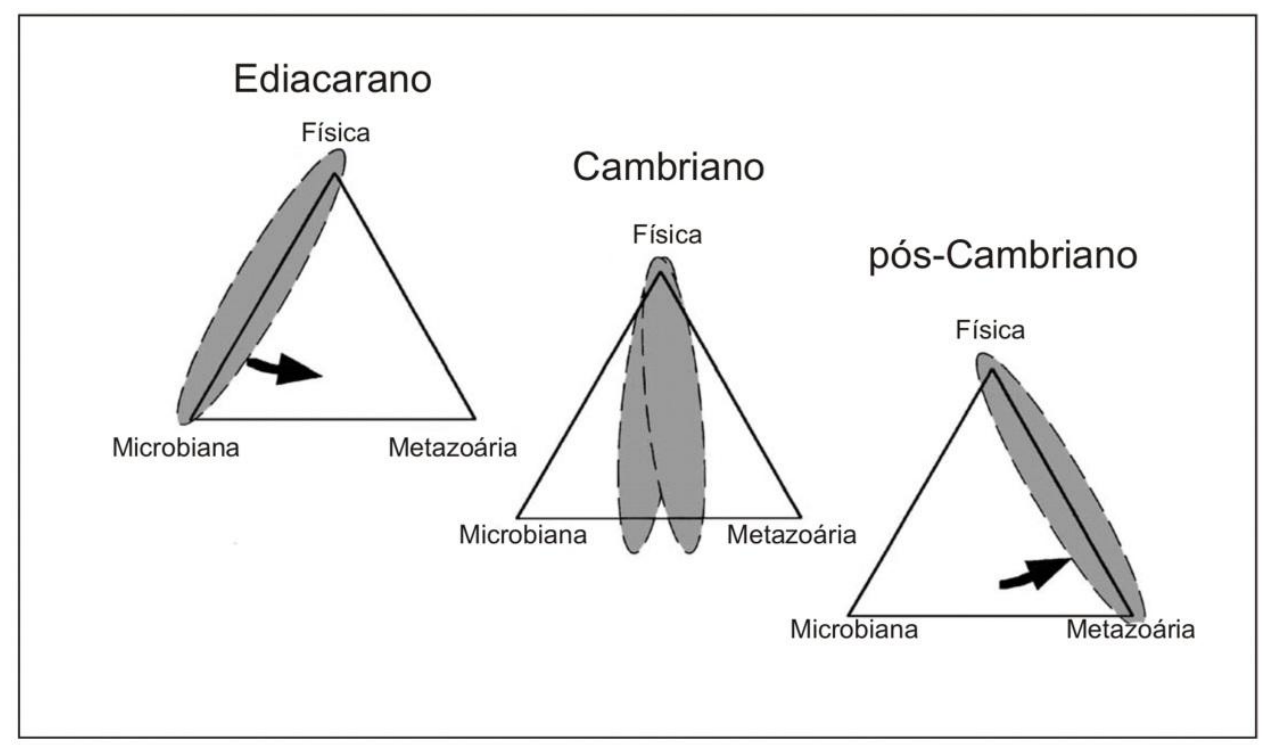

Figura 2.2.1: Diagramas das principais influências no substrato marinho na transição Ediacarano-Cambriano, e após o Cambriano. Notar a gradual redução na influência microbiana, e progressiva participação de metazoários. Extraído de Bottjier et al. (2000).

Plataformas carbonáticas, datadas do final do Ediacarano (Grotzinger et al. 1995) registram a presença dos primeiros metazoários conchíferos, comumente relacionados a microbialitos (e.g., Hofmann \& Mountjoy 2001; Grotzinger et al. 2005). Tais fósseis - Cloudina, Namacalathus, Namapoikia e Sinotubulites -- caracterizam-se por sua baixa diversidade e ampla distribuição geográfica (Knoll 2003). Poucos milhões de anos depois se iniciou a irradiação explosiva de metazoários com conchas, quase que simultaneamente em grupos filogeneticamente distantes. O que teria provocado este fenômeno?

Pesquisas mostram uma relação direta entre a razão $\mathrm{Mg} / \mathrm{Ca}$ nos oceanos e a mineralogia do carbonato adotado pelos primeiros representantes de um determinado clado (Zhuravlev \& Wood 2008). No entanto, a causa do surgimento de esqueletos ainda está em discussão. Dentre as hipóteses levantadas, Degens et al. (1985) e Kempe \& Kazmierkczak (1994) sugeriram que os esqueletos seriam uma resposta fisiológica à supersaturação de cálcio nos oceanos proterozoicos. Para Cohen et al. (2005), a densidade dos esqueletos favoreceria a estabilização dos organismos junto ao substrato, onde a oferta de nutrientes seria maior. Vermeij (1989) sugeriu que, embora houvesse grande disponibilidade de matéria-prima nos oceanos, o fator 
determinante para o surgimento de esqueletos teria sido a emergência de predadores.

Para Bottjier et al. (2000), a predação explicaria tanto as mudanças nas atividades epi- e infaunais no limite Pré-Cambriano - Cambriano, quanto o surgimento de esqueletos. Neste contexto, a descoberta de perfurações circulares, entre 15 e $85 \mu \mathrm{m}$ de diâmetro, em conchas de Cloudina hartmannae, na Formação Dengying (China), foi fundamental para a corroboração desta hipótese, pois tais marcas são interpretadas como as mais antigas evidências de predação em metazoários (Fig. 2.2.2) (Bengtson \& Yue 1992; Hua et al. 2003). Segundo Hua et al. (2003), a relação direta entre o diâmetro da concha na altura das marcas e a distância da abertura apical é coerente com esta interpretação. Wood (2011), por exemplo, sugere que esta estratégia pode ter sido adotada para evitar as defesas do organismo concentradas em torno da abertura da concha. Na Formação Dengying (Hua et al. 2007), metazoários com carapaças orgânicas, representados pelo gênero Conotubus, ocorrem em estratos mais antigos que o fóssil Cloudina. Para estes autores, esta distribuição sugere que Conotubus pode ter sido substituído por Cloudina frente às pressões seletivas impostas pela predação. Assim, o registro da interação predador-presa pode ter surgido numa época bem anterior à explosão cambriana, sendo consistente com o argumento de que a função primária do desenvolvimento de conchas teria sido a defesa contra predadores (Bengtson 1994, 2002).

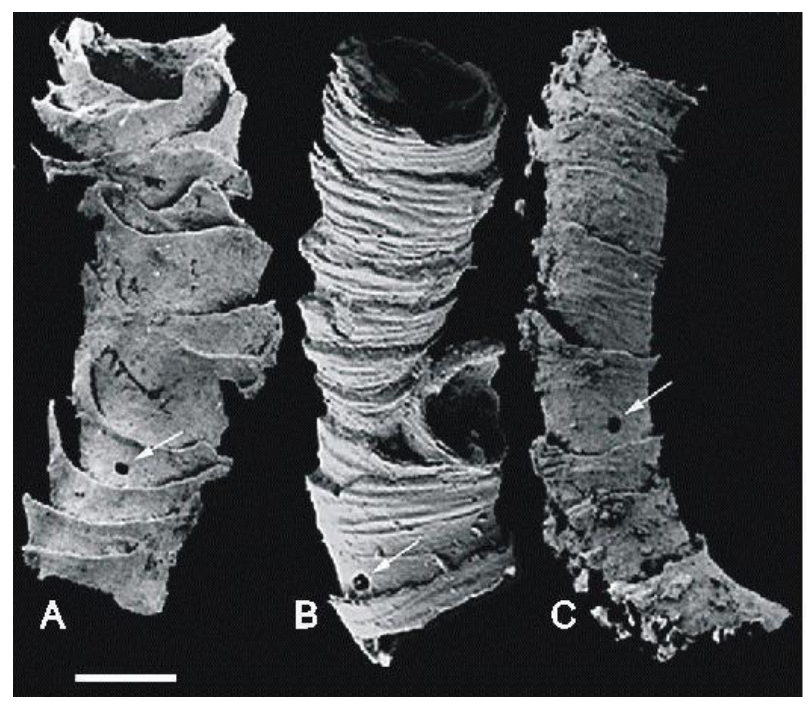

Figura 2.2.2: Conchas de Cloudina hartmannae e com perfurações, indicadas pelas setas, interpretadas como resultado de predação. Notar brotamento em B. Escalas representam $250 \mu \mathrm{m}$ em A, $150 \mu \mathrm{m}$ em B e $350 \mu \mathrm{m}$ em C. Modificado de Hua et al. (2003). 


\section{O estado atual do conhecimento do fóssil Cloudina}

\subsection{Cloudina como fóssil-índice}

Além do Grupo Nama, onde foi primeiramente descrito, Cloudina ocorre em mais 12 localidades, incluindo Brasil, Uruguai e Paraguai (Fig. 3.1.1), principalmente em rochas carbonáticas. Na maioria dos locais, os fósseis têm sido atribuídos à espécie-tipo, C. hartmannae.

Fósseis parecidos com Cloudina foram descritos em depósitos do Cambriano Inferior da Argentina por Yochelson \& Herrera (1974), que os designaram Cloudina? borrelloi. Posteriormente, Hahn \& Pflug (1985) criaram um novo gênero para este material, classificando-o como Acuticloudina borrelloi. Contudo, a semelhança deste fóssil com o gênero cambriano Salterella já havia sido notada por Yochelson \& Herrera (1974), que observaram que a base do fóssil argentino diferia da base pontiaguda observada em Salterella. Por isso, optaram por mantê-lo, ainda que sob ressalva, no gênero Cloudina. Por fim, diferenças morfológicas entre o fóssil argentino e o gênero Cloudina foram ressaltadas por Grant (1990), que concluiu que o material provavelmente pertence ao gênero Salterella.

Também, foram descritos como Cloudina? por Yochelson \& Stump (1977) fósseis encontrados em brechas carbonáticas da Formação Taylor, Antártica, juntamente com supostos fragmentos de trilobitas do Eocambriano. Para Grant (1990), tais fósseis podem representar Cloudina, ainda que sua má preservação não permita inferências mais detalhadas. Do mesmo modo, os fósseis associados a trilobitas não são convincentes, logo a idade destes depósitos permanece incerta (Grant 1990). Outras ocorrências incluem possíveis Cloudina fosfatizados no Grupo Paracuellos, do Neoproterozoico da Espanha, ilustrados por Álvaro e Blanc-Valleron (2002).

Fósseis calcários encontrados nas formações Deep Spring e Reed Dolomite, nos Estados Unidos, originalmente classificados como Wyattia (Taylor 1966) e Nevadatubulus (Signor et al. 1987) e na Formação La Cienéga, no México, 
denominado Sinotubulites (McMenamin et al. 1983), foram reinterpretados por Grant (1990) como variações tafonômicas de Cloudina. Enquanto tal constatação parece verdadeira para Wyattia e Nevadatubulus (vide Figura $10 \mathrm{~A}$ e D em Grant 1990), Chen et al. (2008) demonstraram que, diferentemente de Cloudina, a concha de Sinotubulites da Formação Dengying, China, apresenta enrugamentos nas camadas superficiais, gradando para camadas internas cada vez menos dobradas. Nessa mesma formação, Hua et al. (2003) constataram que as conchas de Sinotubulites são mais espessas (150-600 $\mu \mathrm{m})$ que as de Cloudina.

Estratigraficamente, a posição do gênero Cloudina foi bem estabelecida no final do Ediacarano, pois os calcários onde este metazoário foi encontrado, no Grupo Nama, estão intercalados com arenitos contendo representantes da biota de Ediacara e icnofósseis simples e horizontais, além de uma assembleia tipicamente ediacarana de microfósseis orgânicas nos folhelhos (Germs 1972; Crimes \& Germs 1982; Germs et al. 1986). Adicionalmente, a icnoespécie Treptichnus pedum, cujo aparecimento marca a base do Cambriano (Gehling et al. 2001), está presente no Grupo Nama em arenitos preenchendo vales incisos, acima da última ocorrência de Cloudina (Grant 1990).

Análises geocronológicas, utilizando as razões de urânio e chumbo em cristais de zircão (SHRIMP) a partir de tufos vulcânicos no Grupo Nama permitiram limitar a idade da biozona de Cloudina entre 549 e 542 Ma (Fig. 3.1.2) (Grotzinger et al. 1995). Posteriormente, Amthor et al. (2003) confirmaram a delimitação feita por Grotzinger e colaboradores, ao constatar a ausência de Cloudina em estratos sobrepostos contendo uma camada de rocha vulcanoclástica datada em cerca de $542 \mathrm{Ma}$ e exibindo a excursão negativa de $\delta^{13} \mathrm{C}$ que marca o limite Ediacarano - Cambriano.

Desta forma, A distribuição do gênero Cloudina permite definir uma zona-de-amplitude de táxon, designada a biozona de Cloudina, na qual outros organismos se inserem (Tab. 1), e que permite correlações bioestratigráficas em escala regional (e.g., grupos Corumbá, Itapucumí e Arroyo del Soldado) e mesmo mundial, conforme apresentado na Figura 3.1.1. 


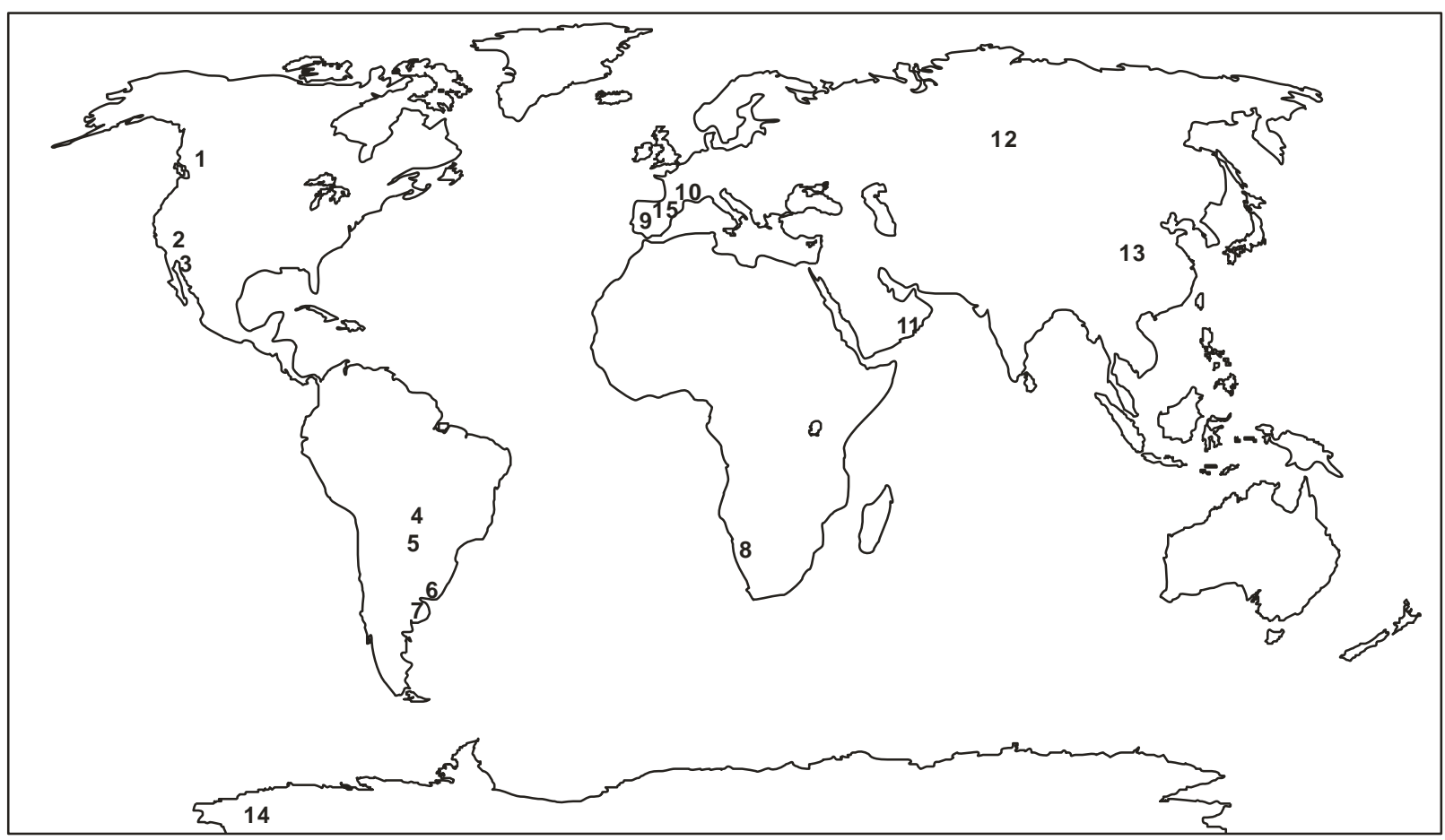

Figura 3.1.1: Distribuição do gênero Cloudina no mundo

Cloudina hartmannae: 1 - Formação Byng, Grupo Miette, Canadá (Hofmann \& Mountjoy 2001); 2 - Formação La Cienéga, México (Sour-Tovar et al. 2007); 8 - Grupo Nama, Namíbia (Germs 1972); 9 - Grupo Ibor, Espanha (Palacios 1989); 11 - Grupo Ara, Omã (Conway Morris et al. 1990); 12 - formações Kotodzha e Raiga, Rússia (Kontorovich et al. 2008); 13 - Formação Dengying, China (Bengtson \& Yue 1992)

Cloudina riemkeae: 6 - Formação Yerbal, Grupo Arroyo del Soldado, Uruguai (Gaucher \& Sprechmann 1999); 7 - Formação Loma Negra, Argentina (Gaucher et al. 2005); 8 - Grupo Nama, Namíbia (Germs 1972)

Cloudina lucianoi: 4 - formações Tamengo (Zaine \& Fairchild 1985) e Guaicurus (presente trabalho), Brasil; 5 - Grupo Itapucumí, Paraguai (Boggiani \& Gaucher 2004)

Cloudina carinata: 9 - Olistostroma Membrillar (provavelmente pertencente ao Grupo Ibor), Espanha (Cortijo et al. 2010)

Cloudina latilabrum nov. sp.: 5 - Formação Tamengo, Brasil (presente trabalho)

Cloudina?: 14 - Formação Taylor, Antártica (Yochelson \& Stump 1977); 15 - Grupo Paracuellos, Espanha (Álvaro \& Blanc-Valleron 2002) 


\section{Sub-bacia Zaris}

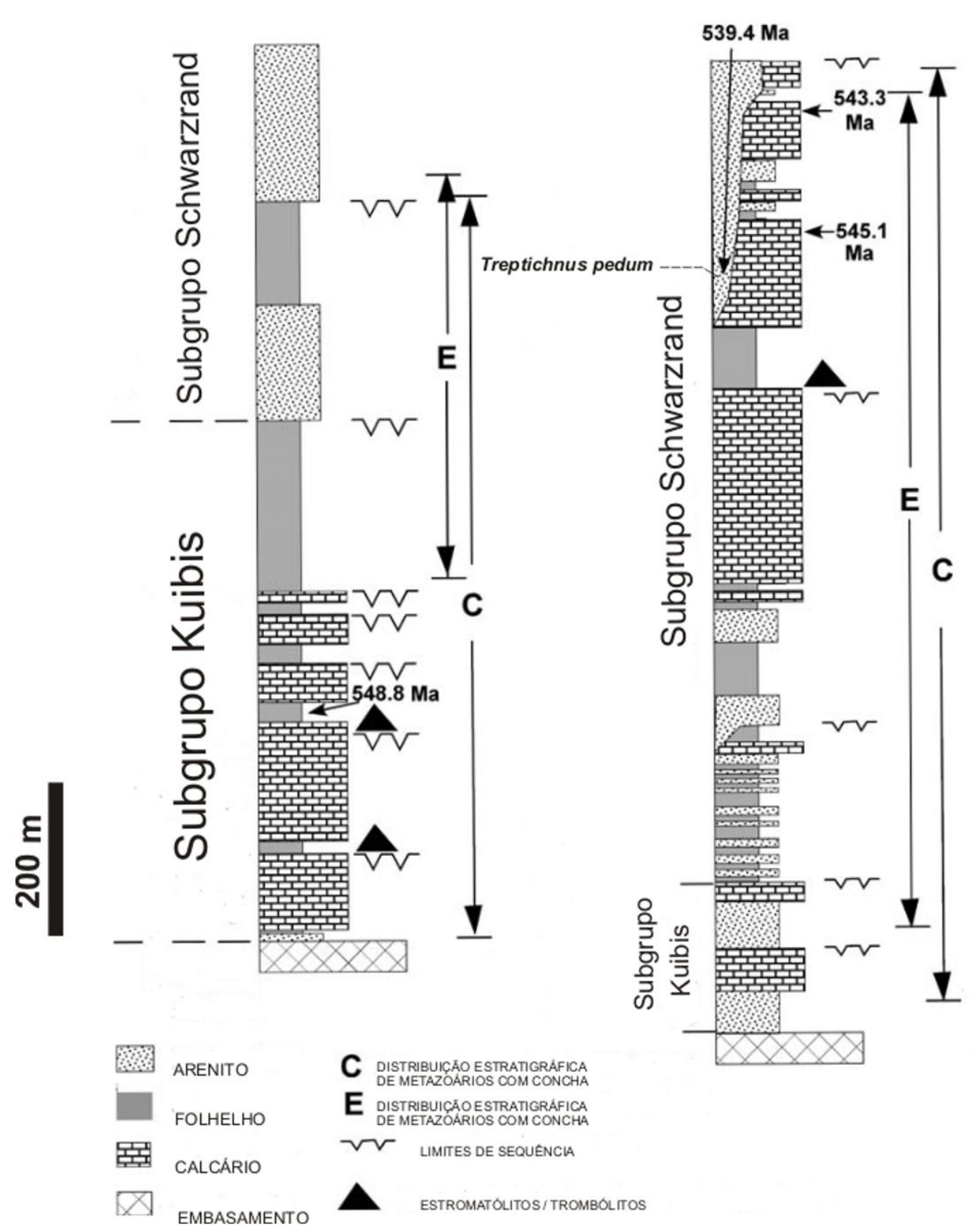

\section{Sub-bacia Witputs}

Figura 3.1.2: Estratigrafia das sub-bacias Zaris e Witputs, Grupo Nama, Namíbia, mostrando a distribuição dos metazoários conchíferos, incluindo Cloudina, juntamente com as datações em tufos vulcânicos e a ocorrência do icnogênero Treptichnus pedum. Extraído de Grotzinger et al. (2000). O posicionamento de T.pedum foi baseado em dados de Grotzinger et al. (1995). 
Tabela 1: Principais organismos associados à biozona de Cloudina, segundo Zaine \& Fairchild (1987), Zaine (1991), Grotzinger et al. (1995, 2000), Amthor et al. (2003), Gaucher et al. (2003), Hua et al. (2007) e o presente trabalho. Vale ressaltar que, embora o microfóssil Bavlinella faveolata também ocorra em depósitos paleozoicos (Vidal 1976), sua presença como principal componente em assembleias microfossilíferas caracteriza o final do Ediacarano (Germs et al. 1986; Palacios 1989).

\begin{tabular}{|c|c|c|c|}
\hline Metazoários & Algas & Microfósseis & Incertae sedis \\
\hline Namacalathus & Vendotaenia antiqua & Bavlinella faveolata & $\begin{array}{c}\text { Waltheria } \\
\text { marburgensis }\end{array}$ \\
\hline Namapoikia & $\begin{array}{c}\text { Eoholynia } \\
\text { corumbensis }\end{array}$ & Titanotheca coimbrae & \\
\hline Sinotubulites & & Soldadophycus bosii & \\
\hline Conotubus & & & \\
\hline Corumbella werneri & & & \\
\hline Gaojiashania & & & \\
\hline
\end{tabular}

\subsection{Morfologia da concha e considerações filogenéticas}

As primeiras descrições da concha de Cloudina (Germs 1972; Glaessner 1976) retrataram-na como uma estrutura robusta, composta por uma parede externa, corrugada, e uma parede interna, lisa (Fig. 3.2.1). Trabalhos subsequentes, contudo, demonstraram que a parede da concha seria extremamente fina (entre 3 e $50 \mu \mathrm{m}$ ) e uniforme ao longo de sua extensão (Grant 1990; Hua et al. 2003, 2005). 


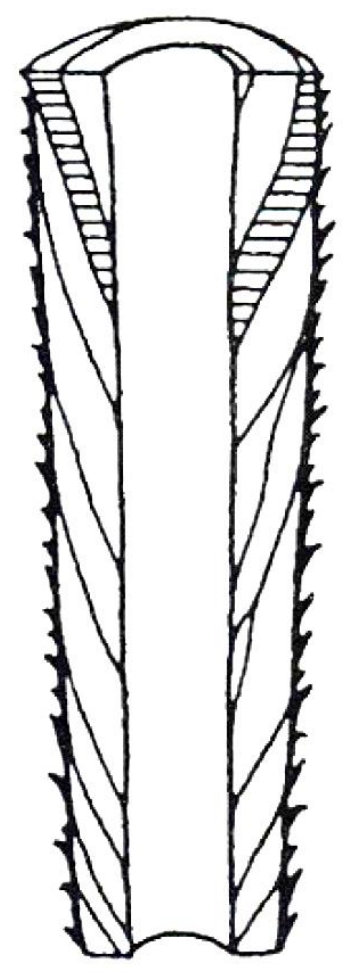

Figura 3.2.1: Reconstituição esquemática de Cloudina proposta por Germs (1972) e Glaessner (1976). Notar as corrugações na superfície externa da concha, e a parede interna lisa. Extraído de Glaessner (1976).

Conforme observado por alguns autores (e.g., Conway Morris 1990; Grant 1990; Zaine 1991; Brain 2001), as conchas de Cloudina apresentam evidências de deformação ora dúctil, ora rúptil (Fig. 3.2.2), que indicariam, segundo Grant (1990), que as paredes teriam se formado pela impregnação de calcita num arcabouço orgânico. Imagens obtidas por microscopia eletrônica de varredura (MEV) conchas de $C$. hartmannae substituídas por fosfato, na Formação Dengying (China), sugerem que a concha deste metazoário era composta por cristais micrométricos de calcita (Hua et al. 2005). Grant (1990) apontou para a existência de cimento carbonático precoce, nos espaços entre os segmentos, que teria reforçado a concha. Wood (2011) chamou a atenção, ainda, à superposição de paredes produzida pela inserção de segmentos sucessivos ao longo da concha como outro fator que teria reforçado a concha. Assim, mesmo com paredes muito finas em seus segmentos individuais, Cloudina pode ter construído conchas relativamente rígidas e resistentes tanto aos movimentos da água quanto ao eventual ataque de predadores. 

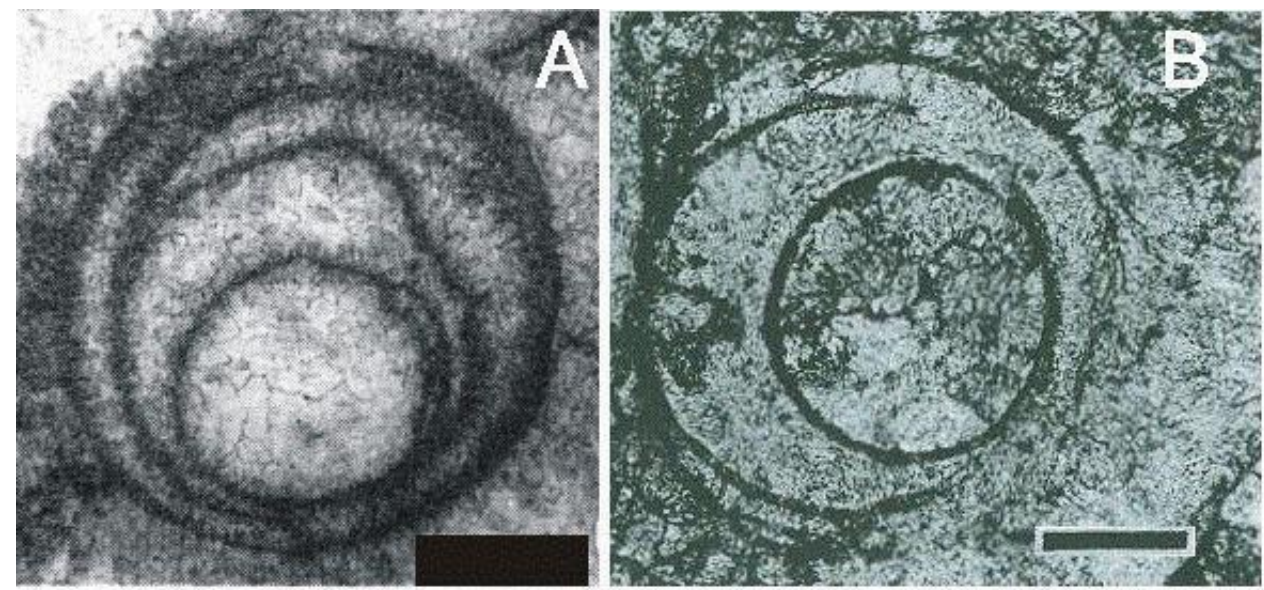

Figura 3.2.2: Deformação dúctil (A) em Cloudina hartmannae do Grupo Ara, Omã; e deformação rúptil (B) em Cloudina riemkeae do Grupo Nama, na Namíbia. Escala representa $700 \mu \mathrm{m}$ em (A) e 180 um em (B). Extraído de Conway Morris (1990) (A) e Grant (1990) (B).

O estudo de seções através de Cloudina no Grupo Nama levou Grant (1990) a inferir que a parte interna da concha seria atravessada por septos, que corresponderiam às bases dos segmentos produzidos pelo organismo. Esta interpretação, no entanto, foi descartada a partir da análise, feita por Hua et al. (2005),, de fósseis fosfatizados de C. hartmannae que revelaram que apenas o segmento inicial, na base da concha, era ocluso. Aparentemente, Grant (1990) interpretou, equivocadamente, seções oblíquas das paredes, vistas em lâminas delgadas, como septos (Fig. 3.2.3).
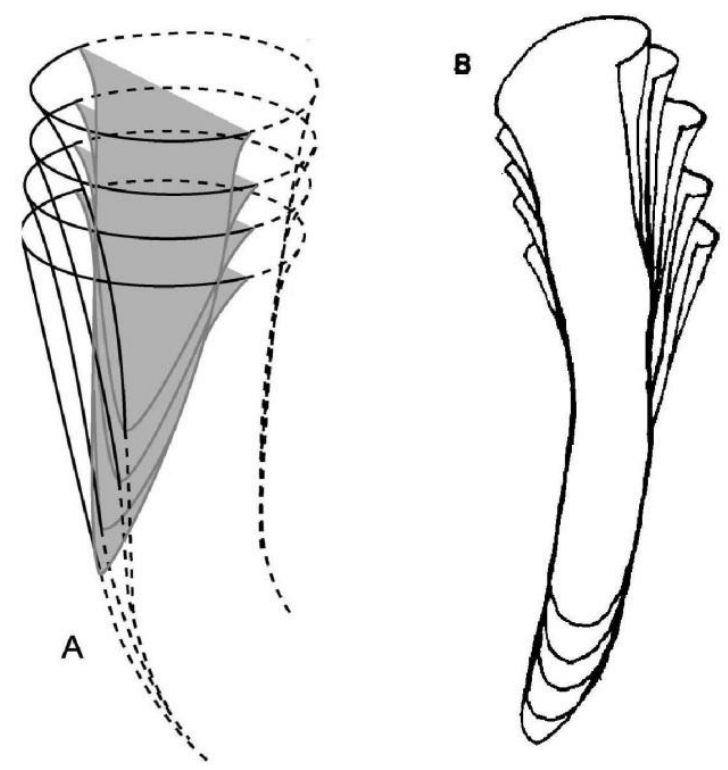

Figura 3.2.3: Esquema de sucessivos cortes oblíquos em Cloudina (A) que poderiam dar a impressão de se tratarem de aparentes septos transversais, como ilustrado em (B) por Grant (1990). Extraído de Hua et al. (2005) (A) e de Grant (1990) (B). 
A afinidade biológica de Cloudina ainda permanece sob discussão. Os primeiros autores que estudaram este gênero (e.g., Germs 1972; Glaessner 1976) sugeriram sua afinidade com fósseis tubulares do Cambriano do clado Cribricyathea, uma possibilidade de certa forma frustrante, uma vez que esse grupo também é enigmático. Entretanto, Hahn \& Pflug (1985) e Grant (1990) questionaram esta hipótese porque as conchas de muitos representantes da Cribricyathea eram porosas, o que não ocorre em Cloudina.

Evidências do modo de reprodução em Cloudina ajudam a limitar a gama de possíveis afinidades filogenéticas. Germs (1972) identificou um único caso de possível brotamento em $C$. hartmannae na Namíbia. Mas este fenômeno foi posteriormente corroborado em conchas da Formação Dengying estudadas por Hua et al. (2005), que ilustraram duas conchas menores se iniciando dentro da concha parental e divergindo abruptamente ao atingir a abertura desta concha (Fig. 3.2.4).

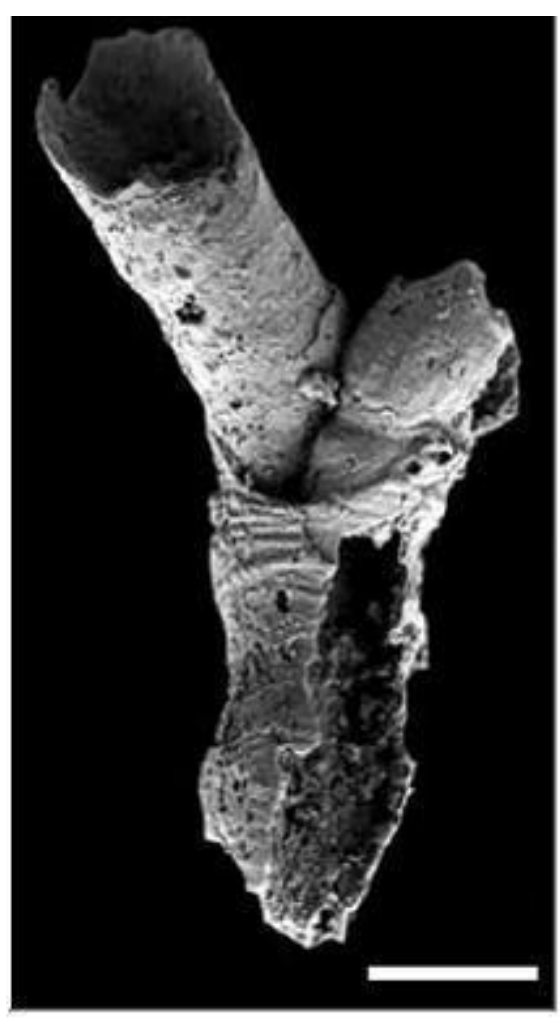

Figura 3.2.4: Evidência de brotamento em Cloudina hartmannae, Formação Dengying, China. Escala: 400 m. Extraído de Hua et al. (2005). 
Com base nesta característica, surgem como candidato a grupo aparentado à Cloudina, os anelídeos Serpulidae, pois alguns apresentam reprodução assexuada por brotamento (Hanson 1948; Pernet 2001). Germs (1972) e Glaessner (1976) chamaram atenção para as seguintes semelhanças entre os dois: ambos possuem conchas tubulares, comumente com uma superfície externa corrugada, superfície interna lisa, fechadas na base, e abertas distalmente. Adicionalmente, Hua et al. (2005) notaram similaridades na microestrutura da concha entre Cloudina e o serpulídeo recente Salmacina dysteri. No entanto, conforme salientado por estes autores, a microestrutura das conchas de Serpulidae varia consideravelmente. Além do mais, a parede da concha em serpulídeos é mais espessa que a observada em Cloudina, e não é composta por uma série de segmentos inseridos, como no fóssil ediacarano (Hua et al. 2005).

Alguns autores, como Grant (1990) e Conway Morris et al. (1990), preferem não atribuir Cloudina a nenhum grupo taxonômico, embora Grant (1990) reconheça que, provavelmente, o fóssil ediacarano seria um metazoário com grau de organização semelhante aos cnidários, ao menos. Mesmo assim, comparações entre Cloudina e os cnidários também revelam algumas inconsistências. Esqueletos de Hydrozoa exibem canais e poros distintos; na Anthozoa, o esqueleto possui septos longitudinais e divisórias transversais (tabulas, dissepimentos); e as carapaças de Scyphozoa são orgânicas (Hua et al. 2005).

\subsection{O modo de vida de Cloudina}

Com base na morfologia da concha de Cloudina, Seilacher (1999) propôs que este táxon viveria como um organismo bentônico, ereto, parcialmente ancorado em sedimentos selados por esteiras microbianas. A formação de novos segmentos ocorreria de modo episódico, acompanhando a sedimentação do ambiente (Seilacher 1999; Wood 2011). O hábito gregário deste organismo (Germs 1972; Grant 1990), junto com sua freqüente associação em grandes acumulações com estromatólitos e trombólitos, ou mesmo preservado em posição vertical ou sub-horizontal dentro de trombólitos, 
apoiam esta concepção, que também é reforçada pela presença de outros metazoários de morfologia compatível a um estilo de vida séssil, como Namacalathus e Namapoikia, no mesmo contexto deposicional (Grotzinger et al. 2000; Horfmann \& Mountjoy 2001; Wood et al. 2002; Amthor et al. 2003; Wood 2011). Estas observações sugerem uma comunidade composta por metazoários filtradores ou microcarnívoros, oportunistas, cujo hábito gregário favoreceria estes organismos na competição por espaço, e também na estabilização do substrato (Jackson 1983; Wood 2011).

Outras evidências relevantes à Paleoecologia de Cloudina incluem agrupamentos in situ deste organismo observados por Germs (1972) na localidade-tipo do gênero (Grupo Nama), e classificados por ele como biohermas. Para Grant (1990), porém, estas estruturas seriam mais estratiformes e melhor classificadas como bioestromas. De qualquer modo, nenhum dos autores chegou a discutir, ou esquematizar satisfatoriamente, a formação destes agrupamentos. Germs (1972) reporta a ocorrência de C. riemkeae fixos sobre conchas de $C$. hartmannae, mas trabalhos subsequentes, não mencionam este modo de ocorrência. 


\section{CAPÍTULO 4}

\section{Contexto Geológico}

\subsection{A Faixa Paraguai}

A Faixa Paraguai (Fig. 4.1.1, A) é uma estrutura geotectônica importante deformada durante o evento orogênico Brasiliano ao fim do Proterozoico e início do Paleozoico na porção oeste do Gondwana (Boggiani 1998; Alvarenga et al. 2000; Boggiani et al. 2010). Ele se estende em forma de arco côncavo para o sudeste desde Paraguai ao longo da borda sudoeste do Brasil através dos estados de Mato Grosso do Sul e Mato Grosso. É dividida em porção norte, representada pelos carbonatos do Grupo Araras e rochas siliciclásticas do Grupo Alto Paraguai, e sul, correspondendo ao Grupo Corumbá (Boggiani 1998; Nogueira 2003). Ambas as porções têm, em sua base, diamictitos da Formação Puga, tidos como glaciogênicos (Alvarenga \& Trompette 1992). Recentemente, no entanto, estes diamictitos foram reinterpretados, pelo menos na região do estratótipo da Formação Puga, na porção sul, como o resultado de fluxos gravitacionais decorrentes de esforços extensivos (Freitas 2010), embora os da porção norte exibam claras evidências de origem glacial (ver Nogueira, 2003). A correlação entre os carbonatos dos grupos Araras (norte) e Corumbá (sul) tem se mostrado difícil, pois apresentam dados quimioestratigráficos, geocronológicos e paleontológicos distintos (Babinski et al. 2006, 2008; Nogueira et al. 2007; Riccomini et al. 2007), sendo que a ocorrência de metazoários é limitada ao último grupo (Zaine 1991; Boggiani et al. 2010). 

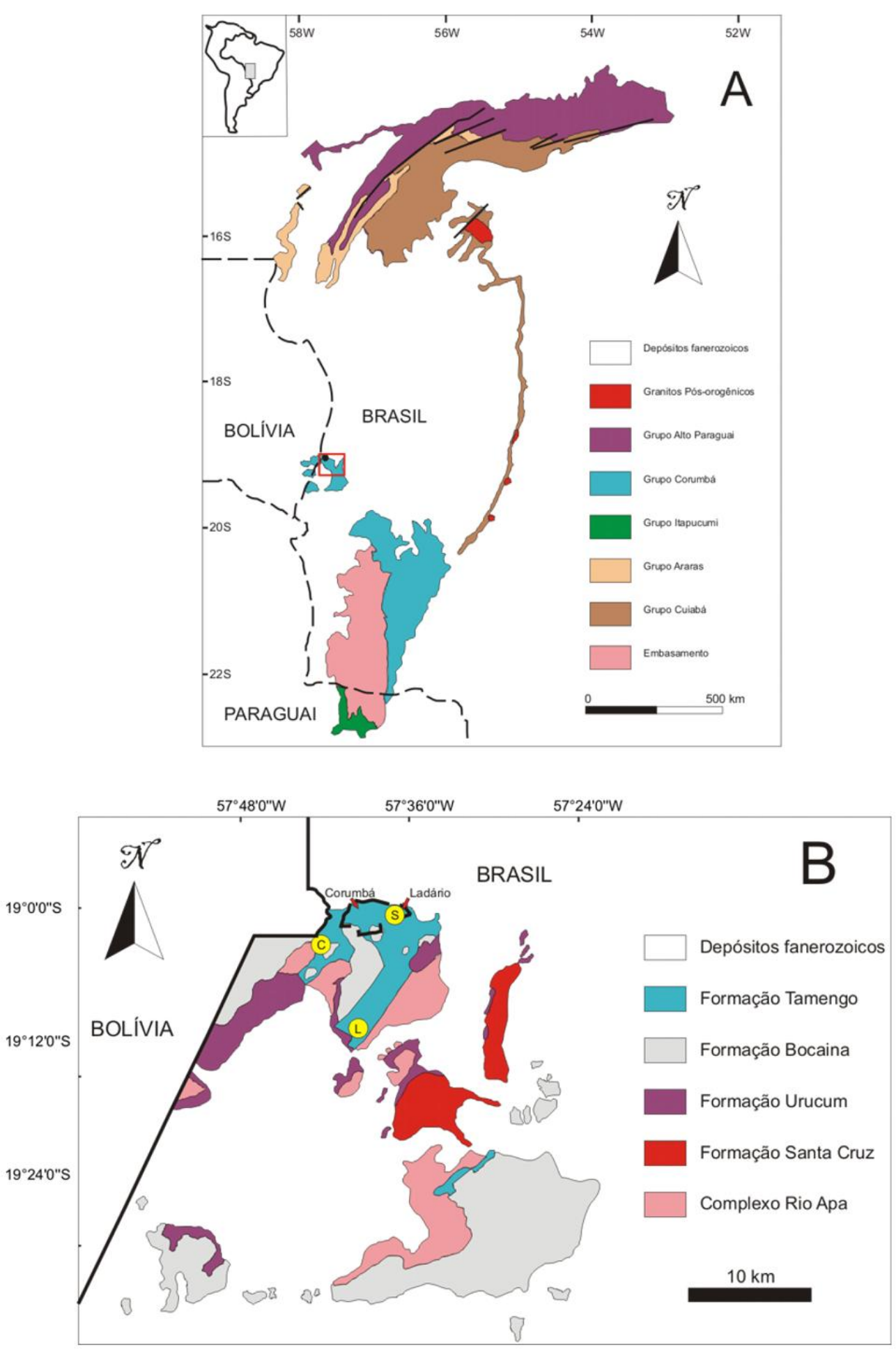

Figura 4.1.1: Mapa geológico da Faixa Paraguai $(A)$ e da área de estudo (B). Em B, círculos amarelos correspondem às pedreiras enfocadas no presente trabalho: $S$ - Pedreira Saladeiro; C - Pedreira Corcal; L - Pedreira Laginha. (A) adaptado de Alvarenga et al. (2000) e Boggiani et al. (2010). (B) adaptado de Oliveira (2010). 


\subsection{O Grupo Corumbá}

O Grupo Corumbá (Tab. 2), com cerca de 600 metros de espessura, se desenvolveu em um contexto tectonossedimentar rift-drift. A fase rift é representada, da base para o topo, pelas formações Cadiueus e Cerradinho, compostas principalmente por rochas sedimentares terrígenas, e interpretados respectivamente, por Boggiani (1998), como depósitos de leques aluviais e o produto do retrabalhamento destes depósitos. Grainstones inicialmente atribuídos à Formação Cerradinho (Boggiani 1998) foram posteriormente assinalados à Formação Tamengo (Boggiani et al. 2010). Sobreposta à Formação Cerradinho, afloram dolomitos variados (inclusive oolíticos e estromatolíticos) e fosforitos associados da Formação Bocaina. Esta unidade representa o início da fase drift da bacia, caracterizada por extensos depósitos de plataforma carbonática rasa. A formação de fosforitos nesta unidade estaria relacionada, segundo Boggiani et al. (1993), à ressurgência de nutrientes na borda da plataforma.

Acima da Formação Bocaina, está a Formação Tamengo, definida por Almeida (1945). A unidade abrange uma área de cerca de $90 \mathrm{~km}^{2}$, com espessura de pelo menos $200 \mathrm{~m}$. Calcários constituem a litologia predominante desta unidade, com folhelhos, siltitos e arenitos subordinados. Também ocorrem brechas carbonáticas de origem sedimentar e/ou tectônica. Os calcários calcíticos (calcarenitos, calcissiltitos, calcilutitos) têm cor cinza-escuro a preto e são, quase sempre, finamente cristalinos, por vezes oolíticos, exibindo, em geral, recristalização. Estratificação plano-paralela, raras estratificações cruzadas tabulares de pequeno porte, estratificação do tipo hummocky e marcas onduladas, são as principais estruturas sedimentares encontradas (Almeida 1965; Del'Arco et al. 1981; Boggiani 1998; Gaucher et al. 2003; Oliveira 2010).

As rochas sedimentares da Formação Tamengo foram depositadas em ambientes desde talude, até a faixa litorânea, e registram oscilações do nível do mar e/ou movimentação tectônica, com consequentes variações no suprimento de sedimentos terrígenos nos sítios deposicionais. Na região de 
estudo (Fig. 4.1.1, B), Oliveira (2010) levantou duas associações de fácies, por ele atribuídas a dois ambientes: shoreface com barras oolíticas e offshore influenciado por tempestade, conforme apresentado na Tabela 3.

Esta formação é a mais fossilífera do Grupo Corumbá, e reveste-se de grande importância por conter os mais antigos metazoários no registro paleontológico brasileiro: Cloudina lucianoi e Corumbella werneri (Fairchild 1978; Walde et al. 1982; Zaine \& Fairchild 1987; Zaine e Fairchild 1985; Hahn \& Pflug 1985; Gaucher et al. 2003).

A idade da Formação Tamengo foi inicialmente situada no Cambriano, por Barbosa (1949) com base nos fósseis agora conhecidos como Cloudina, que ele interpretou como pertencentes ao gênero cambriano Hyolithes. Em 1957, Beurlen e Sommer mantiveram a idade proposta por Barbosa para a unidade quando descreveram formalmente estes fósseis como Aulophycus lucianoi, em alusão a um gênero de alga calcárea do Cambriano Médio da América do Norte cunhado por Fenton \& Fenton (1939), Posteriormente, Fairchild (1978) chamou atenção para a grande semelhança entre Aulophycus Iucianoi e as espécies de Cloudina que haviam sido descritas pouco antes na Namíbia (Germs 1972). Propôs, ainda, que o material brasileiro fosse transferido para o gênero Cloudina e a Formação Tamengo reposicionada no Ediacarano, o período final do Neoproterozoico. Recentemente, análises geocronológicas em zircões detríticos em tufos vulcânicos, nas pedreiras Laginha e Corcal, forneceram uma idade de $543 \pm 3$ Ma para a Formação Tamengo, corroborando, assim, a proposta da idade bem próxima do limite Pré-Cambriano/Cambriano (Babinski et al. 2006, 2008; Boggiani et al. 2010).

A Formação Tamengo grada bruscamente para a Formação Guaicurus. Esta formação foi definida por Almeida (1965) em mapeamento no Planalto da Bodoquena. Segundo Gaucher et al. (2003), tem espessura em torno de 150 m, apesar de Almeida (1965), com base em fotografias aéreas, ter atribuído valores da ordem de $1.000 \mathrm{~m}$. A Formação Guaicurus é constituída por um contínuo e espesso pacote pelítico (Almeida 1965; Boggiani 1998; Gaucher et al. 2003). A brusca transição da deposição carbonática para terrígena pode ter sido causada por diversos fatores, que teria provocado maior aporte 
siliciclástico na bacia, entre os quais tectonismo, afogamento da plataforma carbonática devido à elevação do nível de mar, ou mudanças climáticas. Gaucher et al. (2003) descreveram a ocorrência do vendotenídeo Eoholynia corumbensis, encontrado na base da formação, e relacionado ao final do Ediacarano (vide Gnilovskaya 1985).

Tabela 2: Resumo esquemático da estratigrafia do Grupo Corumbá e Formação Puga no Estado do Mato Grosso do Sul, Brasil. Segundo Almeida (1965), Boggiani (1998), Gaucher et al. (2003), e o presente trabalho.

\begin{tabular}{|c|c|c|c|c|}
\hline & nidade & Espessura & Litologia & Fósseis associados \\
\hline & $\begin{array}{l}\text { Formação } \\
\text { Guaicurus }\end{array}$ & $150 m$ & Folhelho & $\begin{array}{l}\text { Eoholynia corumbensis } \\
\text { Cloudina lucianoi } \\
\text { Soldadophycus bosii }\end{array}$ \\
\hline $\begin{array}{l}\frac{1 \pi}{0} \\
\stackrel{2}{\xi} \\
\vdots \\
0 \\
0 \\
0 \\
0\end{array}$ & $\begin{array}{l}\text { Formação } \\
\text { Tamengo }\end{array}$ & $200 \mathrm{~m}$ & $\begin{array}{l}\text { Calcisiltito com fino nível de } \\
\text { arenito, nível } \\
\text { conglomerático com } \\
\text { intraclastos, calcisiltito, } \\
\text { grainstone oolítico, margas e } \\
\text { calcário bioclástico }\end{array}$ & $\begin{array}{l}\text { Corumbella werneri } \\
\text { Cloudina lucianoi } \\
\text { Bavlinella faveolata } \\
\text { Soldadophycus bosii } \\
\text { Vendotaenia antiqua }\end{array}$ \\
\hline $\bar{\Xi}$ & $\begin{array}{l}\text { Formação } \\
\text { Bocaina }\end{array}$ & $100 \mathrm{~m}$ & $\begin{array}{l}\text { Dolomito e finos níveis de } \\
\text { fosforitos }\end{array}$ & $\begin{array}{c}\text { Estromatólitos de diversas } \\
\text { formas, Titanotheca } \\
\text { coimbrae }\end{array}$ \\
\hline & $\begin{array}{l}\text { Formação } \\
\text { Cerradinho }\end{array}$ & $150 \mathrm{~m}$ & $\begin{array}{c}\text { Arenitos quartzosos, arcósios } \\
\text { e folhelhos }\end{array}$ & $\begin{array}{l}\text { Bavlinella faveolata } \\
\text { Soldadophycus bosii }\end{array}$ \\
\hline & $\begin{array}{l}\text { Formação } \\
\text { Cadiueus }\end{array}$ & $150 \mathrm{~m}$ & $\begin{array}{c}\text { Conglomerados, arcósios e } \\
\text { folhelhos }\end{array}$ & - \\
\hline & lação Puga & $100 \mathrm{~m}$ & $\begin{array}{c}\text { Formações ferríferas, } \\
\text { diaqmictitos e seixos caídos } \\
\text { (dropstones?) }\end{array}$ & - \\
\hline
\end{tabular}


Tabela 3: Esquema das fáceis e associações de fáceis da Formação Tamengo aflorantes na região de Corumbá. Extraído de Oliveira (2010).

\begin{abstract}
ASSOCIAÇÃO/FÁCIES
SHOREFACE COM BARRAS OOLÍTICAS

Grainstone intraclástico maciço (Gim) de coloração escura e formada por fragmentos arredondados de micrito e packstone oolítico. Raros grãos terrígenos Localmente ocorre brecha intraformacional com clastos de até $4 \mathrm{~cm}$.

Grainstone oolítico maciço (Go) Grainstones com ooides compostos e simples de $0,4 \mathrm{~mm}$ de diâmetro, apresentando cimento calcítico em franja. Presença de intraclastos oolíticos. Grãos de quartzo são raros.

Ritmito mudstone calcífero/folhelho (Rmf) com sets variando de 5 a $10 \mathrm{~cm}$ de espessura betuminoso.
\end{abstract}

\section{OFFSHORE INFLUENCIADO POR TEMPESTADE}

\section{Calcário cristalino com estratificação cruzada swaley/hummocky (Csh) Calcário fino de cor cinza escura, com aproximadamente $5 \%$ de grãos terrígenos. Apresenta fragmentos de conchas de Cloudina, com 0,9mm de diâmetro e até 1 $\mathrm{cm}$ de comprimento.}

Calcário cristalino maciço $(\mathrm{Cm})$ Calcário cristalino cinza escuro com até $5 \%$ de terrígenos. Ocorrem fragmentos do macrofóssil Cloudina.
Camada tabulares e

lateralmente contínuas por dezenas de metros.
Ressedimentação através de fluxos trativos/oscilatórios (?).
Camadas de até $1 \mathrm{~m}$ de espessura, tabulares e lateralmente contínuos.
Precipitação carbonática sob atuação de fluxos trativos em ambiente de alta energia
Laminação plana

Estratificação cruzada do tipo hummocky/swaley, e estratificação cruzada de baixo ângulo $\left(<10^{\circ}\right)$.
Deposição por fluxo combinado dominantemente oscilatório por ondas de tempestades.

\section{Camadas planas e lateralmente contínuas.}

\begin{abstract}
Alternância entre precipitação química e deposição de grãos terrígenos em ambientes de baixa energia
\end{abstract}

Precipitação química de carbonato em ambiente com energia moderada a alta 


\section{CAPÍTULO 5}

\section{Material e Métodos}

\subsection{Material examinado}

Foram examinados, no total, 33 amostras de mão e 127 lâminas petrográficas, provenientes de cinco fácies da Formação Tamengo, distribuídas nas pedreiras Saladeiro, Laginha, Corcal e arredores; e de uma fácies da Formação Guaicurus, na Pedreira Corcal (vide Tabs. 1 e 2, Anexo III). O material está depositado na Coleção Científica de Invertebrados GP/1E (amostras) e GP/L1E (lâminas petrográficas) do Laboratório de Paleontologia Sistemática (LPS) do Instituto de Geociências da Universidade de São Paulo (IGc-USP).

\subsection{Atividades de laboratório}

Tendo em vista que a observação da maior parte das feições morfológicas e tafonômicas, analisadas no estudo de Cloudina necessita de auxílio de equipamentos ópticos (e.g., estereomicroscópio, microscópio eletrônico de varredura), grande atenção foi dispensada às preparações físicas e químicas, e observação direta das amostras.

As amostras foram analisadas no Laboratório de Estudos Paleobiológicos do Departamento de Geologia Sedimentar e Ambiental (GSA) do IGc/USP, com o auxílio do estereomicroscópio binocular Zeiss e microscópio petrográfico AxioLab, na finalidade de examinar características morfológicas e tafonômicas em amostras de mão e lâminas petrográficas. Os gráficos de frequência dos espécimes foram confeccionados através dos programas Microsoft Office Excel, e os dados direcionais em azimute das amostras da Pedreira Corcal foram confeccionados através do software Oriana. 
5.2.1. Descrição morfológica e análise sistemática e tafonômica dos espécimes

Foi analisado o conjunto de assinaturas bioestratinômicas e diagenéticas em fósseis de Cloudina lucianoi com o intuito de relacioná-las às interpretações paleoambientais já existentes na literatura para estas localidades (Boggiani 1998; Oliveira 2010).

Esta etapa considerou, na medida do possível, as recomendações sugeridas por Dunham (1962) para a classificação das rochas calcárias; Behrenmeyer \& Kidwell (1985), Kidwell et al. (1986), Speyer \& Brett (1986), Kidwell \& Holland (1991) e Lucas (2001), para as considerações tafonômicas; e Germs (1972), Zaine \& Fairchild (1985, 1987), Grant (1990) e Cortijo et al. (2010) para questões taxonômicas.

\subsubsection{Imagens digitais}

Imagens das amostras em escala macroscópica (centimétrica) foram fotografadas câmera digital Canon Power Shot SX 200 IS, enquanto as imagens em escala meso e microscópica (milimétrica e micrométrica) foram fotografados através do sistema de captura de imagem AxioVision 4.0 e 4.8, acoplado ao estereomicroscópio e microscópio. Esta última técnica foi utilizada em função do alto poder de resolução e da ampliação das imagens oferecidos pelo estereomicroscópio, e pelo fato do aplicativo (software) viabilizar a obtenção dos principais parâmetros biométricos de Cloudina, diretamente na tela do computador. Todas as imagens foram tratadas com o auxílio dos softwares Corel Draw 12 e Microsoft Office Picture Manager.

\subsubsection{Microscopia Eletrônica de Varredura (MEV)}

Os dois espécimes extraídos quimicamente da amostra GP/1E-6219 foram recobertos com carbono e eletromicrografados em aparelho de MEV Leo 440 em conjunto com o Eng. Dr. Isaac Jamil Sayeg (GSA/IGc/USP). A alta resolução do MEV permitiu a ampliação das imagens e possibilitou a observação das principais feições morfológicas e ultraestruturais. 


\subsubsection{Preparações química e física}

A preparação química, realizada no Laboratório de Estudos Paleobiológicos (GSA/IGc/USP), envolveu a aplicação, com o auxílio de um pincel fino, de ácido clorídrico a 10\% sobre a superfície da amostra 6219 , onde ocorrem fósseis de Cloudina lucianoi silicificados. A extração de dois exemplares desta amostra foi possibilitada pela remoção gradual do carbonato adjacente.

A preparação física foi desenvolvida no Laboratório de Preparação de Amostras (GSA/IGc/USP) e consistiu no corte de amostras em serra equipada com um disco diamantado Dinser 0300 para poder selecionar os melhores locais para a confecção de lâminas petrográficas. As superfícies cortadas, uma vez polidas com lixa d'água ou cobertas por um spray plástico incolor permitiram o exame dos fósseis em seu contexto sedimentológico em escala mesoscópica.

As lâminas petrográficas que foram confeccionadas especialmente para este projeto foram produzidas na Seção de Laminação do IGc/USP.

\subsection{Atividades de campo}

Foi realizada uma viagem de campo entre os dias 03 e 07 de dezembro de 2010 para a região de Corumbá na companhia de Prof. Dr. Thomas R. Fairchild, Mirian Liza Alves Forancelli Pacheco e Guilherme R. Romero. Nesta viagem foram examinadas as três pedreiras que melhor expõem a Formação Tamengo naquela região -- Saladeiro (Companhia de Cimento Portland Itaú, em Ladário, na divisa com Corumbá ao oeste), Laginha (Companhia de Cimento Portland Itaú, $16 \mathrm{~km}$ ao sul de Corumbá ao longo da rodovia BR-262, Corumbá-Campo Grande) e Corcal (logo ao oeste de Corumbá) (Capítulo 4, Figura 4.1.1 B) -- bem como o Parque Municipal Marina Gattaz (ao oeste da cidade de Corumbá na estrada principal que vai para Bolívia, aproximadamente $700 \mathrm{~m}$ antes da divisa), que é pavimentado por lajes de calcário fossilífero da Formação Tamengo. 


\section{CAPÍTULO 6}

\section{Resultados}

Cloudina é um fóssil relativamente comum em certas partes da Formação Tamengo na região de Corumbá e no presente trabalho foi encontrado em amostras representativas de quatro fácies, definidas previamente por Boggiani (1998) e Oliveira (2010), nas pedreiras de Laginha, Saladeiro e Corcal (Tab. 4, Fig. 6). A fácies de Cloudina rudstones (sensu Boggiani 1998), correspondente à fácies de calcário cristalino com estratificação cruzada hummocky e swaley de Oliveira (2010), foi aqui considerada como packstones bioclásticos, pois se observou matriz micrítica em lâminas petrográficas, corroborando observações de Zaine (1991) e Boggiani (1998). Também foi analisada uma laje, de procedência geográfica desconhecida, coletada no Parque Marina Gattaz, Município de Corumbá. E, pela primeira vez, Cloudina foi encontrada na Formação Guaicurus, em uma lente carbonática a mais de 40 metros acima do contato com a Formação Tamengo.

Tabela 4: Fácies das formações Tamengo e Guaicurus contendo Cloudina na região de Corumbá, MS. Nome das fácies segundo Oliveira (2010), exceto packstones bioclásticos e mudstones com Cloudina, criadas no presente trabalho.

\begin{tabular}{|l|c|c|c|c|c|}
\hline \multirow{2}{*}{ Fácies } & \multicolumn{1}{|c|}{$\begin{array}{c}\text { Pedreira } \\
\text { Laginha }\end{array}$} & $\begin{array}{c}\text { Pedreira } \\
\text { Saladeiro }\end{array}$ & $\begin{array}{c}\text { Pedreira } \\
\text { Corcal }\end{array}$ & $\begin{array}{c}\text { Pedreira } \\
\text { Corcal }\end{array}$ & $\begin{array}{c}\text { Parque } \\
\text { Marina } \\
\text { Gattaz }\end{array}$ \\
\cline { 2 - 7 } & \multicolumn{2}{|c|}{ Fm. Tamengo } & $\begin{array}{c}\text { Fm. } \\
\text { Guaicurus }\end{array}$ & $\begin{array}{c}\text { Fm. } \\
\text { Tamengo }\end{array}$ \\
\hline $\begin{array}{l}\text { Ritmito mudstone calcífero } \\
\text { / folhelho }\end{array}$ & $\mathbf{X}$ & & & & \\
\hline Grainstones oolíticos & $\mathbf{X}$ & & & & \\
\hline Calcário maciço cristalino & & $\mathbf{X}$ & $\mathbf{X}$ & & \\
\hline Packstones bioclásticos & & $\mathbf{X}$ & & $\mathbf{X}$ & $\mathbf{X}$ \\
\hline Mudstones com Cloudina & & & & & \\
\hline
\end{tabular}


Laginha

Saladeiro

Corcal
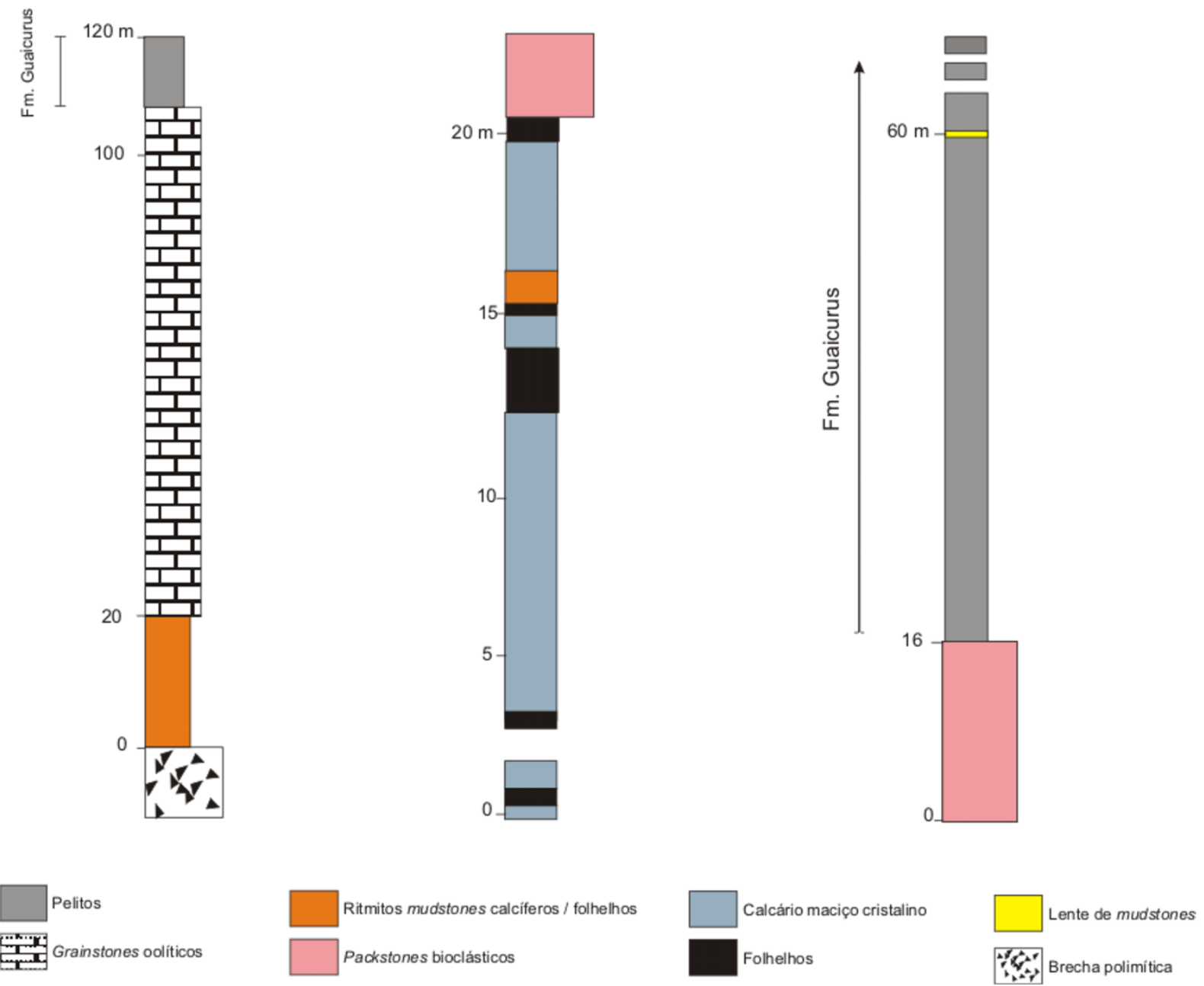

Figura 6: Colunas estratigráficas das pedreiras estudadas. Extraídas de Boggiani et al. (2010). A estratigrafia da Pedreira Corcal foi baseada em T.R. Fairchild (com. pess.).

\subsection{Pedreira Laginha}

Nesta localidade, foram identificadas duas fácies onde ocorrem fósseis de Cloudina: a fácies de ritmito mudstone calcífero / folhelho (Rmf), e a fácies de grainstone oolítico (Go), próximo ao topo da seção (Fig. 6).

6.1.1. Fácies de ritmito mudstone calcífero / folhelho, Rmf:

O material coletado nesta fácies provém da frente oeste de lavra da pedreira, coletado por T. R. Fairchild e M. F. Zaine, em 1984, e da frente leste, a mais de 500m da frente oeste, coletado por F. V. E. Meira, T. R. Fairchild, M. L. A. F. Pacheco e G. R. Romero em dezembro de 2010. Nesta pedreira, esta 
fácies representa um pacote tabular com 10 a 15 metros de espessura, composta por níveis centimétricos com predominância de mudstones alternados com lâminas milimétricas de folhelho. Em rochas frescas, a coloração é tipicamente negra, provavelmente pela presença de matéria orgânica, apresentando-se amarelada em função do intemperismo (Boggiani 1998; Oliveira 2010). Esta fácies também ocorre na Pedreira Saladeiro (Zaine 1991; Boggiani 1998), mas a análise de lâminas petrográficas não revelou evidências convincentes da presença de Cloudina.

Grãos envelopados são comuns nestas rochas, e incluem ooides normais e bentônicos, estes últimos quase sempre muito pequenos, do tamanho de silte ou areia fina, raramente ultrapassando cento e poucos micrômetros (Prancha 1, A e B). Além de ooides, também estão presentes microfitólitos os quais se apresentam, em alguns casos, envolvidos por uma fina lâmina externa (Prancha 1, C). Evidentemente, o ambiente era propício para a precipitação de finas películas em torno de núcleos de qualquer tamanho e natureza.

Os ooides bentônicos merecem atenção especial. Estas estruturas ocorrem tanto no paredão ocidental como no oriental, aonde chegam a ser relativamente comuns. O que os distingue de ooides normais é, além do tamanho pequeno, próximo do limite areia/silte, sua estrutura interna, que consiste em poucas lâminas sem um núcleo aparente. Isto, mais o crescimento assimétrico evidente em vários exemplares (Prancha 1, B e E), sugerem que não devem ter se formado por precipitação em torno de partículas mantidas em suspensão, como é apontado para a origem de ooides normais. Segundo Flügel (2004), estes ooides podem se originar por precipitação em torno de partículas orgânicas (ou até gotas líquidas) dentro de esteiras microbianas. Assim, haveria uma alternânica de precipitação de fibras de aragonita (que deixou sua assinatura palimpséstica nas lâminas claras nos exemplares na Laginha) e recobrimento por biofilmes finos, agora representadas pelas lâminas mais escuras, tingidas pela matéria orgânica.

Do mesmo modo, os microfitólitos também merecem destaque. Microfitólitos são estruturas enigmáticas, comuns em certos carbonatos pré- 
cambrianos, parecidas com alguns tipos de grãos agregados e intraclastos, mas que diferem destes pela presença de contornos com reentrâncias difíceis de explicar pelos processos de cimentação precoce, erosão e abrasão normalmente atuantes na formação de grãos agregados e intraclastos. Swett \& Knoll (1985), entretanto, propuseram que estas estruturas teriam se formado por processos envolvendo atividades microbianas e baixa agitação da água. Com a irradiação evolutiva de organismos macroscópicos (invertebrados, macroalgas), e a subseqüente revolução agronômica (Seilacher \& Pflüger 1994), mencionada previamente, estas estruturas praticamente sumiram do registro geológico quando as condições físico-químicas e ecológicas propícias para a formação de microbialitos foram eliminadas das regiões rasas de ambientes marinhos normais.

Também foram observados aqui intraclastos com aspecto maculado, não laminado, interpretados como fragmentos de microbialitos do tipo trombólito (Prancha 1, D). Curiosamente, na mesma lâmina petrográfica, ocorrem pequenos conjuntos compactos de células cocoides, cada qual entre 10 e $15 \mu \mathrm{m}$ em diâmetro (Prancha 1, E). Pelo tamanho muito pequeno, pela forma simples e pelo arranjo apertado das células, estes conjuntos devem representar pequenos fragmentos desprendidos de uma esteira microbiana não muito longe.

A análise de lâminas petrográficas de material coletado do lado leste da lavra na pedreira Laginha demonstrou que os níveis carbonáticos nos ritmitos variam de mudstones a packstones (Prancha 1, F). Cloudina é comum, ocorrendo predominantemente como fragmentos. Um exemplar exibe aspecto de concha corrugada, podendo representar um corte longitudinal da carapaça de Corumbella, ou mesmo da concha de Sinotubulites (Prancha 1, G e H). Exemplares mais completos também foram vistos, alguns exibindo fraturas por compactação (Prancha 1, F e I). Em um indivíduo, foram observadas abas divergindo do eixo da concha, como na nova espécie, Cloudina latilabrum, descrita no Anexo I (Prancha 1, J).

Dentre os maiores componentes granulares nestas rochas são grãos compostos (ou agregados), microfitólitos, ooides normais, fragmentos de 
Cloudina e outros bioclastos com aspecto de parede de concha corrugada, todos chegando ao tamanho de areia média, ou maior, no caso dos bioclastos. Intraclastos variam muito de tamanho, desde silte até areia média ou maior, enquanto peloides e ooides bentônicos raramente passam do tamanho de areia fina. Deste lado da pedreira, as lâminas petrográficas investigadas apresentam laminação sedimentar menos bem selecionada e menos nítida do que aquela vista do lado oeste. Desta forma, a laminação no leste inclui praticamente todas as categorias de grãos mencionadas acima, enquanto no oeste, parece haver maior frequência de lâminas melhor selecionadas compostas principalmente de ooides normais (Prancha 1, A).

Das amostras coletadas nesta fácies durante as pesquisas de doutoramento de M.F. Zaine (1991), na frente oeste da lavra, três apresentam Cloudina lucianoi, com um indivíduo evidente em cada amostra (Prancha 2, A e B), todos expostos na superfície de camadas muito finas de mudstones ( 3 a 6 $\mathrm{mm}$ de espessura) com laminação interna ainda mais fina. Os fósseis são fragmentos visíveis no plano de acamamento das amostras como seções transversais circulares ou ligeiramente ovaladas (Prancha 2, A - E) com diâmetros próximos das dimensões maiores conhecidas para esta espécie (Tab. 5). Um exemplar apresenta concha composta de dois anéis concêntricos, sendo o mais externo incompleto (Prancha 2, D). Outro espécime apresenta espessamento em um dos lados da parede (Prancha 2, B e C). O terceiro exemplar exibe apenas um anel incompleto; neste caso, possivelmente, parte da estrutura se encontra encoberta pelo sedimento (Prancha 2, E). Duas observações sugerem que estes fósseis não se tratam de seções transversais de conchas inteiras de Cloudina em posição de vida, mas sim de fragmentos: a) embora o diâmetro destes fósseis seja da ordem da espessura da laminação fina nas amostras, nenhum destes fósseis tem continuação no lado oposto da fina amostra em que ocorre; b) estes fósseis de Cloudina são evidentemente muito raros nestas amostras e desacompanhados de qualquer evidência de exemplares de conchas mais completas depositados paralelos ou oblíquos ao acamamento. 
Tabela 5: Diâmetros de Cloudina lucianoi em amostras da fácies ritmitos mudstones / folhelhos da Formação Tamengo. Frente oeste de lavra da Pedreira Laginha.

\begin{tabular}{lc}
\hline Amostra & Diâmetro (mm) \\
\hline GP/1T-109 & 2,0 \\
GP/1E-6215 & 2,8 \\
GP/1T-108 & 2,9 \\
\hline
\end{tabular}

No mesmo intervalo estratigráfico e na mesma fácies, ocorrem fósseis conferidos à Corumbella werneri, (Zaine \& Fairchild 1987). Na amostra GP/1T108 (Prancha 2, A), por exemplo, ao menos três exemplares de $C$. werneri ocorrem próximos a um de $C$. lucianoi. Os fósseis de $C$. werneri são fragmentos achatados, orientados paralelos ao acamamento e com diferentes graus de degradação (Prancha 3, A - D). Por comparação com C. werneri em folhelhos da Pedreira Saladeiro (Prancha 3, E e F), pode se dizer que as feições mais nítidas nestes fósseis correspondem à segmentação e ornamentação transversal da carapaça do organismo. A degradação e o achatamento destes fósseis contrastam com o aspecto mais íntegro e rígido de C. Iucianoi , conforme observado na Prancha 2, B.

\subsubsection{Fácies de grainstone oolítico, Go}

O material examinado desta fácies foi coletado por T.R. Fairchild e M.F. Zaine na frente de lavra oeste da Pedreira Laginha em 1979 e em 1984.

Nesta fácies, os fósseis ocorrem em meio aos ooides, ou como o núcleo de ooides, sendo mais frequentes na lâmina GP/L-1T-1 (Prancha 4, A). São predominantemente fragmentos recristalizados, visíveis em seções longitudinais e, em alguns casos, transversais (Prancha 4, B). Embora seja impossível saber se as seções transversais representam conchas mais ou menos completas ou apenas fragmentos, alguns raros exemplares mostram preservação de boa parte da concha em seção longitudinal (Prancha 4, A). As paredes dos bioclastos exibem superfícies irregulares, talvez devido à dissolução incipiente, e variação na espessura, ou ainda, sinais de deformação dúctil (Prancha 4, C). Os fragmentos que serviram como núcleo para ooides são muito delicados e sem evidências de abrasão (Prancha 4, C e D). 
Alguns ooides apresentam-se fragmentados ou deformados, e, por vezes, a preservação destas estruturas foi comprometida pelo desenvolvimento de estilólitos sub-milimétricos a milimétricos. Observam-se também ooides com o núcleo recristalizado por calcita espática, apresentando apenas o córtex preservado (Prancha 4, E).

\subsection{Pedreira Saladeiro}

Na Pedreira Saladeiro foram estudadas as fácies de calcário maciço cristalino $(\mathrm{Cm})$ e packstone bioclástico (Pkb), coletados por T.R. Fairchild em 1979, e T.R. Fairchild e M.F. Zaine em 1984 (Fig. 6).

\subsubsection{Fácies de calcário maciço cristalino, $\mathrm{Cm}$}

Nestes calcários, Cloudina lucianoi, o único fóssil desta fácies, ocorre como fragmentos recristalizados alongados e em seções transversais, dispersos ou fracamente empacotados (Prancha 5, A). Compreendem menos de $10 \%$ dos componentes da rocha. Apresentam superfície irregular e variação na espessura ao longo da extensão da concha (Prancha 5, B).

O neomorfismo não permite constatar feições sin e epideposicionais, como preenchimento espático do interior da concha ou estruturas geopetais. Os fragmentos alongados, ligeiramente encurvados (Prancha 5, B), são interpretados como parte de seções longitudinais. Os fósseis em seção transversal (Prancha 5, A e C ) têm diâmetros entre 0,2 e 0,6 mm, embora um exemplar com diâmetro bem superior $(1,8 \mathrm{~mm})$ tenha sido visto. Deformação dúctil é evidente em alguns espécimes, como na seção oblíqua do fóssil ilustrado em C (Prancha 5).

\subsubsection{Fácies de packstone bioclástico, Pkb}

Zaine (1991) assinala que as camadas nesta fácies são representadas por níveis fossilíferos, com predominância de cimento espático, onde os bioclastos ocorrem de modo caótico, alternados com níveis micríticos, 
representando uma fase de decantação. Outras assinaturas tafonômicas observadas por Zaine (1991) incluem a recristalização da concha, que apresenta superfície irregular produzida por dissolução; deformação dúctil e rúptil em alguns exemplares; presença de fragmentos de concha no interior de bioclastos maiores; preenchimento espático no interior de conchas, com a ocorrência de diferentes gerações de cimento; estruturas geopetais; e silicificação local de parte dos fósseis e da matriz (Prancha 6, A - D).

O presente trabalho confirmou as observações de Zaine (1991) e foi além, observando que a silicificação que ela observou em blocos soltos coletados em 1979 (Prancha 6, D), restringe-se à superfície superior da camada, conforme indicada por estruturas geopetais observadas em lâminas petrográficas. Medidas do diâmetro de 105 exemplares de conchas de Cloudina na superfície e em cortes polidos nestas amostras apontaram maior frequência de indivíduos com dimensões entre 2 e 2,5 mm (Fig.6.1). Doze exemplares apresentam seções transversais com contorno poligonal da concha (Prancha 6, C), similar ao espécime classificado por Vidal et al. (1994) como ?Cloudina sp., e ilustrado por eles em D, Figura 12. Boggiani (1998) observou feição similar em conchas de Cloudina em packstones bioclásticos da Pedreira Corcal.

Em análises de amostras de mão e lâminas petrográficas do material coletado desta pedreira em 1984 e 1988, não há sinais de silicificação. Nas amostras GP/1E-3870 e GP/1E-3878, entretanto, os fósseis também sobressaem na superfície superior da camada, não por que foram silicificadas, mas porque estão preservados como moldes internos constituídos de calcita espática, que resiste mais à dissolução do que microespato e micrita (Prancha 6, E). Na lâmina petrográfica GP/L1E-24, confeccionada a partir da amostra solta GP/1E-6221, observa-se um nível fossilífero, com cimento espático, entre dois níveis micríticos. Neste nível, ocorre uma seção longitudinal e oblíqua de um exemplar de Cloudina latilabrum nov. sp. (Prancha 6, F). 


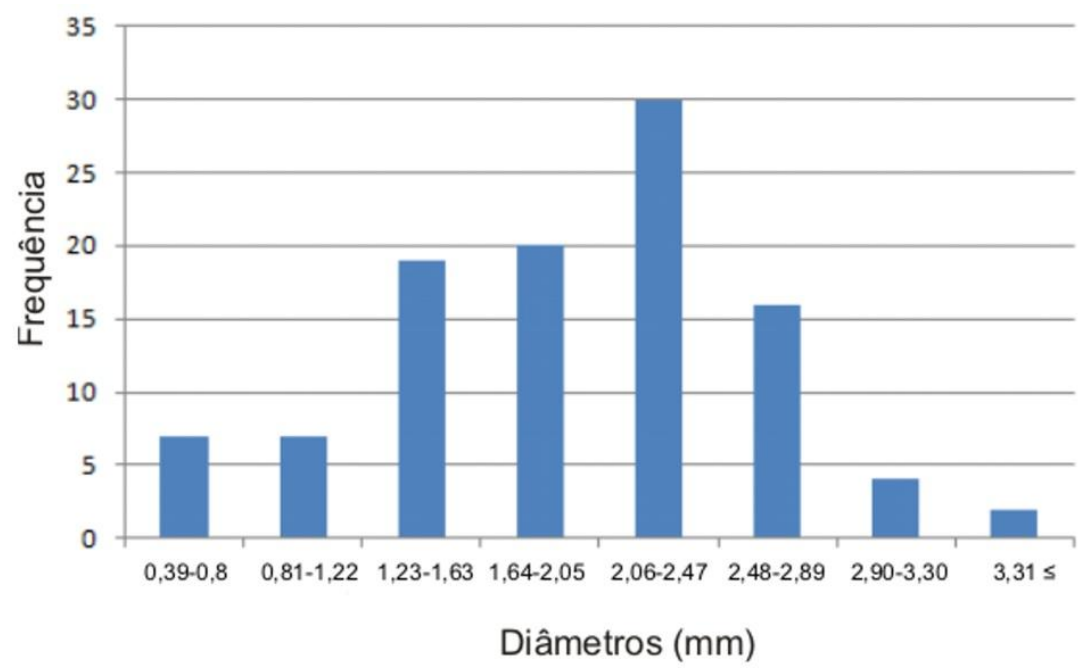

Figura 6.1: Frequência de diâmetros de Cloudina lucianoi na amostra 6219, da fácies packstone bioclástico, Pedreira Saladeiro. $\mathrm{N}=105$; amplitude de classes $=0,4 \mathrm{~mm}$.

\subsection{Pedreira Corcal}

$\mathrm{Na}$ área da pedreira ativa próximo da sede da firma Corcal, observam-se Cloudina na fácies de packstone bioclástico (Pkb), associada a estruturas hummocky (tempestitos) nos carbonatos da Formação Tamengo, e o primeiro registro deste fóssil na Formação Guaicurus, em uma lente fina da fácies de mudstones com Cloudina (Mud) a mais de 40 metros acima do contato com a Formação Tamengo (Fig. 6).

\subsubsection{Fácies de packstone bioclástico, Pkb}

Foram analisadas amostras coletadas na pedreira Corcal em 1994 de uma camada fina, mas lateralmente extensa, de coquinito de Cloudina (Cloudina rudstones de Boggiani 1998), situada entre 11 e $12 \mathrm{~m}$ abaixo do topo da seção carbonática, e cerca de $80 \mathrm{~cm}$ acima da sucessão de pelo menos $1 \mathrm{~m}$ de espessura de calcários e folhelhos alternados, na base da seção da pedreira naquela época (T. R. Fairchild, com. pessoal, julho, 2011). Desde então, o avanço da lavra na pedreira evidentemente consumiu esta lente.

Este coquinito é caracterizado pelo denso empacotamento de fósseis de Cloudina lucianoi, relativamente completos, preservados em três dimensões, ressaltados na superfície superior da camada, e orientados paralelos ao acamamento (Prancha 7, A - C). Ao contrário dos fósseis da fácies de 
packstones bioclásticos da Pedreira Saladeiro, observaram-se poucos exemplares de conchas com bioclastos em seu interior (Prancha 7, D). Medidas do diâmetro de 157 exemplares em lâminas petrográficas mostraram maior frequência de espécimes entre 1,3 e 1,5 mm, dentro da faixa de diâmetros já estabelecidos para Cloudina lucianoi (Fig. 6.2).

A análise das direções dos eixos das conchas de Cloudina expostas no topo de cinco amostras desta camada (GP/1E - 4117; GP/1E - 4119; GP/1E 4121; GP/1E - 4125 e GP/1E - 4127) apresentou resultados variados, com maior dispersão nas modas para as amostras 4117 e 4119, certa bimodalidade para as amostras 4121 e 4127 , e menor dispersão para a amostra 4125 . Além disso, a comparação na distribuição entre as amostras não mostrou nítida correlação entre elas, o que também se torna difícil pelo fato das amostras não terem sido orientadas em azimute no momento da coleta. A baixa dispersão na amostra 4125, contudo, sugere uma influência hidrodinâmica que teria realinhado os bioclastos.

Como na pedreira Saladeiro, é possível observar tanto nas amostras de mão quanto em lâminas petrográficas pelo menos duas gerações de cimento -a primeira fibrosa e a segunda em blocos, que completou o preenchimento de espaços vazios, bem como estruturas geopetais na forma de preenchimento parcial da concha por lama calcária de infiltração (Prancha 7, C, E e F). Assim, a maioria dos espécimes de Cloudina expostos na superfície da camada corresponde a moldes internos espáticos, preenchidas dessa maneira, e atualmente com sua textura granulosa claramente à vista. Evidentemente, a percolação de água, provavelmente em épocas recentes, ao longo da interface entre esta camada e a camada sobrejacente, dissolveu mais intensamente os pequenos cristais associados à parede fina da concha do que o preenchimento espático, mais grosso.

Em algumas das lâminas petrográficas, percebe-se que o neomorfismo produziu uma espécie de preservação reliquiar da concha, na qual se vê apenas o filme orgânico que delimita 0 anel mais interno dos segmentos (Prancha 7, G). Também pela análise da configuração deste filme, detectou-se 
deformação dúctil e deformação rúptil, provocadas por compactação (Prancha 7, $\mathrm{B}$ e H).

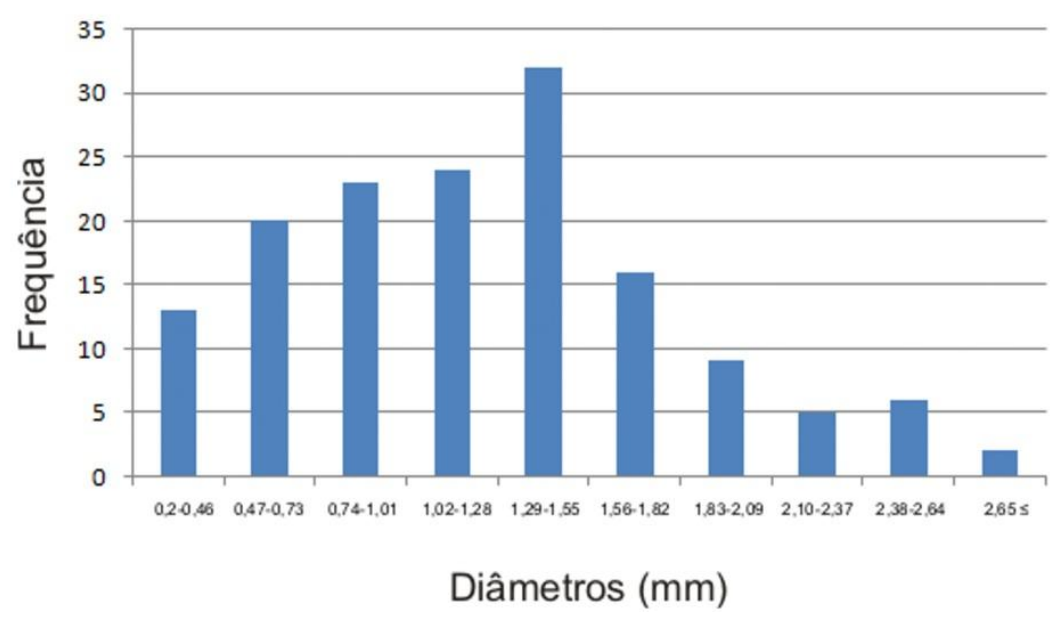

Figura 6.2: Frequência de diâmetros de Cloudina lucianoi nas lâminas petrográficas GP/L1E10 a GP/L1E-20, da fácies packstone bioclástico, Pedreira Corcal. N = 157; amplitude de classes $=0,3 \mathrm{~mm}$.

\subsubsection{Fácies de mudstones com Cloudina, Mud}

Em 2005, em uma cava imediatamente ao norte da pedreira Corcal, T.R. Fairchild, J.M. Leme e P.C. Boggiani coletaram finas placas de calcilutito contendo fósseis em uma área medindo não mais que dois metros quadrados, próxima a uma fina lente de mudstone calcária que aflorava no meio dos pelitos da Formação Guaicurus, cerca de 44 metros acima do contato com os calcários da Formação Tamengo (Fig. 6). Na melhor amostra (GP/1E-6216; Prancha 8, A) ocorrem sete fósseis na forma de seções longitudinais, retilíneas a levemente encurvadas, paralelas ao acamamento, mas aparentemente sem orientação preferencial no plano de acamamento (Prancha 8 , A e B). Individualmente, medem entre 0,8 e 1,7 mm de diâmetro e entre 2,0 e 7,8 mm de comprimento (Tab. 6), dimensões estas condizentes com C. Iucianoi. Embora não se observassem seções oblíquas ou transversais nas laterais desta amostra, que talvez revelassem a inserção sequencial de segmentos diagnóstica de Cloudina, esta feição foi detectada em um exemplar na superfície da amostra (Prancha $8, \mathrm{C}$ ), e projeções laterais, correspondendo às 
continuações das abas das conchas foram identificadas em dois espécimes, (Prancha 8, D e E). Estas observações permitem atribuir estes fósseis ao gênero Cloudina.

Tabela 6: Dimensões de Cloudina provenientes de amostra de calcilutito, Formação Guaicurus, Pedreira Corcal.

\begin{tabular}{cc}
\hline diâmetro $(\mathbf{m m})$ & comprimento $(\mathbf{m m})$ \\
\hline 0,8 & 3,0 \\
0,8 & 2,0 \\
1,4 & 7,8 \\
1,4 & 3,5 \\
1,5 & 5,4 \\
1,6 & 3,8 \\
1,7 & 4,0 \\
\hline
\end{tabular}

\subsection{Fácies de mudstones com Cloudina (Mud) nos arredores do Parque}

\section{Marina Gattaz}

Em uma laje do pavimento nesta localidade observaram-se conchas de Cloudina bem preservadas, quase completas, na superfície de um mudstone calcário. Estes fósseis são estruturas tubulares retas, encurvadas ou sinuosas, principalmente paralelos ou oblíquos ao acamamento, sendo raros os indivíduos perpendiculares (Prancha 9, A). Não se observa orientação preferencial em planta. Como nas outras ocorrências de Cloudina na região, estes fósseis apresentam preenchimento por cimento espático (Prancha 9, B e C).

A análise morfométrica dos espécimes deste nível revelou abas muito extensas, se projetando até $3 \mathrm{~mm}$ para dentro do sedimento a partir das bordas dos segmentos da concha, caracter este nunca observado nas demais espécies de Cloudina (Prancha 9, C e D). O diâmetro analisado em 63 espécimes varia entre 0,2 e 1,2 mm, com maior frequência de indivíduos entre 0,2 e 0,6 mm (Prancha 9, E). O comprimento máximo observado é de 18,5 mm. Os diâmetros obtidos na análise são comparáveis aos menores valores conhecidos em C. lucianoi, e o comprimento é ligeiramente maior. Em conjunto, 
estas informações levaram ao estabelecimento de uma nova espécie para o gênero Cloudina, Cloudina latilabrum nov. sp., descrita no Anexo I. São observados, em menor número, fósseis com diâmetros entre $0,5 \mathrm{~mm}$ e $3,3 \mathrm{~mm}$, sem as extensas abas, atribuídos à Cloudina lucianoi (Prancha 9, F).

Em lâminas petrográficas, observou-se contato erosivo entre um nível de mudstone, contendo bioclastos dispersos, e outro de packstone com predominância de fósseis mais íntegros, e fragmentos em menor quantidade. Este nível, por sua vez, grada para mudstone com fósseis fracamente empacotados, sem claros sinais de conchas fragmentadas (Prancha 9, B). Este nível corresponde ao nível exposto em planta na superfície da amostra (Prancha 9, A).

Embora o material-tipo consista de apenas um bloco de calcário solto, coletado nos arredores do Parque Marina Gattaz (oeste de Corumbá), seu posicionamento estratigráfico deve corresponder à Formação Tamengo, em função de sua litologia (calcário negro) e, principalmente, conteúdo fossilífero (Cloudina). Adicionalmente, um exemplar de Cloudina latilabrum nov. sp. foi observado em lâmina petrográfica de amostra coletada na Pedreira Saladeiro, próximo ao topo da Formação Tamengo (Prancha 6, F). 


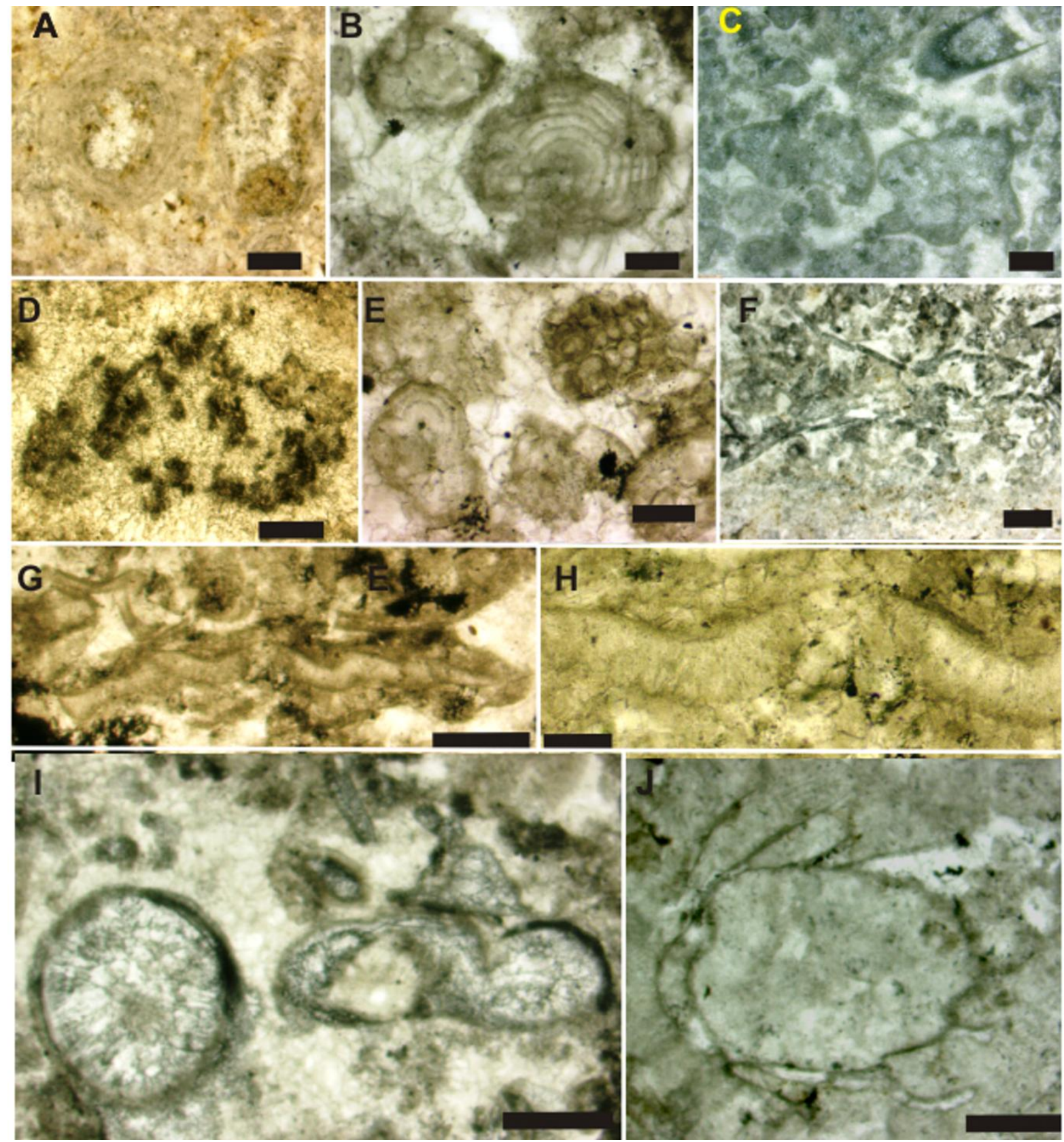

Estruturas de origem sedimentar e fósseis da fácies ritmitos mudstones calcíferos / folhelhos, fotografadas em microscópio petrográfico (Nicóis paralelos). Pedreira Laginha, Formação Tamengo. A) Ooide normal (GP/L1E - 119), proveniente da frente oeste de lavra. Escala = $100 \mu \mathrm{m}$; B) Ooide bentônico (GP/L1E - 111), frente leste de lavra. Escala $=50 \mu \mathrm{m} ; C)$ Microfitólitos (GP/L1E - 108), frente leste de lavra. Notar bioclasto (Cloudina?) no canto superior direito da figura. Escala $=300 \mu \mathrm{m}$; D) Possível trombólito (GP/L1E - 115), frente leste de lavra. Escala $=200 \mu \mathrm{m}$; E) Agregado de células cocoidais (GP/L1E - 111), frente leste de lavra. Notar ooide bentônico no canto inferior esquerdo da figura. Escala $=50 \mu \mathrm{m} ; \mathrm{F}$ ) Cloudina com múltiplas fragmentações (GP/L1E - 111), frente leste de lavra. Escala = $200 \mu \mathrm{m} ; \mathrm{G})$ Bioclasto corrugado (GP/L1E - 110), frente leste de lavra. Escala $=200 \mu \mathrm{m} ; \mathrm{H})$ Detalhe da figura anterior. Escala $=50 \mu \mathrm{m}$; I) Seções transversais de Cloudina (GP/L1E - 109), frente leste de lavra. Notar preenchimento espático em fexemplar à esquerda da figura, e deformação rúptil em fóssil à direita. Escala $=200 \mu \mathrm{m}$; J) Seção transversal a oblíqua de Cloudina, exibindo abas evidentes (GP/L1E - 113), frente leste de lavra. Escala $=200 \mu \mathrm{m}$. 

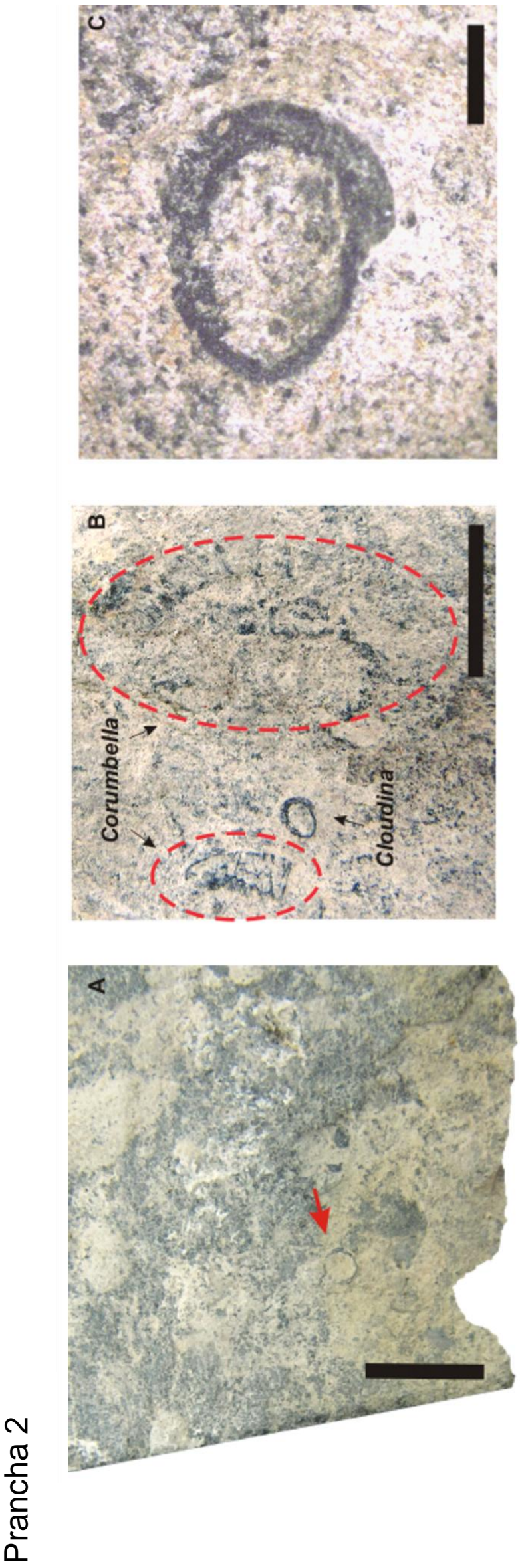

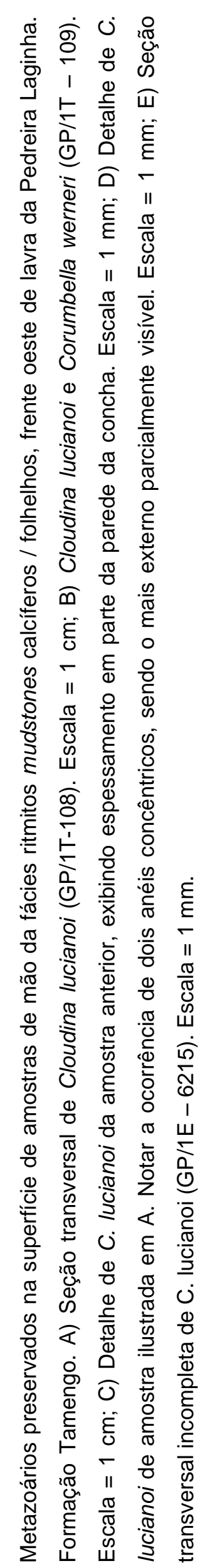

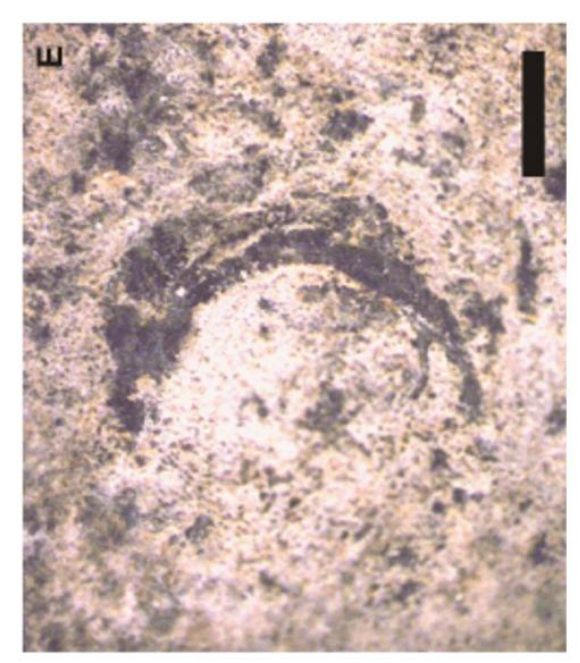

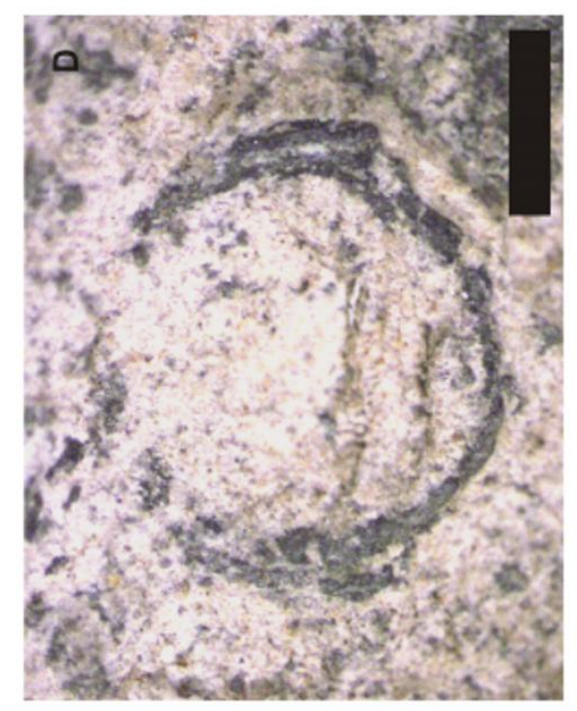




\section{Prancha 3}

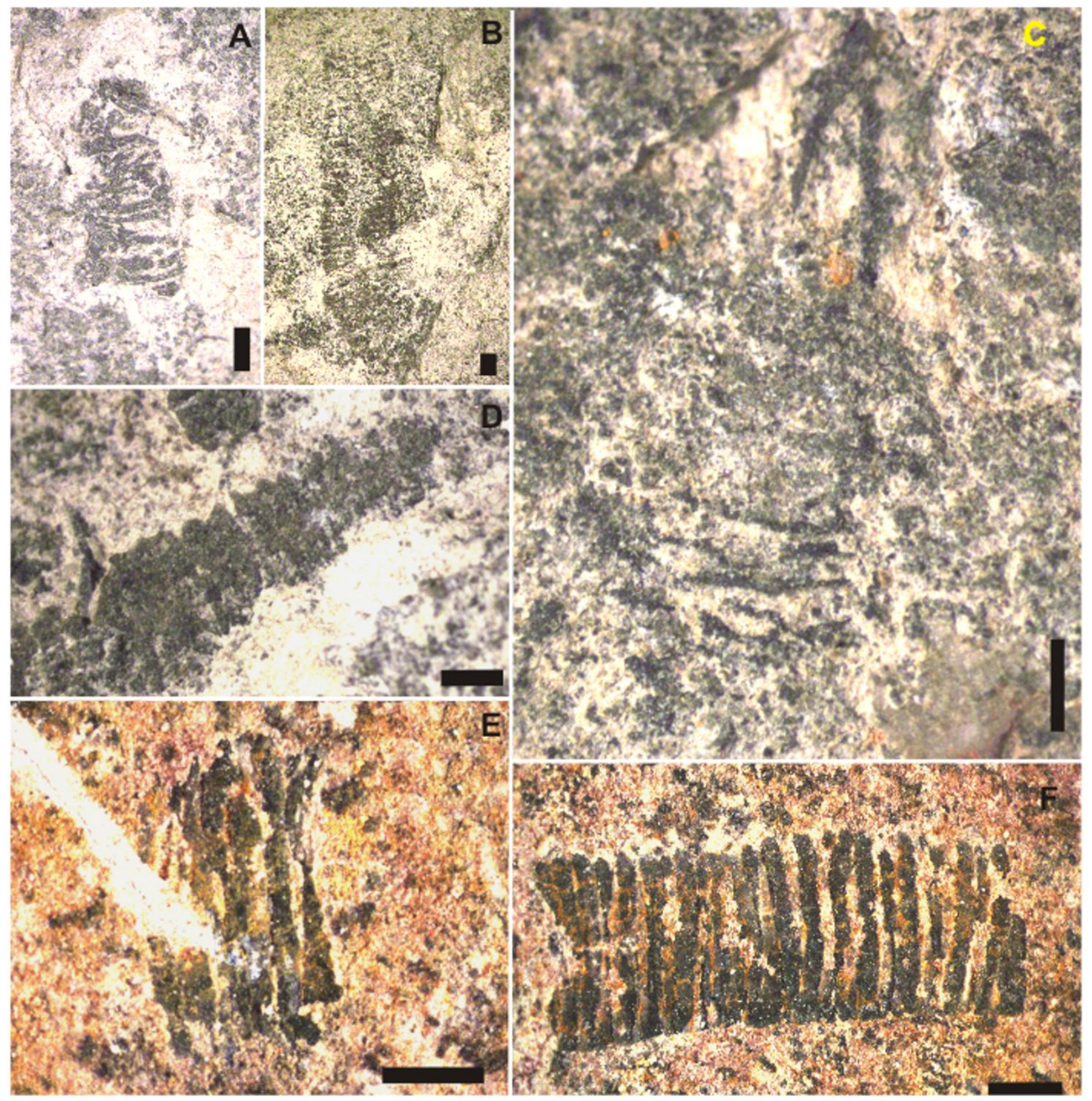

Exemplares de Corumbella werneri em superfície de amostras de mão da fácies ritmitos mudstone calcífero / folhelho, frente oeste de lavra da Pedreira Laginha $(A-D)$, e em folhelhos da Pedreira Saladeiro (E e F). Formação Tamengo. Todas as escalas representam $1 \mathrm{~mm}$. A) GP/1E - 6213; B) GP/1E - 6212; C) GP /1E - 6211; D) GP/1E - 6214; E e F) GP/1E - 5760. 


\section{Prancha 4}

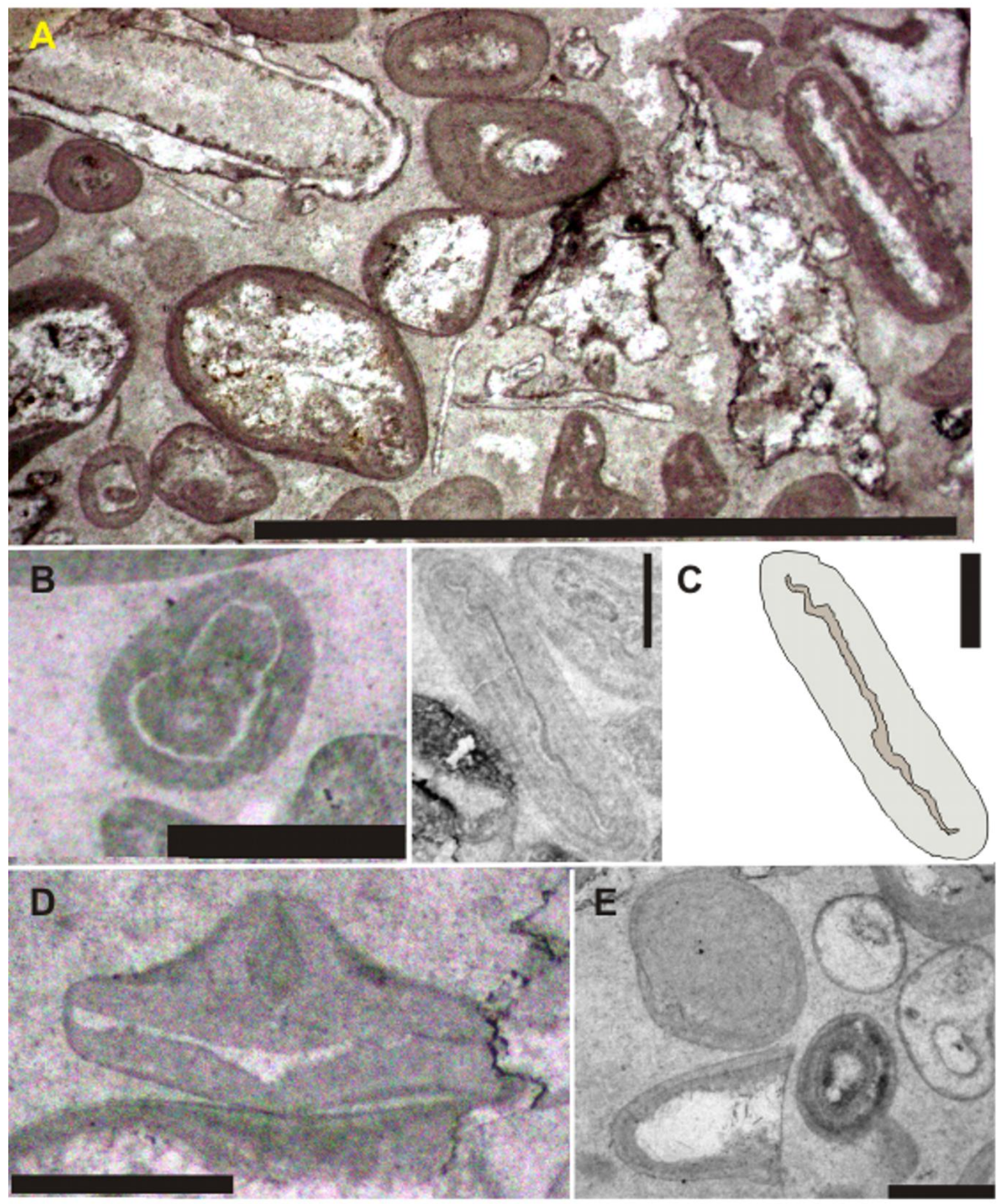

Fósseis e estruturas de origem sedimentar da fácies grainstones oolíticos. Frente de oeste de lavra da Pedreira Laginha. Formação Tamengo. Lâminas petrográficas fotografadas em estereomicroscópio. Todas as escalas representam $1 \mathrm{~mm}$, exceto em A, que representa $5 \mathrm{~mm}$. A) Vista geral da lâmina GP/L1T - 1, evidenciando um exemplar de Cloudina com boa parte da extersão da concha preservada, além de bioclastos em meio a ooides, bem como servindo de nucleação para estes. B) Seção transversal de Cloudina, exibindo envelopamento (GP/L1E - 26); C) Bioclasto com variação de espessura, servindo de núcleo para ooide (GP/L1E - 27); D) Bioclasto envelopado (GP/L1E - 32); E) Ooides com núcleo recristalizado (GP/L1E - 31). 


\section{Prancha 5}
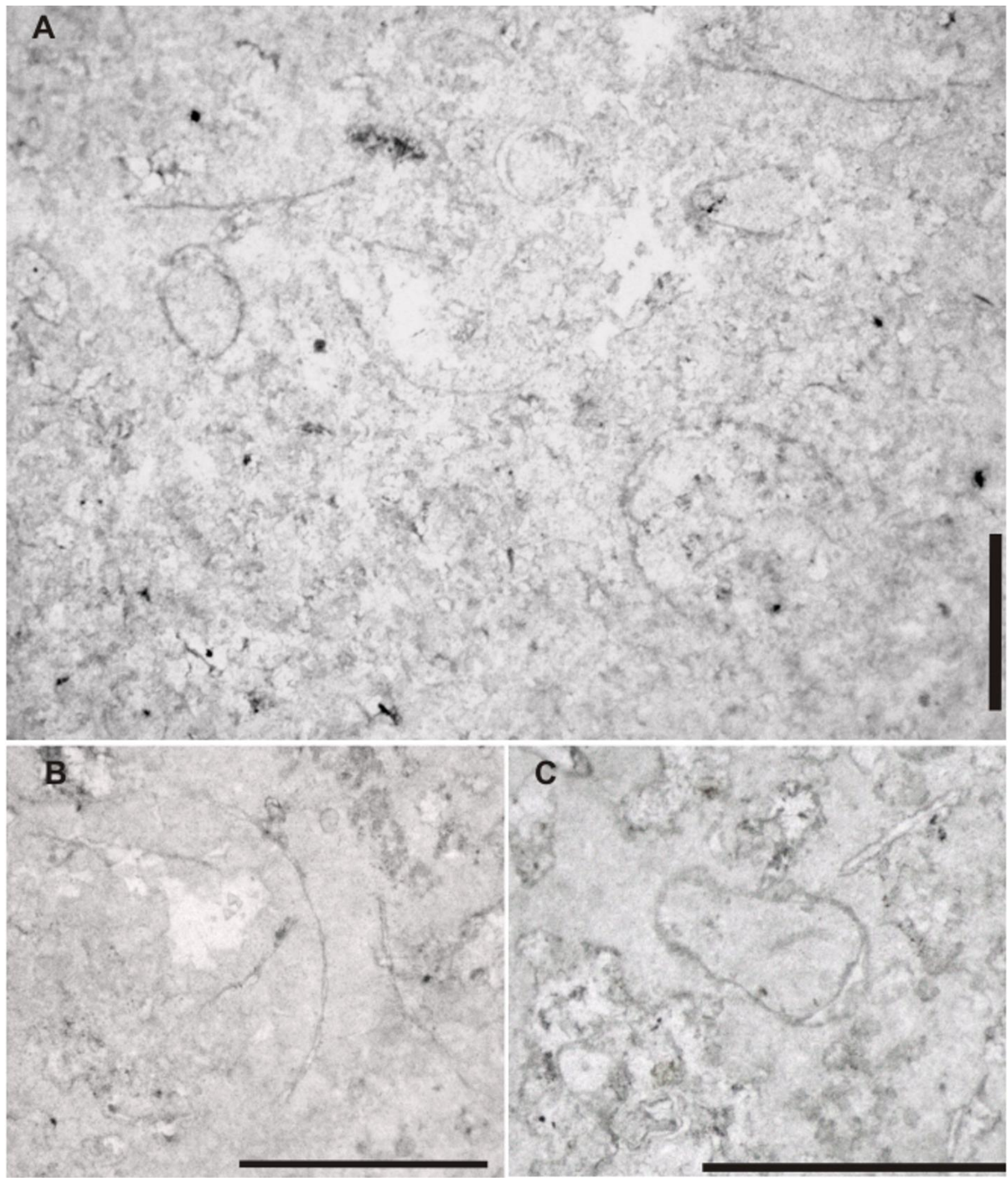

Cloudina em fácies de calcário maciço cristalino. Pedreira Saladeiro. Formação Tamengo. Lâminas petrográficas fotografadas em estereomicroscópio. Todas as escalas representam $1 \mathrm{~mm}$. A) Vista geral da lâmina GP/L1E - 21, onde se nota o empacotamento disperso a fraco dos bioclastos; Seções longitudinais (B) e transversal (C) em Cloudina (GP/L1E - 23). 


\section{Prancha 6}
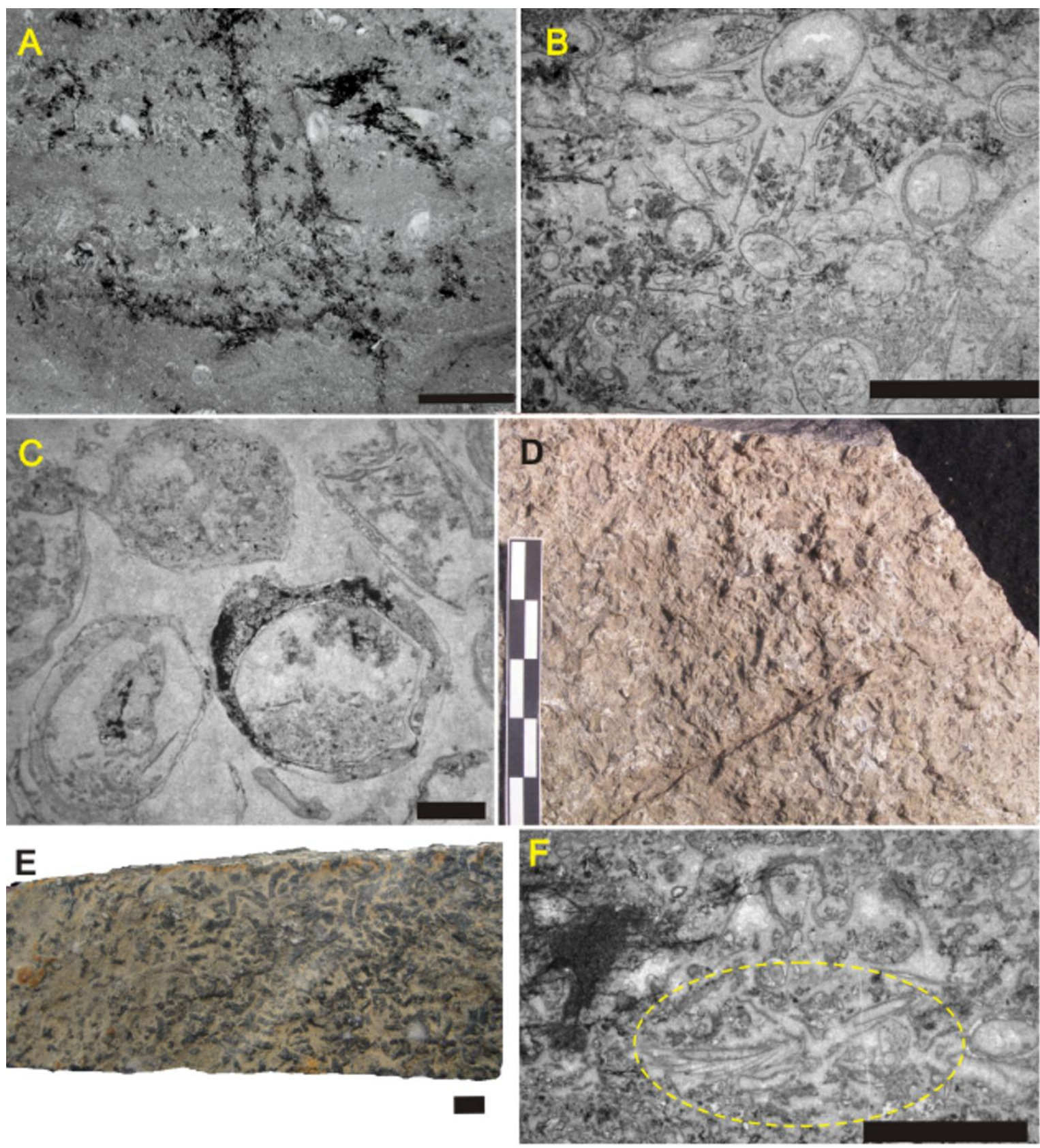

Packstones bioclásticos, provenientes da Pedreira Saladeiro. Formação Tamengo. As lâminas petrográficas (A - C; F) foram fotografadas em estereomicroscópio. A) Alternância entre níveis espáticos (claros), e níveis micríticos (escuros) na lâmina GP/L1E - 45. Escala $=1 \mathrm{~cm}$; B) Nível espático, exibindo fósseis com estrutura geopetal, e diferentes gerações de cimento (exemplar no canto superior) (GP/L1E - 8). Escala $=5 \mathrm{~mm}$; C) Seção transversal de Cloudina, apresentando delineamento poligonal. Notar estrutura geopetal neste fóssil, e fragmentos de concha no interior dos fósseis adjacentes (GP/L1E - 9). Escala $=1 \mathrm{~mm}$. D) Superfície da amostra GP/1E - 6219, com conchas silicificadas, ressaltadas pelo intemperismo. Escala em centímetros; E) Superfície da amostra GP/1E 3878, exibindo moldes internos de Cloudina. Escala $=1 \mathrm{~cm}$; F) Seção oblíqua a longitudinal de Cloudina latilabrum nov. sp. (GP/L1E - 24). Escala $=5 \mathrm{~mm}$. 


\section{Prancha 7}
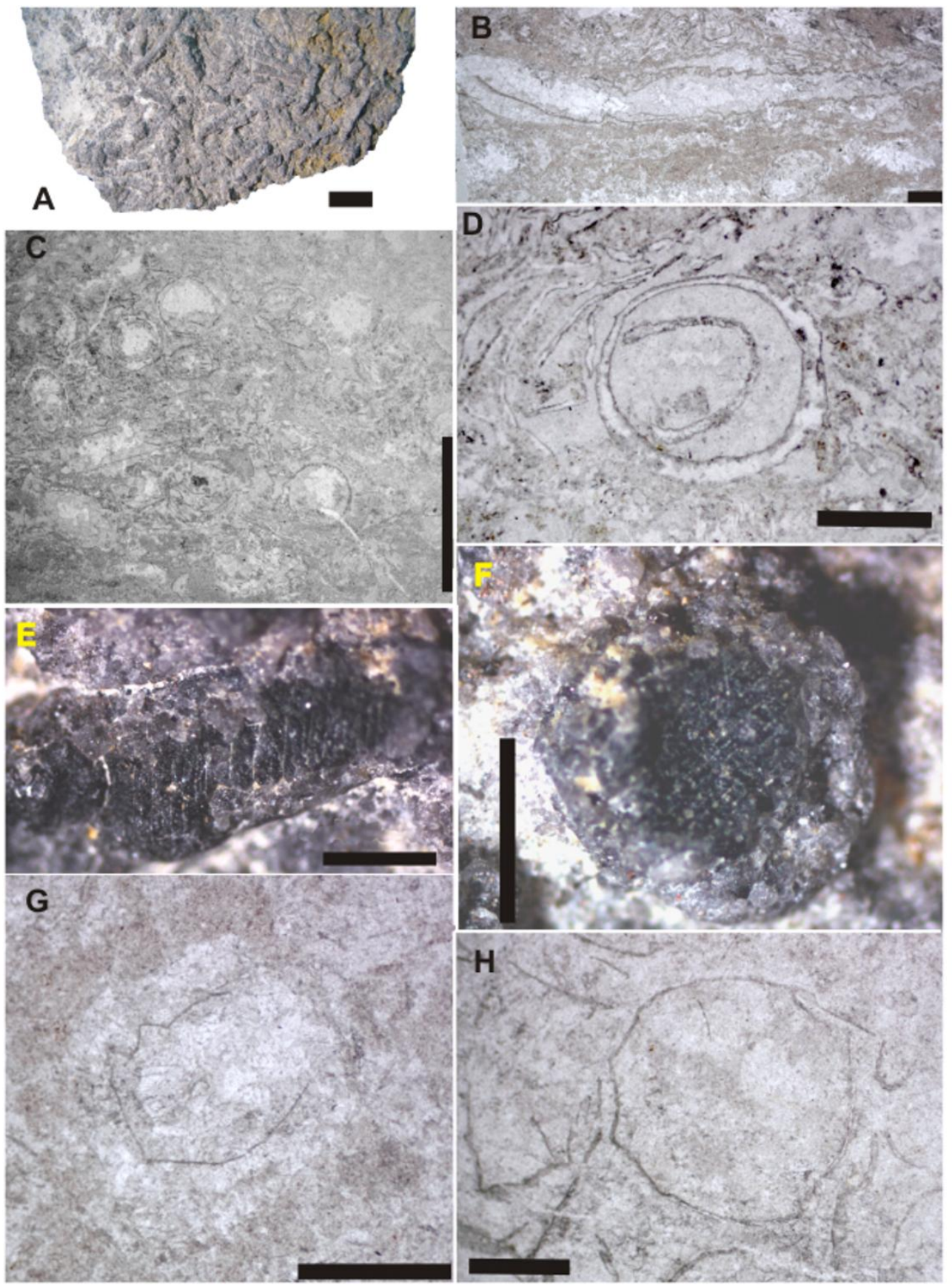

Cloudina formando packstones bioclásticos. Pedreira Corcal. Formação Tamengo. As lâminas petrográficas ( $B-D ; G$ e $H$ ) foram fotografadas em estereomicroscópio. A) Superfície da amostra $\mathrm{GP} / 1 \mathrm{E}-4143$, exibindo fósseis preservados como moldes internos, densamente empacotados. Escala = $1 \mathrm{~cm}$; B) Seção longitudinal de Cloudina, com preenchimento espático, e deformação dúctil da concha $(\mathrm{GP} / \mathrm{L} 1 \mathrm{E}-11)$. Escala $=1 \mathrm{~mm}$; C) Vista geral da lâmina GP/L1E - 17, evidenciando fósseis predominantemente paralelos ao acamamento, e estruturas geopetais, facilmente observáveis em exemplares no canto superior da figura. Escala $=5 \mathrm{~mm}$; D) Detalhe de seção transversal de Cloudina, com fragmento de concha no interior. Escala = $1 \mathrm{~mm}$ (GP/L1E - 17); E e F) Moldes internos na superfície da amostra GP/1E - 4119, apresentando diferentes gerações de cimento. Escala $=1 \mathrm{~mm} ; \mathrm{G}$ ) Seção transversal da lâmina GP/L1E - 14, com preservação reliquiar do segmento mais externo da concha. Escala $=1 \mathrm{~mm} ; \mathrm{H})$ Deformação dúctil em seção transversal $(\mathrm{GP} / \mathrm{L} 1 \mathrm{E}-13)$. Escala $=1 \mathrm{~mm}$. 
Prancha 8

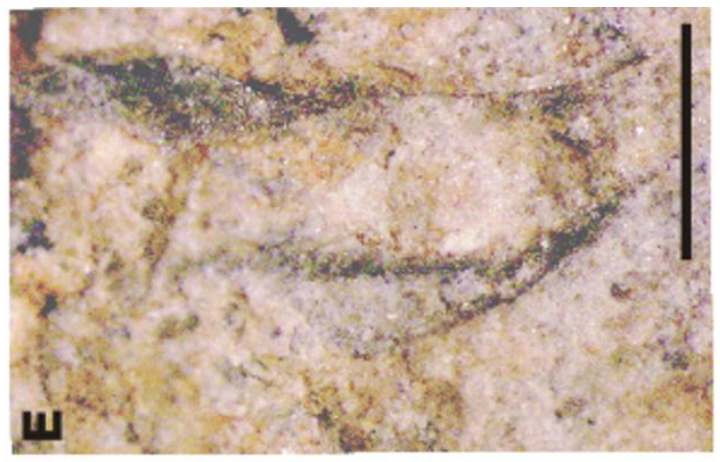

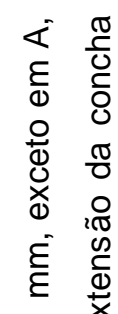
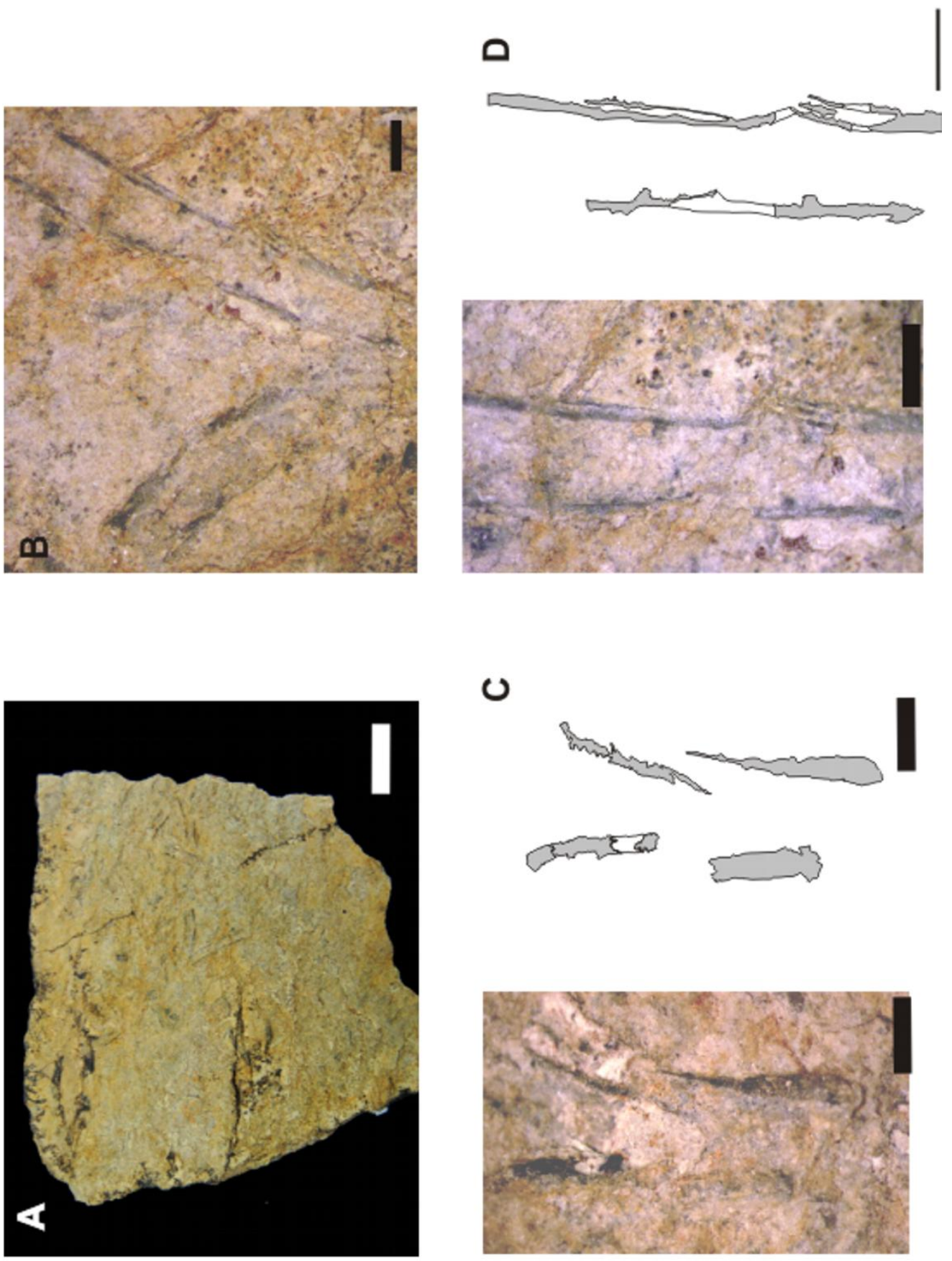

0
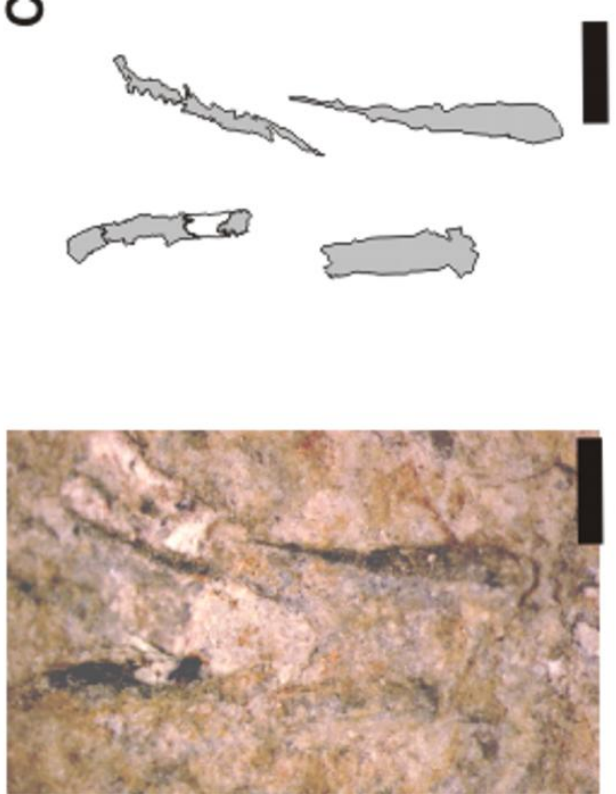

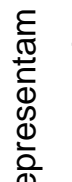

중

$\frac{0}{\frac{T}{\sigma}}$

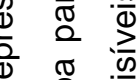

ॠ

苋

\&

융 흥

을

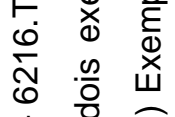

I 0 ய

Ш

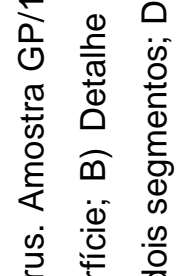

荥

गे क

เป็ ผ ग

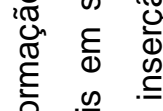

하 $\frac{\infty}{0}$

迥边

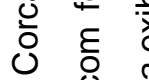

일

ปั

$\triangle \frac{0}{0}$

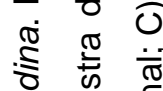

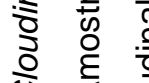

○

ㅎํㅇㅎㅇ

\& हैं

¿ -

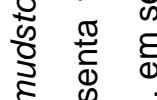

ह

응 흥

\&

㐘 


\section{Prancha 9}
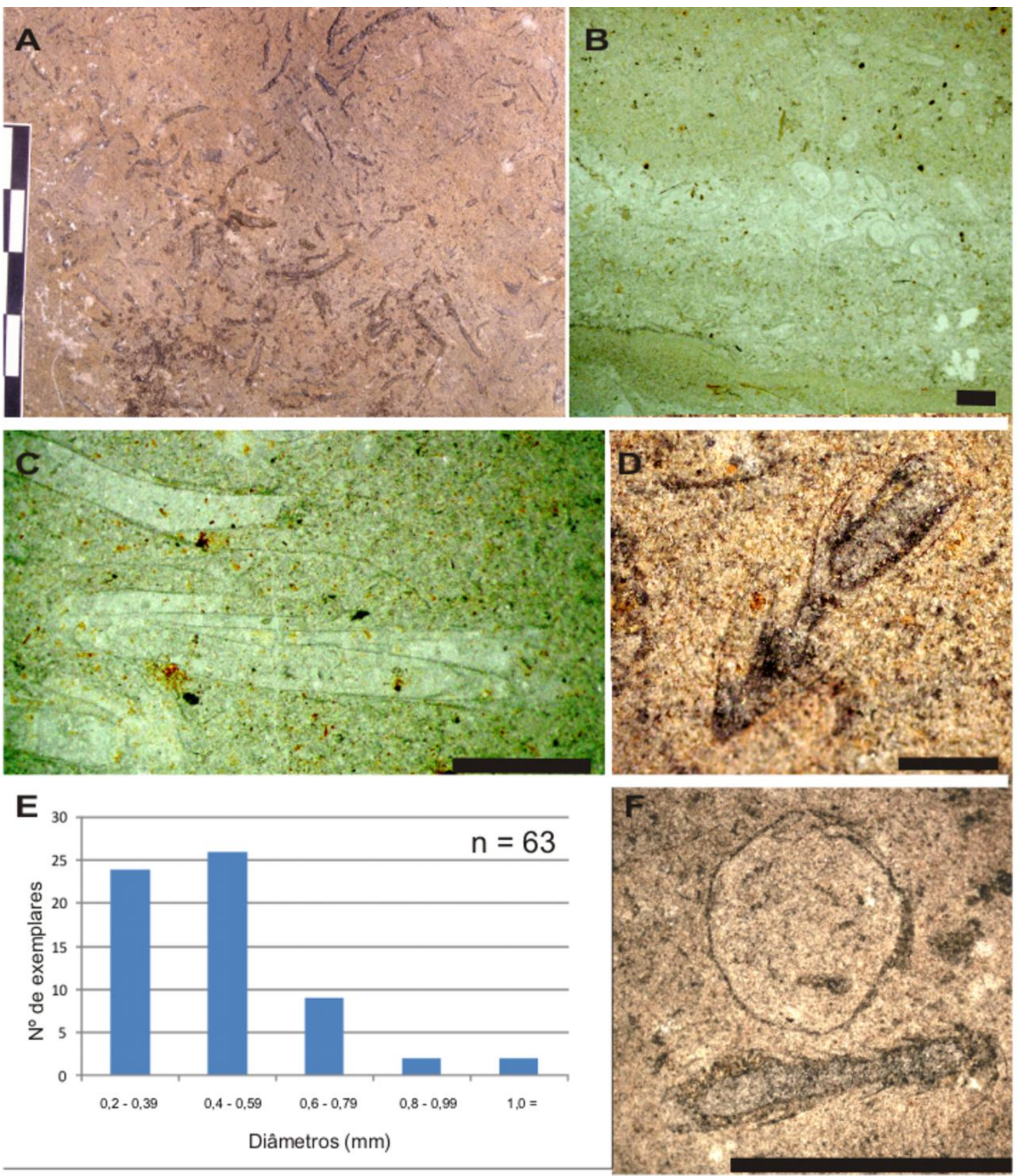

Fácies de mudstones com Cloudina. Arredores do Parque Marina Gattaz. Formação Tamengo. As lâminas petrográficas ilustradas em B e C foram fotografadas em estereomicroscópio. A) Superfície da amostra de mão GP/1E - 6218, exibindo fósseis preferencialmente paralelos ao acamamento, mas sem direção preferencial em azimute. Escala em centímetros; B) Lâmina petrográfica (GP/L1E - 42) do perfil da amostra da figura anterior, exibindo contato erosivo entre mudstones na base e packstones, que por sua vez gradam para mudstones. Notar preenchimento espático dos fósseis. Escala $=1 \mathrm{~mm}$; C) Detalhe de tangencial a longitudinal de Cloudina latilabrum nov. sp. com preenchimento espático em seu interior, e nos espaços entre as abas (GP/L1E - 42). Escala $=1 \mathrm{~mm}$; D) C. latilabrum exibindo extensas abas (GP/1E - 6218). Escala $=1 \mathrm{~mm}$; E) Distribuição da frequência de diâmetros em $C$. latilabrum. Notar predomínio de indivíduos com dimensões entre 0,2 e 0,6 mm; F) C. latilabrum paralela ao acamamento, ao lado de uma seção transversal de Cloudina lucianoi. Notar a diferença nos diâmetros entre os dois táxons (GP - 6218). Escala $=5 \mathrm{~mm}$. 


\section{CAPÍTULO 7}

\section{Discussão}

\subsection{A nova espécie de Cloudina}

Os resultados desta pesquisa têm implicações significativas em relação à variedade, distribuição geográfica e estratigráfica e tafonomia dos fósseis, principalmente, na Formação Tamengo, mas também na Formação Guaicurus. As interpretações apresentadas aqui também contribuem para a consolidação de nosso conhecimento de uma das fases mais importantes da evolução biológica ao final do Pré-Cambriano, e na véspera da "explosão cambriana" e início do Fanerozoico.

Um dos resultados mais importantes deste estudo foi a descoberta de uma nova espécie de Cloudina. A diferenciação entre as espécies de Cloudina descritas por Germs (1972) no Grupo Nama foi justificada por ele com base na distribuição bimodal dos diâmetros dos fósseis (vide Figura 4 em Germs 1972). Uma variação de diâmetro entre $2,5 \mathrm{~mm}$ e $6,5 \mathrm{~mm}$ foi estabelecida para $C$. hartmannae, enquanto que, para $C$. riemkeae, estes valores variam entre 0,3 e 1,3 mm. Grant (1990), no entanto, ressaltou que, à exceção das diferenças de tamanho, as conchas de Cloudina são morfologicamente idênticas, preferindo atribuí-las unicamente à espécie-tipo, C. hartmannae. Desde então, o critério para classificar estes fósseis tem sido quase uma questão de preferência pessoal entre os autores, ora optando pela separação de espécies (e.g., Gaucher et al. 2003, 2005; Sour-Tovar et al. 2007), ora pelo agrupamento dos fósseis em um único táxon (e.g., Bengtson \& Yue 1992; Hua et al. 2003, 2005). Desta forma, ainda não há consenso em relação a este critério como característica diagnóstica em Cloudina.

Recentemente, no entanto, a descrição da nova espécie de Cloudina, $C$. carinata, por Cortijo et al. (2010) demonstrou, pela primeira vez, características 
morfológicas bem distintas das demais espécies, como ornamentação longitudinal na superfície externa da concha e espessamento distal das abas dos segmentos, justificando, assim, seu posicionamento em uma espécie à parte.

Neste contexto, a descrição de Cloudina latilabrum nov. sp., da Formação Tamengo, traz importantes contribuições para esta discussão. Assim como $C$. carinata, $C$. latilabrum foi reconhecida como espécie distinta graças à ocorrência de características morfológicas até então desconhecidas para o gênero - no caso, por extensas abas, que contrastam com abas mais discretas observadas nas demais espécies.

Favoravelmente à hipótese de Cloudina latilabrum como espécie distinta, vale ressaltar que, mesmo em depósitos sedimentares em que o gênero permaneceu pouco tempo na zona tafonomicamente ativa (ZTA) (como também é o caso de $C$. latilabrum), as abas das conchas são mais curtas que aquelas observadas na espécie aqui descrita. Este é o caso de depósitos parautóctones de Cloudina da Formação Dengying, China (Hua et al. 2003). De modo alternativo, a possibilidade de fósseis inicialmente classificados como $C$. lucianoi na Formação Tamengo corresponderem a tafotáxons (sensu Lucas 2001) de C. latilabrum deve ser considerada, visto a ocorrência desta espécie em depósitos formados sob diferentes regimes energéticos, e a presença de conchas melhor preservadas restritas a ambientes de baixa energia (mudstones), à exceção de um espécime, encontrado em packstones bioclásticos na Pedreira Saladeiro do (Prancha 6, F). Até o momento, porém, nenhum exemplar de $C$. latilabrum tem diâmetros superiores àqueles constatados nos diâmetros menores de C. lucianoi (Prancha 9, E). Conclui-se aqui, portanto, que a presença das abas e o diâmetro muito estreito são suficientemente distintos para justificar a criação da nova espécie.

Em contraposição ao estudo de Cloudina em seções delgadas, o que aparentemente pode levar a interpretações equivocadas (Grant 1990), o estudo de fósseis silicificados ou fosfatizados, extraídos quimicamente da rocha, tem se mostrado bem sucedido na análise de materiais da China (Bengtson \& Yue 1992; Hua et al. 2003, 2005) e Espanha (Cortijo et al. 2010), podendo ser 
aplicado a fósseis silicificados de outras localidades. Um método alternativo, quando a extração química é impossível, é a reconstrução de fósseis através do agrupamento digital de séries de fotografias tiradas de fatias do material em análise, em intervalos de poucos micrômetros. Este procedimento foi realizado por Watters \& Grotzinger (2001) em Namacalathus do Grupo Nama.

Com estas técnicas, questões ainda pendentes no âmbito da morfologia, taxonomia e paleoecologia de Cloudina poderiam ser melhor elucidadas.

\subsection{Caracterização tafonômica de Cloudina no Grupo Corumbá}

Embora os primeiros animais a desenvolverem esqueletogênese tenham sido caracterizados por esqueletos orgânicos não mineralizados, ainda ao final do Eon Proterozoico, alguns táxons evoluíram padrões fisiológicos requisitados para a produção de esqueletos de calcita, aragonita e sílica, em um processo conhecido como biomineralização, em que os organismos utilizam minerais para a síntese de esqueletos (Lowenstam \& Weiner 1989; Weiner \& Dove 2003).

Mesmo tendo sido um dos primeiros Metazoa a construir esqueletos, as evidências levantadas permitiram constatar o quão simples eram os padrões tafonômicos na época do surgimento de Cloudina, pois foi ele o primeiro organismo a contribuir material como bioclastos para o regime sedimentar. A estrutura simples, composta por paredes muito finas e fracamente biomineralizadas deste gênero, não permitem resgatar a gama de informações que conchas tipicamente fanerozoicas fornecem. Adicionalmente, as perfurações descritas em Cloudina da Formação Dengying, consistem nas únicas evidências de predação no Pré-Cambriano, ainda que incipientes. De fato, se considerar o contexto evolutivo da época, feições como bioincrustações ou evidências de bioerosão nos bioclastos não são esperadas. Possíveis exceções seriam fungos ou esponjas (que se fixam em conchas e as deixam crivadas de galerias) ou possíveis algas vermelhas incrustantes.

Embora metazoários normalmente associados à Cloudina
(Namacalathus, Sinotubulites) não tenham sido identificados no presente 
trabalho, a associação de diferentes espécies de animais bentônicos (Cloudina e Corumbella; Cloudina lucianoi e Cloudina latilabrum) em mudstones e ritmitos da Formação Tamengo, além de possíveis estruturas trombolíticas e microorganismos formadores de esteiras indicam área de vida muito próxima, provavelmente neste contexto de fácies, para estes organismos, corroborando associações entre metazoários e microbialitos na literatura (e.g., Hofmann \& Mountjoy 2001; Grotzinger et al. 2005) e inferências feitas por Oliveira (2010) para o ambiente de vida de Cloudina. Alternativamente, os bioclastos fragmentados na fácies de ritmitos mudstones calcíferos / folhelhos, podem representar longo período de exposição das conchas na ZTA, em função da baixa sedimentação no local; ou mesmo o peso de sedimentos sobrepostos poderia causar tal feição, conforme evidenciado no capítulo anterior.

Assinaturas tafonômicas indicam que os fósseis atribuídos a Cloudina lucianoi, dentro da Formação Guaicurus, não aparentam ter sido retrabalhados a partir dos calcários da Formação Tamengo, localizada mais de 40 metros abaixo do ponto de coleta, e próxima a uma fina lente de carbonato. Adicionalmente, boa parte da extensão de alguns indivíduos está preservada, e as abas das conchas, delicadas demais para sobreviver na zona tafonomicamente ativa (ZTA), estão presentes em alguns fósseis. Embora os fósseis de $C$. lucianoi no topo da Formação Tamengo nesta pedreira também apresentem boa parte da extensão da concha preservada, a litologia em que ocorrem - packstone bioclástico, difere do mudstone no qual os fósseis da Formação Guaicurus se encontram.

\subsection{Implicações estratigráficas}

Com base nas evidências apontadas no parágrafo anterior, o presente trabalho demonstra a primeira ocorrência de Cloudina no Grupo Corumbá fora da Formação Tamengo. Para a base da Formação Guaicurus, Gaucher et al. (2003) descreveram a presença do vendotenídeo Eoholynia corumbensis, cujo gênero foi atribuído ao final do Ediacarano (Gnilovskaya 1985). Logo, a ocorrência de Cloudina, com distribuição temporal limitada entre 549 e $542 \mathrm{Ma}$ (Grotzinger et al. 1995; Amthor et al. 2003), consiste em uma importante 
contribuição para a idade relativa desta formação, posicionando a sequência, pelo menos até 44 metros acima do contato com a Formação Tamengo, dentro da biozona deste táxon e do final do Ediacarano. Adicionalmente, a mudança abrupta na sedimentação na bacia observada entre a Formação Tamengo e a Guaicurus, inclusive, a passagem abrupta de grainstones oolíticos da Formação Tamengo para pelitos da Formação Guaicurus, nas frentes de lavra da Pedreira Laginha, tem de ser explicada dentro do contexto temporal desta biozona. 


\section{CAPÍTULO 8}

\section{Conclusões}

A presente pesquisa permitiu concluir que,

1. No Grupo Corumbá, ocorre nova espécie de Cloudina (C. latilabrum) e outros fósseis, como cianobactérias cocoides preservadas no carbonato, associadas a fragmentos de trombólitos. Além disso, também ocorrem fósseis em forma de paredes corrugadas, remetendo à carapaça de Corumbella werneri, ou mesmo à concha de Sinotubulites.

2. As distintas assinaturas tafonômicas em Corumbella e Cloudina, nos níveis aonde ambos os táxons ocorrem, refletem as diferenças nas características físicas e químicas dos materiais que constituem seus exoesqueletos. Além disso, a concentração de formas bem preservadas de Corumbella em folhelhos ou margas na Pedreira Saladeiro, e a associação de Cloudina com trombólitos parece indicar preferências ambientais distintas para os dois metazoários da Formação Tamengo: Corumbella em ambientes mais turvos, e Cloudina em associação com esteiras microbianas em águas mais límpidas. Este último ambiente poderia estar preservado mais para o leste da Pedreira Laginha, onde foram observados grumos trombolíticos e fragmentos de colônias de cianobactérias.

3. O preenchimento parcial ou total das conchas por espato sugere que os organismos teriam sido transportados, talvez em diferentes estágios de decomposição, dentro das conchas até o sítio de deposição, impedindo, assim, a infiltração de lama micrítica.

4. A fragmentação moderada e baixa, observada respectivamente nos fósseis em packstones bioclásticos das pedreiras Saladeiro e Corcal, indica certa resistência da concha a impactos e abrasão durante o transporte. Tal resistência pode ter sido possível graças a mecanismos que manteriam a 
integridade da estrutura, como a presença de uma capa orgânica recobrindo a parte externa do exoesqueleto.

5. A extensão da biofácies de Cloudina para dentro da Formação Guaicurus traz novas evidências paleontológicas do limite Pré-Cambriano Cambriano na Faixa Paraguai, e reforça a necessidade de mais estudos nesta unidade do Grupo Corumbá. 


\section{Referências Bibliográficas}

Almeida, F.F.M. 1945. Geologia do Sudoeste mato-grossense. Rio de Janeiro, Departamento Nacional da Produção Mineral, Divisão de Geologia e Mineralogia, 118 p. (Boletim 116).

Almeida, F.F.M. 1965. Geologia da Serra do Bodoquena (Mato Grosso), Brasil. Boletim de Divulgação de Geologia e Mineralogia- DNPM, 117:1-11.

Alvarenga, C.J.S.; Moura, C.A.V.; Gorayeb, P.S.S.; Abreu, F.A.M. Paraguay and Araguaia Belts. In: Cordani, U.G.; Milani, E.J.; Thomaz-Filho, A.; Campos, D.A. Tectonic evolution of South America. Rio de Janeiro: 2000. p. 183-193.

Alvarenga, C.J.S.; Trompette, R. 1992. Glacially influenced sedimentation in the later Proterozoic of the Paraguay belt (Mato Grosso, Brazil). Palaeogeography, Palaeoclimatology. Palaeoecology, 92: 85-105.

Amthor, J.E.; Grotzinger, J.P.; Schröder, S.; Bowring, S.A.; Ramezani, J.; MArtin, M.W.; Matter, A. 2003. Extinction of Cloudina and Namacalathus at the Precambrian-Cambrian boundary in Oman. Geology, 31: 431-434.

Álvaro, J.J.; Blanc-Valleron, M.M. 2002. Stratigraphic and structural framework of the Neoproterozoic Paracuellos Group, Iberian Chains, NE Spain. Bulletin de la Societe Geologique de France, 173(3):219-227.

Babinski, M.; Trindade, R.I.F.; Alvarenga, C.J.S.; Boggiani, P.C.; Liu, D.; Santos, R.V.; Brito-Neves, B.B. 2006. Chronology of Neoproterozoic ice ages in central Brazil. In: V South American Symposium on Isotope Geology, 2006, Punta del Leste, Montevideo. Short Papers, 1: 223-226.

Babinski, M.; Boggiani, P.C.; Fanning, C.M.; Fairchild, T.R.; Simon, C.M.; Sial, A.N. 2008. U-Pb SHRIMP geochronology and isotope chemostratigraphy (C, $\mathrm{O}, \mathrm{Sr}$ ) of the Tamengo Formation, Southern Paraguay Belt, Brazil. In: South 
American Symposium on Isotope Geology, 6, San Carlos de Bariloche, 2008. Book of Abstracts: 160.

Barbosa, O. 1949. Contribuição à geologia da região Brasil-Bolívia. Mineração e Metalurgia, 13: 271-278.

Behrensmeyer, A.K.; Kidwell, S.M. 1985. Taphonomy's main contributions to paleobiology. Paleobiology, 11 (1): 105-119.

Bengtson, S.; Yue, Z. 1992. Predatorial borings in late Precambrian mineralized exoskeletons. Science, 257: 367-369.

Bengtson, S. 1994. The advent of animal skeletons. In: Bengtson, S. (ed.). Early Life on Earth. Nobel Symposium No. 84. Columbia University Press, New York: 412-425.

Bengtson, S. 2002. Origins and early evolution of predation. In: Kowalewski, M.; Kelley, H. (eds). The fossil record of predation. The Paleontological Society Papers, 8: 289-317.

Beurlen, K.; Sommer, F.W. 1957. Observações estratigráficas e paleontológicas sobre o calcário Corumbá. Boletim de Geologia e Mineralogia / DNPM, 168: 1-35.

Boggiani, P. C. 1998. Análise estratigráfica da Bacia Corumbá (Neoproterozóico) - Mato Grosso do Sul. Tese de Doutoramento, Instituto de Geociências, Universidade de São Paulo. São Paulo.

Boggiani, P.C., Fairchild, T.R.; Coimbra, A.M. 1993. O Grupo Corumbá (Neoproterozóico-Cambriano) na região Central da Serra da Bodoquena, Mato Grosso do Sul (Faixa Paraguai). Revista Brasileira de Geociências, 23(3): 301-305.

Boggiani, P.C.; Alvarenga, C.J.S. Faixa Paraguai. In: Mantesso-Neto, V.; Bartorelli, A.; Carneiro, C. D. R.; Brito-Neves, B. B. Geologia do continente sul-americano: evolução da obra de Fernando Flávio Marques de Almeida. São Paulo: Beca, 2004.113-121. 
Boggiani, P.C.; Gaucher, C. 2004. Cloudina from the Irapucumi Group (Ediacaran), SW Brazil, South America. In: 1st Symposium on Neoproterozoic-Early Paleozoic in SW-Gondwana, IGCP Project 478, São Paulo, SP. Extended Abstract, 1: 13-15.

Boggiani, P.C.; Gaucher, C.; Sial, A.N.; Babinski, M.; Simon, C.M.; Riccomini, C.; Ferreira, V. P.; Fairchild, T. R. 2010. Chemostratigraphy of the Tamengo Formation (Corumbá Group, Brazil): a contribution to the calibration of the Ediacaran carbon-isotope curve. Precambrian Research, 182: 382-401.

Bowring, S.; Myrow, P.; Landing, E.; Ramezani, J.; Grotzinger,J. 2003. Geochronological constraints on Terminal Neoproterozoic events and the rise of metazoans. Geophysical Research Abstracts, 5:13219.

Brain, C.K. 2001. Some observations on Cloudina, a terminal Proterozoic index fossil from Namibia. African Earth Sciences, 33: 475-480.

Brett, C.E.; Baird, G.C.1986. Comparative Taphonomy: a key to Paleoenvironmental Interpretation Based on Fossil Preservation. Palaios, 1: 207-227.

Chen, D.F.; Dong, W.Q.; Zhu, B.Q.; Chen, X.P. 2004. Pb-Pb ages of Neoproterozoic Doushantuo phosphorites in South China: constraints on early metazoan evolution and glaciation events. Precambrian Research, 132 (1-2): 123-132.

Chen, Z.; Bengtson, S.; Zhou, C.M.; Hua, H.; Yue, Z. 2008. Tube structure and original composition of Sinotubulites: shelly fossils from the late Neoproterozoic in southern Shaanxi, China. Lethaia, 41: 37-45.

Clausen, S.; Álvaro, J. 2004. Implications biostratigraphiques et paléobiogéographiques de la découverte du métazoaire néoprotérozoïque Cloudina dans le versant nord de la Montagne Noire (France). Colloque de Paléogéographie. Société géologique de France. Program with abstracts: 42-43.

Cohen, B.L. 2005. Not armour, but biomechanics, ecological opportunity and increased fecundity as keys to the origin and expansionof the mineralized 
benthic metazoan fauna. Biological Jornal of the Linnean Society, 85:483490.

Condon, D.; Zhu, M.; Bowring, S.; Wang, W.; Yang, A.; Jin, Y. 2005. U-Pb ages from the Neoproterozoic Doushantuo Formation, China. Science, 308: 9598.

Conway Morris, S.; Mattes, B.W.; Menge, C. 1990. The early skeletal organism Cloudina: new occurrences from Oman and possibly China. Journal of Science, 290-A: 245-260.

Cortijo, I.; Martímus, M.; Jensen, S.; Palacios, T. 2010. A new species of Cloudina from the terminal Ediacaran of Spain. Precambrian Research, 176: $1-10$.

Crimes, T.P.1987. Trace fossils and correlation of late Precambrian and early Cambrian strata. Geological Magazine, 124:97-119.

Crimes, T.P.; Germs, G.J.B. 1982. Trace fossils from the Nama Group (Precambrian-Cambrian) of Southwest Africa (Namibua). Journal of Paleontology, 56: 890-907.

Degens, E.T.; Kazmierczak, J.; Ittekott, V. 1985. Cellular response to Ca2+ stress and its geological implications. Acta Palaeontologica Polonica, 30: 115-135.

Del'Arco, J.O.; Trapanoff, I.; Pereira, L.G.M.; Souza, S.L.; Luz, D.S. Da;. 1981. Geologia do Pré-Cambriano na folha SE-21 Corumbá. In: Anais do simpósio de geologia do centro-oeste, Goiânia, SBG. p.154-176.

Dunham R.J. 1962. Classification of carbonate rocks according to depositional texture. In: W.E. Ham (Ed.). Classification of Carbonate rocks. Am. Ass. Petrol. Geol., p.108-121 (Memoir 1).

Fairchild, T.R. 1978. Evidências paleontológicas de uma possível idade "ediacarana" ou cambriana inferior, para parte do Grupo Corumbá (Mato Grosso do Sul). In: $30^{\circ}$ Congresso Brasileiro de Geologia, Recife. Boletim Resumos das Comunicações, 1: 181. 
Fedonkin, M.A.; Waggoner, B.M. 1997. The Late Precambrian fossil Kimberella is a mollusc-like bilaterian organism. Nature, 388:868-871.

Fenton, C.L.; Fenton, M.A. 1939. Precambrian and Paleozoic algae. Geological Society of America Bulletin, 50(1):89-126.

Finnerty, J.R.; Martindale, M.Q. 1999. Ancient origins of axial patterning genes: Hox genes and Parahox genes in Cnidaria. Evolution and Development, 1:16-23.

Flügel,E. Microfacies of Carbonate Rocks. Analysis, Interpretation and Application. New York:Springer-Verlag,2004.976p.

Freitas, B. T. 2010. Tectônica e sedimentação do Grupo Jacadigo (Neoproterozóico, MS). Dissertação de mestrado, Universidade de São Paulo.

Gaucher, C.; Sprechmann, P. 1999. Upper Vendian skeletal fauna of the Arroyo del Soldado Group, Uruguay. Beringeria, 23: 55-91.

Gaucher, C.; Boggiani, P.C.; Sprechmann, P.; Sial, A.N.; Fairchild, T.R. 2003. Integrated correlation of the Vendian to Cambrian Arroyo del Soldado and Corumbá Group (Uruguay and Brazil): palaeogeographic, palaeoclimatic and palaeobiologic implications. Precambrian Research, 120: 241-278.

Gaucher, C.; Poire, D.G.; Gomez-Peral, L.; Chiglino, L. 2005. Litoestratigrafia, bioestratigrafia y correlaciones de las sucessiones sedimentarias del Neoproterozoico-Cambrico del Craton del Rio de la Plata (Uruguay y Argentina). Latin American Journal of Sedimentology and Basin Analysis, 12 (2): 145-160.

Gaucher,C.; Sprechmann, P.1999. Upper Vendian skeletal fauna of the Arroyo del Soldado Group, Uruguay. Beringeria, 23, 55-91.

Gehling, J. G. 1999. Microbial mats in terminal Proterozoic silicilastis: Ediacaran death mask. Palaios, ,14:40-57. 
Gehling, J.; Jensen, S.R.; Droser, M.; Myrow, P.; Narbonne, G. 2001. "Burrowing below the basal Cambrian GSSP, Fortune Head, Newfoundland. Geological Magazine, 138 (2): 213-218.

Germs, G.J.B. 1972. New shelly fossils from Nama Group, South West Africa. American Journal of Science, 272: 752-761.

Germs, G.J.B.; Knoll, A.H.; Vidal, G. 1986. Latest Proterozoic microfossils from the Nama Group, Namibia (South West Africa). Precambrian Research, 32: 45-62.

Glaessner, M.F. 1959. Precambrian Coelenterata from Australia, Africa and England. Nature, 183: 1472-1473.

Glaessner, M.F. 1976. Early Phanerozoic annelid worms and their geological and biological significance. Journal of the Geological Society, 132: 259-275.

Glaessner, M.F. 1984. The Dawn of Animal Life: a biohistorical study. Cambridge, UK: Cambridge University Press. 244 p.

Gradstein, F.M.; Ogg, J.G.; Smith, A.G. 2004. A geologic time scale 2004. Cambridge University Press. 610 p.

Grotzinger,J.P.; Knoll, A.H. 1995. Anomalous carbonate precipitates: Is the Precambrian the key to the Permian?. Palaios, 10:578-596.

Gnilovskaya,M.B. Vendotaenids-Vendian Metaphytes. In: Sokolov,B.S.; Iwanowski,A.B. (Eds.) 1985. The Vendian System. Springer, Berlin, pp. 138-147.

Grant, S.W.F. 1990. Shell structure and distribution of Cloudina, a potential index fossil for the terminal Proterozoic. American Journal of Science, 290A: 261-294.

Grotzinger, J.P.; Bowring, S.A.; Saylor, B.Z.; Kaufman, A.J. 1995. Biostratigraphic and geochronologic constrains on early animal evolution. Science, 270: 598-604. 
Grotzinger, J.P.; Watters, W.A.; Knoll, A.H. 2000. Calcified metazoans in thrombolite-stromatolite reefs of the terminal Proterozoic Nama Group, Namibia. Paleobiology, 26 (3): 334-359.

Grotzinger, J; Adams, E.W.; Schröder, S. 2005. Microbial-metazoan reefs of the terminal Proterozoic Nama Group (c. 550-543 Ma), Namibia. Geological Magazine, 142 (5): 499-517.

Hagadorn, J.W.; Waggoner, B. 2000. Ediacaran fossils from the southwestern Great Basin, United States. Journal of Paleontology, 74: 349-359.

Hagadorn, J.W.; Xiao, S.; Donoghue, P.C.J.; Bengtson, S.; Gostling, N.J.; Pawlowska, M.; Raff, E.C.; Raff, R.A.; Turner, R.; Chongyu, Y.; Zhou, C.; Yuan, X.; McFeely, M.B.; Stampanoni, M.; Nealson, K.H. 2006. Cellular and Subcellular Structure of Neoproterozoic Animal Embryos. Science, 314: 291294.

Hahn, G.; Pflug, H.D. 1985. Die Cloudinidae n. fam., Kalk-Röhren aus dem Vendium und Unter-Kambrium. Senckenbergiana lethaea, 65: 413-431.

Halverson,G.P.; Hoffman, P.F.; Schrag, D.P.; Maloof, A.C.; Rice, A.H.N. 2005. Toward a Neoproterozoic composite carbon-isotope record. GSA Bulletin, 117 (9-10): 1181-1207.

Hanson, J. 1948. Formation and breakdown of serpulid tubes. Nature, 161: 610611.

Hoffman, P.F.; Kaufman, A.J.; Halverson, G.P.; Schrag, D.P. 1998. A neoproterozoic Snowball Earth. Science, 281:1342-1346.

Hoffman, P.F.; Schrag, D.P. 2002. The snowball Earth hypothesis: testing the limits of global change. Terra Nova, 14: 129-155.

Hofmann, H.J.; Mountjoy, E.W. 2001. Namacalathus-Cloudina assemblage in Neoproterozoic Miette Group (Byng Formation), British Columbia: Canada's oldest shelly fossils. Geology, 29: 1091-1094. 
Hua, H.; Pratt, B.R.; Zhang, L.Y. 2003. Borings in Cloudina shells: complex predator-prey dynamics in the terminal Neoproterozoic. Palaios, 18: 454459.

Hua, H.; Chen, Z.; Yuan, X.; Zhang, L.Y.; Xiao, S. 2005. Skeletogenesis and asexual reproduction in the earliest biomineralizing animal Cloudina. Geology, 33(4): 277-280.

Hua, H.; Chen, Z.; Xunlai, Y. 2007. The advent of mineralized skeletons in Neoproterozoic metazoa - new fossil evidence from the Gaojiashan fauna. Geological Journal, 42: 263-279.

Jackson, J.B.C. Biological determinants of present and past sessile animal distributions. In:Tevez, M.; McCall, P.W. (Eds). Biotic Interactions in Recent and Fossil Benthic Communities. New York: Plenum Press, 1983, pp 39120.

Kempe, S.; Kazmierczak, J. 1994. The role of alkalinity in the evolution of ocean chemistry, organization of living systems and biocalcification processes. Bulletin de la Institut Oceanographique Monaco, 13: 61-117.

Kennedy, M.J.; Runnegar, B.; Prave, A.R.; Hoffman, K. H.; Arthur, M.A. 1998. Two or four Neoproterozoic glaciations? Geology, 26: 1059-1063.

Kidwell, S.M.; Fürsich, F.T; Aigner, T. 1986. Conceptual framework for the analysis and classification of fossil concentrations. Palaios, 1: 228-238.

Kidwell, S.M.; Holland, S.M. 1991. Field description of Coarse Bioclastic Fabrics. Palaios, 6 (4): 426-434.

Kimura, H.; Watanabe, Y. 2001. Oceanic anoxia at the Precambrian-Cambrian boundary. Geology, 29: 995-998.

Kirschvink,J.L. Late Proterozoic low-latitude global glaciation: the Snowball Earth. In: The Proterozoic Biosphere. Schopf, J.W.; Klein,C. (eds.) New York: Cambridge University Press, 1992. pp.51-52. 
Knoll, A.H. 2003. Biomineralization and Evolutionary History. Reviews in Mineralogy and Geochemistry, 54: 329-356.

Kontorovich, A.E.; Varlamov, A.I.; Grazhdankin, D.V.; Karlova, G.A.; Klets, A.G.; Kontorovich, V.A.; Saraev, S.V.; Terleev, A.A.; Belyaev, S.Y.; Varaksina, I.V.; Efimov, A.S.; Kochnev, B.B.; Nagovitsin, K.E.; Postnikov, A.A.; Filippov, Y.F. 2008. A section of Vendian in the east of West Siberian Plate (based on data from the Borehole Vostok 3). Russian Geology and Geophysics, 49: 932-939.

Li, C.W.; Chen, J.Y.; Hua,T.E. 1998. Precambrian sponges with Cellular Structures. Science, 279: 879-882.

Li,X.; Bogdanova, S.V.; Collins, A.S.; Davidson, A.; De Waele, B.; Ernst,R.E.; Fitzsimons, I.C.W.; Fuck, R.A.; Gladkochub, D.P.; Jacobs, J.; Karlstrom, K.E.; Lu,S.; Natapov,L.M.; Pease,V.; Pisarevsky,S.A.; Thrane, K.; Vernikovsky,V.2008.Assembly, configuration, and break-up history of Rodinia: a synthesis. Precambrian Research, 160: 179-210.

Li, X.; Droser, M.L. 1997. Nature and distribution of Cambrian Shell Concentrations: Evidence from the Basin and Range Province of the Western United States (California, Nevada and Utah). Palaios, 12 (2)- 111126.

Liu, P.; Xiao, S.; Yin, C.; Zhou, C.; Gao, L.; Tang, F. 2008. Systematic description and phylogenetic affinity of tubular microfossils from the Ediacaran Doushantuo Formation at Weng'an, South China. Palaeontology, 51(2): 339-366.

Lowenstam, H.A.; Weiner, S. 1989. On Biomineralization. Oxford University Press, Oxford. $324 \mathrm{p}$.

Lucas, S.G. 2001. Taphotaxon. Lethaia, 34: 30.

Marshall, C.R. 2006. Explaining the Cambrian "explosion" of animals. Annual Review of Earth and Planetary Science, 34: 355-384. 
Martin, M.W.; Grazhdankin, D.V.; Bowring, S.A.; Evans, D.A.D., Fedonkin, M.A.; Kirschvink, J.L. 2000. Age of Neoproterozoic bilaterian body and trace fossils, White Sea, Russia: implications for metazoan evolution. Science, 288: 841-845.

McMenamin, M.A.S.; Awramik, S.M.; Stewart, J. H. 1983. PrecambrianCambrian transition problem in western North America: Part II . Early Cambrian skeletonized fauna and associated fossils from Sonora, Mexico. Geology, 11:227-230.

Morales, A.B. 2007. Paleoenvironments and ocean chemistry of the first biomineralizer: evidence from Cloudina-bearing strata of the southwestern, US and northwestern, Mexico. Unpublished thesis. Amherst College, Massachusetts. 92p.

Narbonne, G. M. 1998. The Ediacara biota: a terminal Neoproterozoic experiment in the evolution of life. GSA Today, 8 (2): 1-6.

Narbonne, G.M. 2004. Modular construction of early Ediacaran complex life forms. Science, 305: 1141-1144.

Narbonne, G. M. 2005. The Ediacara biota: Neoproterozoic origin of animals and their ecosystems. Annual Review of Earth and Planetary Sciences, 33: 421-442.

Narbonne, G.M.; Saylor, B.Z.; Grotzinger, J.P. 1997. The youngest ediacaran fossils from southern Africa. Journal of Paleontology, 71(6): 953-967.

Narbonne, G.M.; Gehling, J.G. 2003. Life after snowball: the oldest complex Ediacaran fossils. Geology,31 (1): 27-30.

Nogueira, A.C.R. 2003. A plataforma carbonática Araras no sudeste do Cráton Amazônico, Mato Grosso: estrigráfica, contexto paleoambiental e correlação com os eventos glaciais do Neoproterozóico. Tese de Doutorado, Universidade de São Paulo.

Nogueira, A.C.R.; Riccomini, C.; Sial, A.N.; Moura, C.A.V.; Fairchild, T.R. 2003. Soft-sediment deformation at the Neoproterozoic Puga cap carbonate 
(southwestern Amazon Craton, Brazil): conformation of rapid icehouse to greenhouse transition in Snowball Earth. Geology, 31:613-616.

Oliveira,R.S. 2010. Depósitos de rampa carbonática ediacarana do Grupo Corumbá, região de Corumbá, Mato Grosso do Sul. Dissertação de Mestrado- Instituto de Geociências, Universidade Federal do Pará, Pará.

Palacios, T. 1989. Microfósiles de pared orgánica del Proterozoico superior (region central de la Península lbérica). Memorias del Museo Paleontológico de la Universidad de Zaragoza, 3(2): 1-91.

Pernet, B. 2001. Escape hatches for the clonal offspring of serpulid polychaetes. Biological Bulletin, 200: 107-117.

Riccomini,C.; Nogueira,A.C.R.; Sial, A.N. 2007. Carbon and oxygen isotope geochemistry of Ediacaran outer plataform carbonates, Paraguay Belt, Central Brazil. Anais da Academia Brasileira de Ciências, 79(3): 519-527.

Ride, W.D.L.; Sabroskyg, C.W.; Bernardia, N.D.; Melvile, R.V. (eds.). 1985. International Code of Zoological Nomenclature. The University of California Press, Berkeley. 338p.

Seilacher, A. 1992. Vendobionta and Psammocorallia: lost constructions of Precambrian evolution. Journal of the Geological Society of London, 149: 607-613.

Seilacher, A. 1999. Biomat-related lifestyles in the Precambrian. Palaios, 14: 86-93.

Seilacher, A.; Grazhdankin, D.; Legouta, A. 2003. Ediacaran biota: the dawn of animal life in the shadow of giant protists. Palaeontological Research, $7(1)$ : 43-54.

Signor, P.W.; Mount, J.F.; Onken, B.R. 1987. A pre-trilobite shelly fauna from the White-Inyo region of eastern California and western Nevada. Journal of Paleontology, 61: 425-438. 
Seilacher,A.; Pflüger, F. From biomats to benthic agriculture: A biohistoric revolution. In: Krumbein,W.E. Biostabilizaztion of Sediments: Oldenburg, 1994, Oldenburg, Alemanha, 1: 97-105.

Simon, C.M. 2007. Quimioestratigrafia isotópica (C, O, Sr) dos carbonatos da Formação Tamengo, Grupo Corumbá, MS. Monografia de trabalho de formatura, Instituto de Geociências, Universidade de São Paulo. São Paulo. 43pp.

Sour-Tovar, F.; Hagadorn, J.W.; Huitrón-Rubio, T. 2007. Ediacaran and Cambrian index fossils from Sonora, Mexico. Paleontology, 50 (1): 169-175.

Speyer, S.E.; Brett, C.E. 1986. Trilobite taphonomy and Middle Devonian taphofacies. Palaios, 3(1): 312-327.

Swett, K.; Knoll, A.H. 1985. Stromatolic bioherm and microphytolites from Late Proterozoic Draken Conglomeratic Formation. Precambrian Research, 28:327-347.

Taylor, M.E. 1966. Precambrian mollusk-like fossils from Inyo County, California. Science, 153: 198-201.

Valentine, J.W. 2007. Swing ghosts: Neoproterozoic bilaterian body plans. In: Vickers-Rich, P.; Komarower,P. (eds.). The rise and fall of the Ediacaran Biota. Geological Society, London, Special Publications,286:369-375.

Vermeij, G.J. 1989. The origin of skeletons. Palaios, 4 :585-589.

Vidal, G. 1976. Late Precambrian microfossils from the Visingso Beds in southern Sweden. Fossils and Strata, 9: 1-57.

Vidal, G.; Palacios, T.; Díez Balda, M.A.; Gámez Vintaned, J.A.; Grant, S.W.F. 1994. Neoproterozoi-early Cambrian geology and paleontology of Iberia. Geological Magazine, 131: 729-765.

Wade,M. 1968. Preservation of soft-bodied animals in Precambrian sandstone at Ediacara, South Australia. Lethaia, 1: 238-267. 
Waggoner, B.; Hagadorn, J.W. 2002. New fossils from terminal Neoproterozoic strata of southern Nye County, Nevada. In: Corsetti, F.A. (ed). ProterozoicCambrian of the Great Basin and beyond, Pacific Section SEPM Book 93: 87-96.

Walde, D.H.G., Leonardos, O.H., Hahn, G. Hahn, R., Pflug, H. 1982. The first Precambrian megafossil from South America, Corumbella werneri. Anais da Academia Brasileira de Ciências, 54 (2): 461.

Walter, M.R.; Heys, G.R. 1985. Links between the rise of the Metazoa and the decline of stromatolites. Precambrian Research, 29: 149-174.

Watters, W.A.; Grotzinger, J.P. 2001. Digital reconstruction of calcified early metazoans, terminal Proterozoic Nama Group, Namibia. Paleobiology, 27 (1): 159-171.

Weiner, S.; Dove, P.M. 2003. An overview of biomineralization processes and the problem of the vital effect. Reviews of Mineralogy and Geochemistry, 54: 1- 29.

Wood, R.A. 2011. Paleoecology of the earliest skeletal metazoan communities: Implications for early biomineralization. Earth- Science Reviews, 106:184190.

Wood, R.A.; Grotzinger, J.P.; Dickson, J.A.D. 2002. Proterozoic modular biomineralized metazoan from the Nama Group, Namibia. Science, 296: 2383-2386.

Xiao, S.; Zhang, Y.; Knoll, A. 1998. Three-dimensional preservation of algae and animal embryos in a Neoproterozoic phosphorite. Nature, 391: 553-558.

Xiao, S.; Yuan, X.; Knoll, A.H. 2000. Eumetazoan fossils in terminal Proterozoic phosphorites. PNAS, 97 (25): 13684-13689.

Yochelson, E.L.; Herrera, H.E. 1974. Un fosil enigmatico del Cambrico Inferior de Argentina. Ameghiniana, 11: 283-294. 
Yochelson, E.L.; Stump, E. 1977. Discovery of early Cambrian fossils at Taylor Nunatak, Antarctica. Journal of Paleontology, 51: 872-875.

Zaine, M.F. 1991. Análise de fósseis de parte da faixa Paraguai (MS, MT) e seu contexto temporal e paleoambiental. São Paulo. Tese de Doutoramento, Instituto de Geociências, Universidade de São Paulo. São Paulo.

Zaine, M.F.; Fairchild, T.R.1985. Comparision of Aulophycus lucianoi Beurlen \& Sommer from Ladário (MS) and the genus Cloudina Germs, Ediacaran of Namibia. Anais da Academia Brasileira de Ciências, 57(1): 130.

Zaine, M.F.; Fairchild, T.R. 1987. Novas considerações sobre os fósseis da Formação Tamengo, Grupo Corumbá, SW do Brasil. In: Anais do X Congresso Brasileiro de Paleontologia, Rio de Janeiro. Resumo das Comunicações, 2: 797-807.

Zhuravlev, A.Y.; Wood, R.A. 2008. Eve of biomineralization: Controls on skeletal mineralogy. Geology, 36 (12): 923-926. 
ANEXOS 


\section{Anexo I}

Paleontologia Sistemática

Filo ?Annelida Lamarck, 1809

Classe ?Polychaeta Grube, 1850

Ordem Indeterminada

Família Cloudinidae Hahn \& Pflug, 1985

Gênero Cloudina Germs, 1972

Espécie-tipo Cloudina hartmannae Germs, 1972

Cloudina latilabrum nov. sp.

Pr. 6 F; Pr. 9; Pr. 10

Etimologia: latilabrum, das palavras latinas latus, amplo, largo, e labrum, borda, em alusão à extensão das abas dos segmentos do fóssil.

Espécie-tipo: Espécime ilustrado em A, na Prancha 10, foi designado como holótipo; espécimes ilustrados em B e C foram designados como parátipos. Estes espécimes encontram-se no material-tipo (GP/1E - 6218).

Material: O material-tipo está depositado na Coleção Científica do Laboratório de Paleontologia Sistemática do Instituto de Geociências da Universidade de São Paulo, correspondendo a uma amostra de mão (GP/1E-6218) e lâminas petrográficas (GP/L1E-42 e GP/L1E-43). Além deste material, está depositada uma amostra de mão (GP/1E-6221) e uma lâmina petrográfica (GP/L1E-24), proveniente da Pedreira Saladeiro (Prancha 10, H).

Ocorrência e Posição Estratigráfica: Imediações do Parque Marina Gattaz, a oeste de Corumbá, e Pedreira Saladeiro, em Ladário. MS, Brasil. Formação Tamengo, Grupo Corumbá. 
Diagnose: Conchas tubulares estreitas, compostas por segmentos com extensas abas de aparência delicada.

Descrição: Cloudina latilabrum nov. sp. tem diâmetros entre 0,2 e 1,2 mm, com predomínio de dimensões entre 0,2 e 0,6 mm (Prancha 10, D). O diâmetro é aparentemente uniforme ao longo da extensão da concha. $O$ comprimento máximo observado é de $18,5 \mathrm{~mm}$. A característica mais marcante desta espécie é a presença de extensas abas, as quais se projetam até $3 \mathrm{~mm}$ a partir da porção distal de cada segmento. No material-tipo, os fósseis estão ressaltados em uma das superfícies, ocorrendo predominantemente paralelos ao acamamento, sem orientação azimutal (Prancha 10, E). A maioria dos exemplares consiste de Cloudina latilabrum; em menor número, ocorrem fósseis de Cloudina lucianoi, com diâmetros entre 0,5 mm e 3,3 $\mathrm{mm}$ (Prancha 10, E e F). Boa parte da extensão da concha de é observada em alguns exemplares, embora a porção basal oclusa, característica do gênero, não tenha sido notada (Prancha 10, A). As seções transversais dos fósseis apresentam a disposição excêntrica das paredes dos segmentos, típica do gênero Cloudina (Prancha 10, G). Tanto na superfície da amostra, quanto em lâminas petrográficas, se observa calcita espática preenchendo o interior da concha e os espaços entre as abas. Em lâmina petrográfica, os fósseis apresentam, entre os preenchimentos, um delineamento negro, correspondendo à matéria orgânica que teria servido de base para a construção da estrutura (Prancha 10, G).

Discussão: Cloudina latilabrum exibe diâmetros inferiores aos valores conhecidos de Cloudina hartmannae, apresentando correspondência com Cloudina riemkeae, e situando-se nas dimensões inferiores de Cloudina lucianoi e Cloudina carinata. O comprimento máximo analisado foi é pouco maior do que $C$. riemkeae e C. lucianoi, mas inferior ao valor máximo observado em $C$. hartmannae e $C$. carinata. A principal feição que distingue $C$. latilabrum das demais espécies é a ampla projeção das abas de seus segmentos, contrastando com abas mais discretas observadas em outras espécies de Cloudina. Não foram observadas cristas longitudinais na superfície externa de $C$. latilabrum, nem espessamento na porção distal das abas dos segmentos, como ocorre em C. carinata. 


\section{Prancha 10}

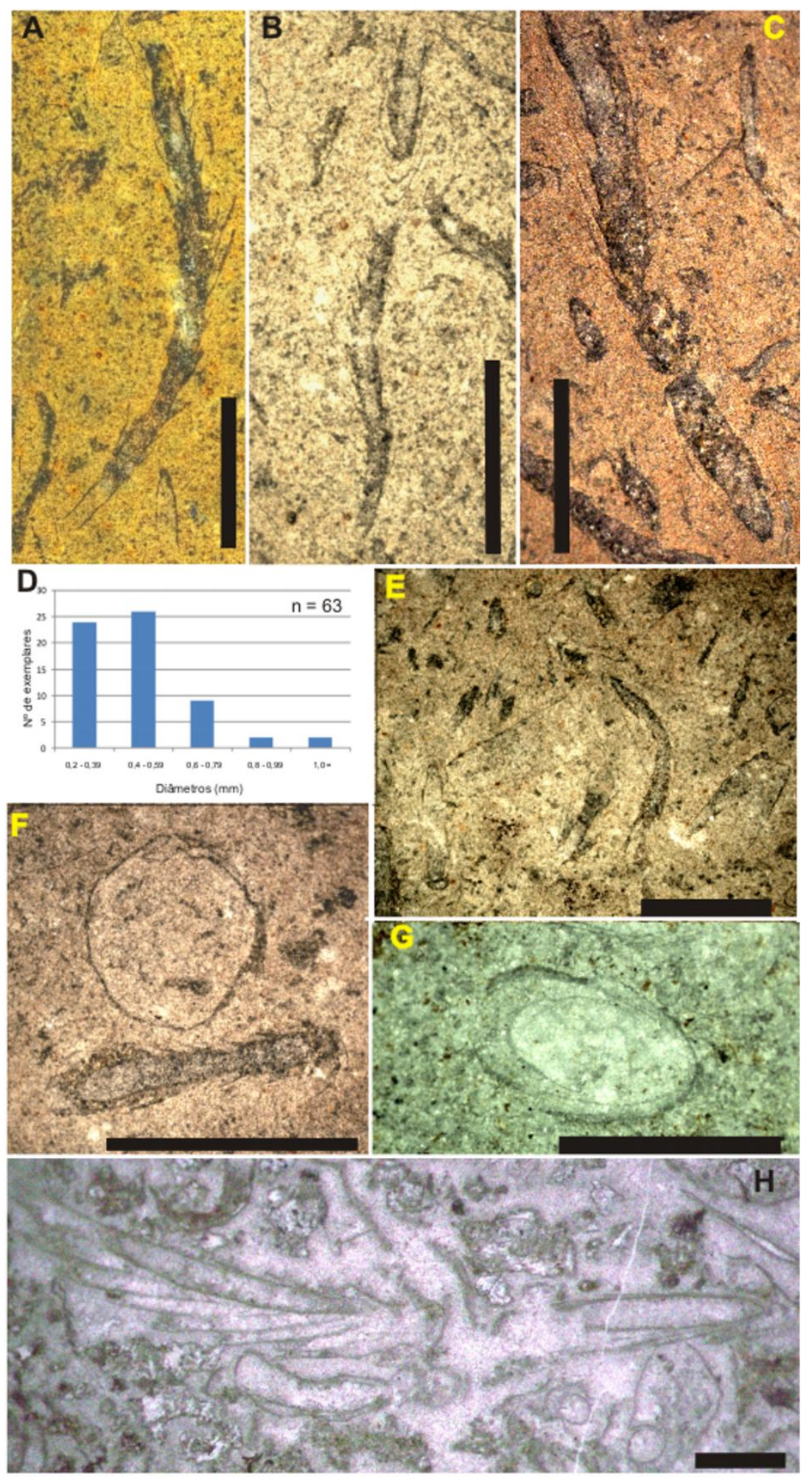

Cloudina latilabrum nov. sp. Holótipo (A) e parátipos (B e C). Escala $=5 \mathrm{~mm}$; D) Distribuição da frequência dos diâmetros; E e F) Superfície do material-tipo (GP/1E - 6218), com fósseis de $C$. latilabrum e Cloudina lucianoi. Notar o pequeno diâmetro da primeira espécie, em relação à segunda. Escala $=5 \mathrm{~mm}$; G) Seção transversal de $C$. latilabrum, exibindo escentricidade dos segmentos, e preenchimento espático. $O$ delineamento escuro da concha representa $\mathrm{o}$ arcabouço orgânico. Escala $=$ $1 \mathrm{~mm}$; H) C. latilabrum em lâmina petrográfica (GP/L1E - 24) da fácies packstones bioclásticos, da Pedreira Saladeiro. Notar as extensas abas, diagnóstico para a espécie. Escala $=1 \mathrm{~mm}$. 


\author{
ANEXO II \\ THE LATE EDIACARAN SHELLY FOSSIL Cloudina GERMS, 1972: PRESENT \\ STATUS OF KNOWLEDGE. \\ Felipe van Enck Meira ${ }^{1} \&$ Thomas Rich Fairchild ${ }^{2}$ \\ ${ }^{1}$ Programa de Pós-graduação em Geoquímica e Geotectônica, Instituto de \\ Geociências da Universidade de São Paulo, Rua do Lago, nº 562, CEP 05508- \\ 080, Cidade Universitária, São Paulo, SP, Brasil. \\ ${ }^{2}$ Departamento de Geologia Sedimentar e Ambiental, Instituto de Geociências \\ da Universidade de São Paulo, Rua do Lago, nº 562, CEP 05508-080, Cidade \\ Universitária, São Paulo, SP, Brasil. \\ ${ }^{1}$ fvemeira@gmail.com, ${ }^{2}$ trfairch@ $@$ hotmail.com
}

\title{
RESUMO
}

Muito tem se descoberto sobre o fóssil-índice do final do Ediacarano Cloudina Germs, desde sua descrição em 1972, especialmente nos últimos 20 anos, em relação à sua biologia, taxonomia, paleoecologia e bioestratigrafia. No entanto, como a maioria dos fósseis eucarióticos do Pré-Cambriano, características importantes ainda permanecem indefinidas. O presente artigo sintetiza o que se sabe de Cloudina atualmente.

Palavras-chave: Cloudina, Ediacarano, fóssil-índice.

\begin{abstract}
Much has been learned about the late Ediacaran index fossil Cloudina Germs since its description in 1972, specially in the last twenty years with regard to its biology, taxonomy, paleoecology and biostratigraphy. Nonetheless, like most Precambrian eukaryotic fossils, important characteristics still remain undefined. The current report synthesizes what we know of Cloudina to date.
\end{abstract}

Key-words: Cloudina, Ediacaran, index fossil. 


\section{INTRODUCTION}

The Ediacaran period marked the appearance of the first complex macroscopic fossils. Among them is the Ediacara biota (Narbonne, 1998, 2005) and the first biomineralizing metazoans (Germs, 1972; Grotzinger et al., 1995, 2000). Of the latter, the genus Cloudina Germs, 1972, is by far the most important, because of its use as a late Ediacaran index fossil (Grant, 1990) and also because it bears the oldest evidence of predation in meatzoans (Bengtson \& Yue, 1992; Hua et al., 2003).

The genus Cloudina was erected by Germs (1972) to include straight, curved or sinuous tubular, organic-rich calcareous shells up to $3.5 \mathrm{~cm}$ long, closed at their base and open distally. These shells are made up of short, slightly flaring, partial to entire annular segments inserted, not uncommonly asymmetrically, one inside the other (see Fig. 1) (Germs, 1972; Glaessner, 1976; Grant, 1990). Since its discovery, members of this genus have been described from 13 localities worldwide, including sites in Brazil, Uruguay, Argentina and Paraguay (see Fig. 2) (Zaine \& Fairchild, 1985; Grant, 1990; Hagadorn \& Waggoner, 2000; Boggiani \& Gaucher, 2004; Clausen \& Álvaro, 2004; Gaucher et al., 2005; Kontorovich et al., 2008; Cortijo et al., 2010). This paper summarizes current knowledge of this pivotal fossil and comments upon the direction of future research.

\section{Cloudina AS AN INDEX FOSSIL}

A late Ediacaran age was ascribed to Cloudina by Germs (1972) because it was first found in limestones interbedded with siliciclastic rocks in the Nama Group (Namibia) that contain impressions of undisputed soft-bodied representatives of the Ediacara biota. Later studies revealed the presence of Ediacaran organic-walled microfossil assemblages and simple, horizontal trace fossils within this succession (Grant, 1990 and references therein) and established that the ichnospecies Treptichnus pedum, a basal Cambrian index fossil, first appears above the last occurrence of Cloudina (Grant, 1990).

Uranium-lead SHRIMP geochronological analyses of zircon crystals from ash beds in the Nama Group (Grotzinger et al., 1995) determined the age for the stratigraphic range of Cloudina as 549 to $543 \mathrm{Ma}$. The younger date is taken as the age 
of the Ediacaran-Cambrian boundary, which is also marked in Namibia and globally by a negative carbon isotope excursion and faunal turnover suggestive of an endProterozoic extinction event (Grotzinger et al., 1995; Knoll \& Carroll, 1999; Kimura \& Watanabe, 2001). In Oman, Cloudina occurs below both an ash layer dated at ca. 542 $\mathrm{Ma}$, and the negative carbon isotope excursion at the Precambrian-Cambrian boundary (Amthor et al., 2003). Together, these data suggest that Cloudina became extinct at the end of the Ediacaran period (Amthor et al., 2003).

\section{THE SPECIES OF Cloudina}

In the original description of this genus, Germs (1972) differentiated two species of Cloudina within the Nama Group, Namibia: Cloudina hartmannae (the type-species) and Cloudina riemkeae, based on differences in shell diameters. The former is considerably larger (2.5 to $6.5 \mathrm{~mm}$ ) than the latter (0.3 to $1.3 \mathrm{~mm})$ (Germs, 1972).

In Brazil, the fossil was first observed by Barbosa (1949) in limestones of the Tamengo Formation, southwestern Brazil, and he likened it to the Paleozoic genus Hyolithes. Beurlen \& Sommer (1957) described it formally as Aulophycus lucianoi, reinterpreting it as new species of a genus of Cambrian algae known from North America (Fenton \& Fenton, 1939). Hence, a Cambrian age was thus established for the Tamengo Formation. The similarity between Aulophycus lucianoi and Cloudina as described by Germs led Fairchild (1978) to suggest that the Brazilian material should be transferred to the genus Cloudina, and that the Tamengo Formation was probably Ediacaran and not Cambrian in age. Ash layers within limestones of this formation have been dated at 543 Ma (Babinski et al., 2008), thereby corroborating Fairchild's suggestion and reinforcing the correlation with Namibia and Oman (Grotzinger et al., 1995; Amthor et al., 2003).

Aulophycus lucianoi was formally transferred to Cloudina by Zaine \& Fairchild (1985). Shell diameters in C. lucianoi range between 0.2 and $3.8 \mathrm{~mm}$ (Zaine \& Fairchild, 1987; Zaine, 1991) and thus overlap the size range of $C$. riemkeae and the lower part of the range of $C$. hartmannae.

Recently, a fourth species of Cloudina, C. carinata, was described in Ediacaran rocks of central Spain. This material differs from the other species in exhibiting 
longitudinal ridges and segments with a distinctly flared distal rim (see Fig. 3) (Cortijo et al., 2010).

Tubular calcareous shells of several different genera were reinterpreted by Grant (1990) as taphonomic variations of Cloudina. While this seems reasonable for some of them (e.g., Figs. 10 A and D in Grant, 1990), the shells in the genus Sinotubulites exhibit surficial wrinkling and folding that grades inward to less folded layers (see Fig. 4) (Chen et al., 2008) in clear contrast to the wall structure of Cloudina. in addition, shells in Sinotubulites are also much thicker (150-600 $\mu \mathrm{m}$ ) than those of Cloudina (Hua et al., 2003).

\section{SHELL MORPHOLOGY AND PHYLOGENETIC CONSIDERATIONS}

Early descriptions of the shells of Cloudina (Germs, 1972; Glaessner, 1976) pictured them as thick and made up of a corrugated outer wall and a smooth inner one (see Fig. 5.1). Subsequent reports demonstrated rather that they were extremely thin (3$50 \mu \mathrm{m}$ ) and uniform throughout their length (Grant, 1990; Hua et al., 2003, 2005). Grant (1990) further noted that the spaces between the walls of different segments were commonly filled by early marine carbonate cement (see Fig. 5.2), which, he suggested, may have reinforced the structure.

Shells of Cloudina show signs of plastic and brittle behavior (see Fig. 6) (e.g., Conway Morris et al., 1990; Grant, 1990; Zaine, 1991; Brain, 2001). For Grant (1990), these features indicate that shells originally formed by impregnation of a very thin organic template, clearly evident in Figure 6.

Analysis of cross-sections of shells on polished surfaces led Grant (1990) to interpret the shell of Cloudina as subdivided internally by cross-walls, corresponding to the base of each segment. This interpretation was abandoned, when whole, phosphatized shells of $C$. hartmannae from the Dengying Formation, China, revealed that only the base of the shell is closed (Hua et al., 2005). For Hua et al. (2005), Grant (1990) misidentified oblique sections through sidewalls as crosswalls in his petrographic studies

Possible budding was reported by Germs (1972) in a single specimen of Cloudina hartmannae from Namibia. This interpretation was later corroborated in the 
Chinese material studied by Hua et al. (2005) who demonstrated that daughter tubes arose deep within the parent shell and diverged abruptly upon reaching the aperture (see Fig. 7).

The phylogenetic affinity of Cloudina has yet to be resolved. Early authors (e.g. Germs, 1972; Glaessner, 1976) suggested affinities of Cloudina with the Early Cambrian calcareous tubular fossils of the clade Cribricyathea. This hypothesis, however, was questioned by Hahn \& Pflug (1985) and Grant (1990) who pointed out that Cloudina lacks the porous shells characteristic of many representatives of the Cribricyathea. It has also been suggested that Cloudina should be positioned among the serpulid annelids, as both possess tubular shells with a corrugated outer and a smooth inner surfaces that are closed at the base and open distally (Germs, 1972; Glaessner, 1976). Some members of the Serpulidae reproduce asexually by budding (Hua et al., 2005 and references therein). Furthermore, similarities in shell microstructure in Cloudina and the recent Serpulidae Salmacina dysteri were observed through scanning electron microscopy (Hua et al., 2005). However, as highlighted by Hua et al. (2005), serpulid shells vary considerably in microstructure, are much thicker than Cloudina shells, and are not made up of nested shells.

Comparisons between Cloudina and cnidarians also show some inconsistencies. Hydrozoan skeletons have distinct canals and pores, anthozoan tubes typically possess vertical septa and transverse walls, and scyphozoans bear organic carapaces (Hua et al., 2005).

Some authors, like Grant (1990) and Conway Morris et al. (1990), prefer not to ascribe Cloudina to any taxonomic group, although Grant (1990) recognizes that Cloudina was probably a metazoan of at least a cnidarian-grade of organization.

\section{PALEOECOLOGICAL INFERENCES}

Possibly, the main contribution of the study of the Dengying fossils was the discovery of holes, 15 to $85 \mu \mathrm{m}$ in diameter, located preferentially on smooth areas of Cloudina shells. These have been interpreted as the oldest known evidence of predation in metazoans (see Fig. 7) (Bengtson \& Yue, 1992; Hua et al., 2003). According to Hua et al. (2003), the direct relation between the diameter of the shell at the level of the hole and distance of the hole from the aperture supports this hypothesis. This finding pushes 
predator-prey interactions back to before the Cambrian explosion and is consistent with suggestions that the primary function of early shells was to protect against predators (Bengtson, 2002). For Hua et al. (2007), additional support for this interpretation is the apparent replacement of the organic-walled tubular fossil Conotubus by Cloudina within the Dengying Formation. Moreover, similarities in the tube construction of these two taxa further suggest that Conotubus may be ancestral to Cloudina (Hua et al., 2007).

Regarding the growth position of Cloudina, Seilacher (1999) proposed a very novel model in which he suggested that Cloudina lived partially embedded upright in a biomat-sealed substrate. Grotzinger et al. (2005) interpreted fossils of Cloudina within thrombolitic structures in Namibia as having been originally loosely attached to the thrombolitic substrate, in a manner similar to Seilacher's proposal. Unlike Seilacher (1999), however, Grotzinger et al. (2005) believed that Cloudina was positioned parallel to the substrate.

\section{LIMITATIONS OF THE STUDY AND FINAL CONSIDERATIONS}

Like most Neoproterozoic-Cambrian tubular macrofossils, the phylogenetic affinities of Cloudina remain conjectural (Hua et al., 2005). Similarities in shell construction and asexual reproduction between Cloudina and some Serpulidae (Hua et $a l ., 2005)$ are consistent with the hypothesis that it may have been an annelid, as suggested originally by Germs (1972) and Glaessner (1976). However, given the simplicity of this and other Ediacaran tubular fossils, proof of this hypothesis may have to await the fortuitous discovery of soft tissues (Hua et al., 2005).

A second problem concerns the taxonomy of Cloudina. Except for C. carinata, the species of Cloudina have been differentiated mainly on the range of their diameters. Some authors, such as Bengtson \& Yue (1992) and Hua et al. (2003, 2005), lump all within a single species (C. hartmannae), while others, like Hahn \& Pflug (1985), Zaine \& Fairchild (1985), Gaucher et al. (2003), Sour-Tovar et al. (2007), treat them as separate taxa. Hence, there is still no consensus.

In contrast to the traditional petrographic analysis of Cloudina in thin sections, which has apparently led to some misinterpretation (Grant, 1990), the examination of silica- or phosphate-replaced three-dimensional fossils chemically extracted from the 
rock matrix has been successful in the studies of the Chinese (Bengtson \& Yue, 1992; Hua et al., 2003, 2005) and Spanish (Cortijo et al., 2010) material, as amply discussed above, and should be applied to silica-replaced fossils of Cloudina reported from northwestern Mexico (Sour-Tovar et al., 2007), southwestern Brazil (Zaine, 1991) and Namibia (Brain, 2001). An alternative approach when chemical extraction is impossible is the digital reconstruction of fossils through assembling serial micrometer-thick crosssections. This technique was successfully applied to the reconstruction of the shelly metazoan Namacalathus (Watters \& Grotzinger, 2001) and later of Cloudina (Miller, 2004) from the Nama Group. Thus, remaining questions on the morphology, taxonomy, and paleoecology of Cloudina could be further elucidated by applying this technique at Cloudina localities worldwide.

\section{REFERENCES}

AMTHOR, J.E.; GROTZINGER, J.P.; SCHRÖDER, S.; BOWRING, S.A.; RAMEZANI, J.; MARTIN, M.W. \& MATTER, A. 2003. Extinction of Cloudina and Namacalathus at the Precambrian-Cambrian boundary in Oman. Geology, 31: 431-434.

BABINSKI, M.; BOGGIANI, P.C.; FANNING, C.M.; FAIRCHILD, T.R.; SIMON, C.M. \& SIAL, A.N. 2008. U-Pb SHRIMP geochronology and isotope chemostratigraphy $(\mathrm{C}, \mathrm{O}, \mathrm{Sr})$ of the Tamengo Formation, Southern Paraguay Belt, Brazil. In: SOUTH AMERICAN SYMPOSIUM ON ISOTOPE GEOLOGY, 6, San Carlos de Bariloche, 2008. Book of Abstracts, p. 160.

BARBOSA, O. 1949. Contribuição à geologia da região Brasil-Bolívia. Mineração e Metalurgia, 13: 271-278.

BENGTSON, S. 2002. Origins and early evolution of predation. In: KOWALEWSKI, M. \& KELLEY, H. (eds.). The fossil record of predation. The Paleontological Society Papers 8, p. 289-317.

BENGTSON, S. \& YUE, Z. 1992. Predatorial borings in late Precambrian mineralized exoskeletons. Science, 257: 367-369. 
BEURLEN, K. \& SOMMER, F.W. 1957. Observações estratigráficas e paleontológicas sobre o calcário Corumbá. Rio de Janeiro, Departamento Nacional da Produção Mineral / Divisão de Geologia e Mineralogia, 35p. (Boletim 168).

BOGGIANI, P.C. \& GAUCHER, C. 2004. Cloudina from the Itapucumí Group (Vendian, Paraguay): Age and Correlations. In: SYMPOSIUM ON NEOPROTEROZOIC-EARLY PALEOZOIC EVENTS IN SW-GONDWANA, 1, São Paulo, 2004. Extended Abstracts, IGCP Project 478. p. 13-15.

BRAIN, C.K. 2001. Some observations on Cloudina, a terminal Proterozoic index fossil from Namibia. Journal of African Earth Sciences, 33: 475-480.

CHEN, Z.; BENGTSON, S.; ZHOU, C.-M.; HUA, H. \& YUE, Z. 2008. Tube structure and original composition of Sinotubulites: shelly fossils from the late Neoproterozoic in southern Shaanxi, China. Lethaia, 41: 37-45.

CLAUSEN, S. \& ÁLVARO, J. 2004. Implications biostratigraphiques et paléobiogéographiques de la découverte du métazoaire néoprotérozoïque Cloudina dans le versant nord de la Montagne Noire (France). In: COLLOQUE DE PALÉOGÉOGRAPHIE. SOCIÉTÉ GÉOLOGIQUE DE FRANCE, Paris, 2004. Program with abstracts, p. 42-43.

CONWAY MORRIS, S.; MATTES, B.W. \& MENGE, C. 1990. The early skeletal organism Cloudina: new occurrences from Oman and possibly China. American Journal of Science, 290-A: 245-260.

CORTIJO, I.; MARTÍ MUS, M.; JENSEN, S. \& PALACIOS, T. 2010. A new species of Cloudina from the terminal Ediacaran of Spain. Precambrian Research, 176: 1-10.

FAIRCHILD, T.R. 1978. Evidências paleontológicas de uma possível idade "Ediacariana" ou Cambriana Inferior, para a parte leste do Grupo Corumbá (Mato Grosso do Sul). In: CONGRESSO BRASILEIRO DE GEOLOGIA, 30, Recife, 1978. Resumos das Comunicações, p. 181. 
FENTON, C.L. \& FENTON, M.A. 1939. Precambrian and Paleozoic algae. Geological Society of America Bulletin, 50 (1): 89-126.

GAUCHER, C.; POIRE, D.G.; GOMEZ PERAL, L. \& CHIGLINO, L. 2005. Litoestratigrafia, bioestratigrafia y correlaciones de las sucessiones sedimentarias del Neoproterozoico-Cambrico del Craton del Rio de la Plata (Uruguay y Argentina). Latin American Journal of Sedimentology and Basin Analysis, 12 (2): 145-160.

GERMS, G.J.B. 1972. New shelly fossils from Nama Group, South West Africa. American Journal of Science, 272: 752-761.

GLAESSNER, M.F. 1976. Early Phanerozoic annelid worms and their geological and biological significance. Journal of the Geological Society, 132: 259-275.

GRANT, S.W.F. 1990. Shell structure and distribution of Cloudina, a potential index fossil for the terminal Proterozoic. American Journal of Science, 290-A: 261-294.

GROTZINGER, J.P.; BOWRING, S.A.; SAYLOR, B.Z. \& KAUFMAN, A.J., 1995. Biostratigraphic and geochronologic constraints on early animal evolution. Science, 270: 598-604.

GROTZINGER, J.P.; WATTERS, W.A. \& KNOLL, A.H. 2000: Calcified metazoans in thrombolite-stromatolite reefs of the terminal Proterozoic Nama Group, Namibia. Paleobiology, 26 (3): 334-359.

GROTZINGER, J; ADAMS, E. W. \& SCHRÖDER, S. 2005. Microbial-metazoan reefs of the terminal Proterozoic Nama Group (c. 550-543 Ma), Namibia. Geological Magazine, 142 (5): 499-517.

HAHN, G. \& PFLUG, H.D. 1985. Die Cloudinidae n. fam., Kalk-Röhren aus dem Vendium und Unter-Kambrium. Senckenbergiana Lethaea, 65: 413-431. 
HOFMANN, H.J. \& MOUNTJOY, E.W. 2001. Namacalathus-Cloudina assemblage in Neoproterozoic Miette Group (Byng Formation), British Columbia: Canada's oldest shelly fossils. Geology, 29: 1091-1094.

HUA, H.; PRATT, B.R. \& ZHANG, L.-Y. 2003. Borings in Cloudina shells: complex predator-prey dynamics in the terminal Neoproterozoic. Palaios, 18: 454-459.

HUA, H.; CHEN, Z.; YUAN, X.; ZHANG, L.-Y. \& XIAO, S. 2005. Skeletogenesis and asexual reproduction in the earliest biomineralizing animal Cloudina. Geology, 33(4): 277-280.

HUA, H.; CHEN, Z. \& XUNLAI, Y. 2007. The advent of mineralized skeletons in Neoproterozoic metazoa - new fossil evidence from the Gaojiashan fauna. Geological Journal, 42: 263-279.

KIMURA H. \& WATANABE Y. 2001. Oceanic anoxia at the Precambrian-Cambrian boundary. Geology, 29: 995-998.

KNOLL, A.H. \& CARROLL, S.B. 1999. Early animal evolution; emerging views from comparative biology and geology. Science, 284: 2129-2137.

KONTOROVICH, A.E.; VARLAMOV, A.I.; GRAZHDANKIN, D.V.; KARLOVA, G.A.; KLETS, A.G.; KONTOROVICH, V.A.; SARAEV, S.V.; TERLEEV, A.A.; BELYAEV, S.Yu.; VARAKSINA, I.V.; EFIMOV, A.S.; KOCHNEV, B.B.; NAGOVITSIN, K.E.; POSTNIKOV, A.A. \& FILIPPOV, Yu.F. 2008. A section of Vendian in the east of West Siberian Plate (based on data from the Borehole Vostok 3). Russian Geology and Geophysics, 49: 932-939.

MILLER, A.J. 2004. A revised morphology of Cloudina with ecological and phylogenetic implications. Unpublished technical report. Harvard University, Cambridge. 21p. Available at:

$<$ http://ajm.pioneeringprojects.org/files/CloudinaPaper_Final.pdf >.

NARBONNE, G.M. 1998. The Ediacara biota: A terminal Neoproterozoic experiment in the evolution of life. Geological Society of America Today, 8 (2): 1-6. 
NARBONNE, G.M. 2005. The Ediacara biota: Neoproterozoic origin of animals and their ecosystems. Annual Review of Earth Planetary Sciences, 33: 421-442.

SEILACHER , A. 1999. Biomat-related lifestyles in the Precambrian. Palaios, 14: 8693.

SOUR-TOVAR, F.; HAGADORN, J.W. \& HUITRÓN-RUBIO, T. 2007. Ediacaran and Cambrian index fossils from Sonora, Mexico. Palaeontology, 50 (1): 169-175.

WATTERS, W.A. \& GROTZINGER, J.P. 2001. Digital reconstruction of calcified early metazoans, terminal Proterozoic Nama Group, Namibia. Paleobiology, 27 (1): 159-171.

ZAINE, M.F. 1991. Análise dos fósseis de parte da Faixa Paraguai (MS, MT) e seu contexto temporal e paleoambiental. Programa de Pós-graduação em Geologia Sedimentar, Universidade de São Paulo, Tese de Doutoramento, 215p.

ZAINE, M.F. \& FAIRCHILD, T.R., 1985. Comparison of Aulophycus lucianoi Beurlen \& Sommer from Ladário (MS) and the genus Cloudina Germs, Ediacaran of Namibia. Anais Academia Brasileira de Ciências, 57: 130.

ZAINE, M.F. \& FAIRCHILD, T.R. 1987. Novas considerações sobre os fósseis da Formação Tamengo, Grupo Corumbá, SW do Brasil. In: CONGRESSO BRASILEIRO DE PALEONTOLOGIA, 10, Rio de Janeiro, 1987. Anais. p. 797-807. 


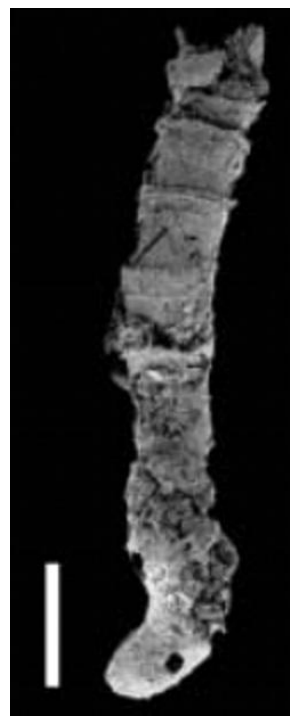

Figure 1:

Cloudina

hartmannae from

the Dengying

Formation, China.

Note successive

slightly-flaring

segments inserted

one within the

other. Scale bar

represents 280

$\mu \mathrm{m}$. After Chen et

al. (2008).

:

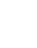

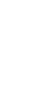




\section{Anexo III}

Tabela 1. Relação de amostras de mão examinadas, depositadas na Coleção Científica do Laboratório de Paleontologia Sistemática do Instituto de Geociências da Universidade de São Paulo.

\begin{tabular}{|c|c|c|c|}
\hline Exemplar & $\begin{array}{c}\text { Unidade } \\
\text { litoestraigráfica }\end{array}$ & Procedência & Espécie (s) \\
\hline GP/1T-108 & $\begin{array}{c}\text { Formação } \\
\text { Tamengo, Grupo } \\
\text { Corumbá }\end{array}$ & $\begin{array}{c}\text { Pedreira } \\
\text { Laginha, } \\
\text { Corumbá, MS }\end{array}$ & Cloudina lucianoi \\
\hline GP/1T-109 & $\begin{array}{c}\text { Formação } \\
\text { Tamengo, Grupo } \\
\text { Corumbá }\end{array}$ & $\begin{array}{c}\text { Pedreira } \\
\text { Laginha, } \\
\text { Corumbá, MS }\end{array}$ & $\begin{array}{c}\text { Cloudina lucianoi } \\
\text { e Corumbella } \\
\text { werneri }\end{array}$ \\
\hline GP/1E-6211 & $\begin{array}{c}\text { Formação } \\
\text { Tamengo, Grupo } \\
\text { Corumbá }\end{array}$ & $\begin{array}{c}\text { Pedreira } \\
\text { Laginha, } \\
\text { Corumbá, MS }\end{array}$ & $\begin{array}{c}\text { Corumbella } \\
\text { werneri }\end{array}$ \\
\hline GP/1E-6212 & $\begin{array}{c}\text { Formação } \\
\text { Tamengo, Grupo } \\
\text { Corumbá }\end{array}$ & $\begin{array}{c}\text { Pedreira } \\
\text { Laginha, } \\
\text { Corumbá, MS }\end{array}$ & $\begin{array}{c}\text { Corumbella } \\
\text { werneri }\end{array}$ \\
\hline GP/1E-6213 & $\begin{array}{c}\text { Formação } \\
\text { Tamengo, Grupo } \\
\text { Corumbá }\end{array}$ & $\begin{array}{c}\text { Pedreira } \\
\text { Laginha, } \\
\text { Corumbá, MS }\end{array}$ & $\begin{array}{c}\text { Corumbella } \\
\text { werneri }\end{array}$ \\
\hline GP/1E-6214 & $\begin{array}{c}\text { Formação } \\
\text { Tamengo, Grupo } \\
\text { Corumbá }\end{array}$ & $\begin{array}{c}\text { Pedreira } \\
\text { Laginha, } \\
\text { Corumbá, MS }\end{array}$ & $\begin{array}{c}\text { Corumbella } \\
\text { werneri }\end{array}$ \\
\hline GP/1E-6215 & $\begin{array}{c}\text { Formação } \\
\text { Tamengo, Grupo } \\
\text { Corumbá }\end{array}$ & $\begin{array}{c}\text { Pedreira } \\
\text { Laginha, } \\
\text { Corumbá, MS }\end{array}$ & Cloudina lucianoi \\
\hline GP/1E-4173 & $\begin{array}{c}\text { Formação } \\
\text { Tamengo, Grupo } \\
\text { Corumbá }\end{array}$ & $\begin{array}{c}\text { Pedreira } \\
\text { Laginha, } \\
\text { Corumbá, MS }\end{array}$ & Cloudina Iucianoi \\
\hline GP/1E-5760 & $\begin{array}{c}\text { Formação } \\
\text { Tamengo, Grupo } \\
\text { Corumbá }\end{array}$ & $\begin{array}{c}\text { Pedreira } \\
\text { Saladeiro, } \\
\text { Ladário, MS }\end{array}$ & $\begin{array}{c}\text { Corumbella } \\
\text { werneri }\end{array}$ \\
\hline GP/1E-6219 & $\begin{array}{c}\text { Formação } \\
\text { Tamengo, Grupo }\end{array}$ & $\begin{array}{l}\text { Pedreira } \\
\text { Saladeiro, }\end{array}$ & Cloudina lucianoi \\
\hline
\end{tabular}




\begin{tabular}{|c|c|c|c|}
\hline & Corumbá & Ladário, MS & \\
\hline GP/1E-3870 & $\begin{array}{c}\text { Formação } \\
\text { Tamengo, Grupo } \\
\text { Corumbá }\end{array}$ & $\begin{array}{c}\text { Pedreira } \\
\text { Saladeiro, } \\
\text { Ladário, MS }\end{array}$ & Cloudina Iucianoi \\
\hline GP/1E-3878 & $\begin{array}{c}\text { Formação } \\
\text { Tamengo, Grupo } \\
\text { Corumbá }\end{array}$ & $\begin{array}{l}\text { Pedreira } \\
\text { Saladeiro, } \\
\text { Ladário, MS }\end{array}$ & Cloudina Iucianoi \\
\hline GP/1E-4117 & $\begin{array}{c}\text { Formação } \\
\text { Tamengo, Grupo } \\
\text { Corumbá }\end{array}$ & $\begin{array}{c}\text { Pedreira } \\
\text { Corcal, } \\
\text { Corumbá, MS }\end{array}$ & Cloudina Iucianoi \\
\hline GP/1E-4118 & $\begin{array}{c}\text { Formação } \\
\text { Tamengo, Grupo } \\
\text { Corumbá }\end{array}$ & $\begin{array}{c}\text { Pedreira } \\
\text { Corcal, } \\
\text { Corumbá, MS }\end{array}$ & Cloudina lucianoi \\
\hline GP/1E-4119 & $\begin{array}{c}\text { Formação } \\
\text { Tamengo, Grupo } \\
\text { Corumbá }\end{array}$ & $\begin{array}{c}\text { Pedreira } \\
\text { Corcal, } \\
\text { Corumbá, MS }\end{array}$ & Cloudina Iucianoi \\
\hline GP/1E-4120 & $\begin{array}{c}\text { Formação } \\
\text { Tamengo, Grupo } \\
\text { Corumbá }\end{array}$ & $\begin{array}{c}\text { Pedreira } \\
\text { Corcal, } \\
\text { Corumbá, MS }\end{array}$ & Cloudina Iucianoi \\
\hline GP/1E-4121 & $\begin{array}{c}\text { Formação } \\
\text { Tamengo, Grupo } \\
\text { Corumbá }\end{array}$ & $\begin{array}{c}\text { Pedreira } \\
\text { Corcal, } \\
\text { Corumbá, MS }\end{array}$ & Cloudina Iucianoi \\
\hline GP/1E-4123 & $\begin{array}{c}\text { Formação } \\
\text { Tamengo, Grupo } \\
\text { Corumbá }\end{array}$ & $\begin{array}{c}\text { Pedreira } \\
\text { Corcal, } \\
\text { Corumbá, MS }\end{array}$ & Cloudina lucianoi \\
\hline GP/1E-4124 & $\begin{array}{c}\text { Formação } \\
\text { Tamengo, Grupo } \\
\text { Corumbá }\end{array}$ & $\begin{array}{c}\text { Pedreira } \\
\text { Corcal, } \\
\text { Corumbá, MS }\end{array}$ & Cloudina Iucianoi \\
\hline GP/1E-4125 & $\begin{array}{c}\text { Formação } \\
\text { Tamengo, Grupo } \\
\text { Corumbá }\end{array}$ & $\begin{array}{c}\text { Pedreira } \\
\text { Corcal, } \\
\text { Corumbá, MS }\end{array}$ & Cloudina lucianoi \\
\hline GP/1E-4126 & $\begin{array}{c}\text { Formação } \\
\text { Tamengo, Grupo } \\
\text { Corumbá }\end{array}$ & $\begin{array}{c}\text { Pedreira } \\
\text { Corcal, } \\
\text { Corumbá, MS }\end{array}$ & Cloudina lucianoi \\
\hline GP/1E-4127 & $\begin{array}{c}\text { Formação } \\
\text { Tamengo, Grupo } \\
\text { Corumbá }\end{array}$ & $\begin{array}{c}\text { Pedreira } \\
\text { Corcal, } \\
\text { Corumbá, MS }\end{array}$ & Cloudina Iucianoi \\
\hline
\end{tabular}




\begin{tabular}{|c|c|c|c|}
\hline GP/1E-4128 & $\begin{array}{c}\text { Formação } \\
\text { Tamengo, Grupo } \\
\text { Corumbá }\end{array}$ & $\begin{array}{c}\text { Pedreira } \\
\text { Corcal, } \\
\text { Corumbá, MS }\end{array}$ & Cloudina lucianoi \\
\hline GP/1E-4129 & $\begin{array}{c}\text { Formação } \\
\text { Tamengo, Grupo } \\
\text { Corumbá }\end{array}$ & $\begin{array}{c}\text { Pedreira } \\
\text { Corcal, } \\
\text { Corumbá, MS }\end{array}$ & Cloudina lucianoi \\
\hline GP/1E-4138 & $\begin{array}{c}\text { Formação } \\
\text { Tamengo, Grupo } \\
\text { Corumbá }\end{array}$ & $\begin{array}{c}\text { Pedreira } \\
\text { Corcal, } \\
\text { Corumbá, MS }\end{array}$ & Cloudina lucianoi \\
\hline GP/1E-4143 & $\begin{array}{c}\text { Formação } \\
\text { Tamengo, Grupo } \\
\text { Corumbá }\end{array}$ & $\begin{array}{c}\text { Pedreira } \\
\text { Corcal, } \\
\text { Corumbá, MS }\end{array}$ & Cloudina lucianoi \\
\hline GP/1E-4144 & $\begin{array}{c}\text { Formação } \\
\text { Tamengo, Grupo } \\
\text { Corumbá }\end{array}$ & $\begin{array}{c}\text { Pedreira } \\
\text { Corcal, } \\
\text { Corumbá, MS }\end{array}$ & Cloudina Iucianoi \\
\hline GP/1E-4147 & $\begin{array}{c}\text { Formação } \\
\text { Tamengo, Grupo } \\
\text { Corumbá }\end{array}$ & $\begin{array}{c}\text { Pedreira } \\
\text { Corcal, } \\
\text { Corumbá, MS }\end{array}$ & Cloudina lucianoi \\
\hline GP/1E-4155 & $\begin{array}{c}\text { Formação } \\
\text { Tamengo, Grupo } \\
\text { Corumbá }\end{array}$ & $\begin{array}{c}\text { Pedreira } \\
\text { Corcal, } \\
\text { Corumbá, MS }\end{array}$ & Cloudina Iucianoi \\
\hline GP/1E-4164 & $\begin{array}{c}\text { Formação } \\
\text { Tamengo, Grupo } \\
\text { Corumbá }\end{array}$ & $\begin{array}{c}\text { Pedreira } \\
\text { Corcal, } \\
\text { Corumbá, MS }\end{array}$ & Cloudina Iucianoi \\
\hline GP/1E-4167 & $\begin{array}{c}\text { Formação } \\
\text { Tamengo, Grupo } \\
\text { Corumbá }\end{array}$ & $\begin{array}{c}\text { Pedreira } \\
\text { Corcal, } \\
\text { Corumbá, MS }\end{array}$ & Cloudina lucianoi \\
\hline GP/1E-6216 & $\begin{array}{c}\text { Formação } \\
\text { Guaicurus, Grupo } \\
\text { Corumbá }\end{array}$ & $\begin{array}{c}\text { Pedreira } \\
\text { Corcal, } \\
\text { Corumbá, MS }\end{array}$ & Cloudina lucianoi \\
\hline GP/1E-6218 & $\begin{array}{c}\text { Formação } \\
\text { Tamengo, Grupo } \\
\text { Corumbá }\end{array}$ & $\begin{array}{l}\text { Arredores do } \\
\text { Parque } \\
\text { Marina } \\
\text { Gattaz, } \\
\text { Corumbá, MS }\end{array}$ & $\begin{array}{c}\text { Cloudina } \\
\text { latilabrum nov. } \\
\text { sp. e Cloudina } \\
\text { lucianoi }\end{array}$ \\
\hline GP/1E-6221 & $\begin{array}{c}\text { Formação } \\
\text { Tamengo, Grupo } \\
\text { Corumbá }\end{array}$ & $\begin{array}{l}\text { Pedreira } \\
\text { Saladeiro, } \\
\text {,Corumbá, }\end{array}$ & Cloudina lucianoi \\
\hline
\end{tabular}




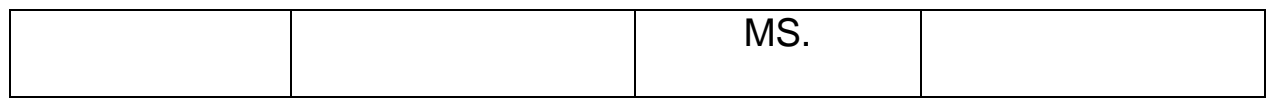

Tabela 2. Relação de lâminas petrográficas examinadas, depositadas na Coleção Científica do Laboratório de Paleontologia Sistemática do Instituto de Geociências da Universidade de São Paulo.

\begin{tabular}{|c|c|c|c|}
\hline Exemplar & $\begin{array}{c}\text { Unidade } \\
\text { litoestraigráfica }\end{array}$ & Procedência & Espécie (s) \\
\hline GP/L1E-21 & $\begin{array}{c}\text { Formação } \\
\text { Tamengo, Grupo } \\
\text { Corumbá }\end{array}$ & $\begin{array}{c}\text { Pedreira } \\
\text { Saladeiro, } \\
\text { Ladário, MS }\end{array}$ & Cloudina Iucianoi \\
\hline GP/L1E-22 & $\begin{array}{c}\text { Formação } \\
\text { Tamengo, Grupo } \\
\text { Corumbá }\end{array}$ & $\begin{array}{c}\text { Pedreira } \\
\text { Saladeiro, } \\
\text { Ladário, MS }\end{array}$ & Cloudina Iucianoi \\
\hline GP/L1E-23 & $\begin{array}{c}\text { Formação } \\
\text { Tamengo, Grupo } \\
\text { Corumbá }\end{array}$ & $\begin{array}{c}\text { Pedreira } \\
\text { Saladeiro, } \\
\text { Ladário, MS }\end{array}$ & Cloudina Iucianoi \\
\hline GP/L1E-24 & $\begin{array}{c}\text { Formação } \\
\text { Tamengo, Grupo } \\
\text { Corumbá }\end{array}$ & $\begin{array}{c}\text { Pedreira } \\
\text { Saladeiro, } \\
\text { Ladário, MS }\end{array}$ & $\begin{array}{c}\text { Cloudina } \\
\text { latilabrum nov. } \\
\text { sp. }\end{array}$ \\
\hline GP/L1E-55 & $\begin{array}{c}\text { Formação } \\
\text { Tamengo, Grupo } \\
\text { Corumbá }\end{array}$ & $\begin{array}{c}\text { Pedreira } \\
\text { Saladeiro, } \\
\text { Ladário, MS }\end{array}$ & Cloudina Iucianoi \\
\hline GP/L1E-8 & $\begin{array}{c}\text { Formação } \\
\text { Tamengo, Grupo } \\
\text { Corumbá }\end{array}$ & $\begin{array}{c}\text { Pedreira } \\
\text { Saladeiro, } \\
\text { Ladário, MS }\end{array}$ & Cloudina Iucianoi \\
\hline GP/L1E-9 & $\begin{array}{c}\text { Formação } \\
\text { Tamengo, Grupo } \\
\text { Corumbá }\end{array}$ & $\begin{array}{c}\text { Pedreira } \\
\text { Saladeiro, } \\
\text { Ladário, MS }\end{array}$ & Cloudina Iucianoi \\
\hline GP/L1E-3 & $\begin{array}{c}\text { Formação } \\
\text { Tamengo, Grupo } \\
\text { Corumbá }\end{array}$ & $\begin{array}{c}\text { Pedreira } \\
\text { Saladeiro, } \\
\text { Ladário, MS }\end{array}$ & Cloudina lucianoi \\
\hline GP/L1E-33 & $\begin{array}{c}\text { Formação } \\
\text { Tamengo, Grupo } \\
\text { Corumbá }\end{array}$ & $\begin{array}{c}\text { Pedreira } \\
\text { Saladeiro, } \\
\text { Ladário, MS }\end{array}$ & Cloudina Iucianoi \\
\hline GP/L1E-34 & $\begin{array}{c}\text { Formação } \\
\text { Tamengo, Grupo }\end{array}$ & $\begin{array}{l}\text { Pedreira } \\
\text { Saladeiro, }\end{array}$ & Cloudina Iucianoi \\
\hline
\end{tabular}




\begin{tabular}{|c|c|c|c|}
\hline & Corumbá & Ladário, MS & \\
\hline GP/L1E-35 & $\begin{array}{c}\text { Formação } \\
\text { Tamengo, Grupo } \\
\text { Corumbá }\end{array}$ & $\begin{array}{c}\text { Pedreira } \\
\text { Saladeiro, } \\
\text { Ladário, MS }\end{array}$ & Cloudina Iucianoi \\
\hline GP/L1E-36 & $\begin{array}{c}\text { Formação } \\
\text { Tamengo, Grupo } \\
\text { Corumbá }\end{array}$ & $\begin{array}{c}\text { Pedreira } \\
\text { Saladeiro, } \\
\text { Ladário, MS }\end{array}$ & Cloudina Iucianoi \\
\hline GP/L1E-37 & $\begin{array}{c}\text { Formação } \\
\text { Tamengo, Grupo } \\
\text { Corumbá }\end{array}$ & $\begin{array}{c}\text { Pedreira } \\
\text { Saladeiro, } \\
\text { Ladário, MS }\end{array}$ & Cloudina Iucianoi \\
\hline GP/L1E-38 & $\begin{array}{c}\text { Formação } \\
\text { Tamengo, Grupo } \\
\text { Corumbá }\end{array}$ & $\begin{array}{c}\text { Pedreira } \\
\text { Saladeiro, } \\
\text { Ladário, MS }\end{array}$ & Cloudina Iucianoi \\
\hline GP/L1E-39 & $\begin{array}{c}\text { Formação } \\
\text { Tamengo, Grupo } \\
\text { Corumbá }\end{array}$ & $\begin{array}{c}\text { Pedreira } \\
\text { Saladeiro, } \\
\text { Ladário, MS }\end{array}$ & Cloudina lucianoi \\
\hline GP/L1E-40 & $\begin{array}{c}\text { Formação } \\
\text { Tamengo, Grupo } \\
\text { Corumbá }\end{array}$ & $\begin{array}{c}\text { Pedreira } \\
\text { Saladeiro, } \\
\text { Ladário, MS }\end{array}$ & Cloudina lucianoi \\
\hline GP/L1E-41 & $\begin{array}{c}\text { Formação } \\
\text { Tamengo, Grupo } \\
\text { Corumbá }\end{array}$ & $\begin{array}{c}\text { Pedreira } \\
\text { Saladeiro, } \\
\text { Ladário, MS }\end{array}$ & Cloudina Iucianoi \\
\hline GP/L1E-44 & $\begin{array}{c}\text { Formação } \\
\text { Tamengo, Grupo } \\
\text { Corumbá }\end{array}$ & $\begin{array}{c}\text { Pedreira } \\
\text { Saladeiro, } \\
\text { Ladário, MS }\end{array}$ & Cloudina Iucianoi \\
\hline GP/L1E-45 & $\begin{array}{c}\text { Formação } \\
\text { Tamengo, Grupo } \\
\text { Corumbá }\end{array}$ & $\begin{array}{c}\text { Pedreira } \\
\text { Saladeiro, } \\
\text { Ladário, MS }\end{array}$ & Cloudina lucianoi \\
\hline GP/L1E-46 & $\begin{array}{c}\text { Formação } \\
\text { Tamengo, Grupo } \\
\text { Corumbá }\end{array}$ & $\begin{array}{c}\text { Pedreira } \\
\text { Saladeiro, } \\
\text { Ladário, MS }\end{array}$ & Cloudina Iucianoi \\
\hline GP/L1E-47 & $\begin{array}{c}\text { Formação } \\
\text { Tamengo, Grupo } \\
\text { Corumbá }\end{array}$ & $\begin{array}{c}\text { Pedreira } \\
\text { Saladeiro, } \\
\text { Ladário, MS }\end{array}$ & Cloudina Iucianoi \\
\hline GP/L1E-48 & $\begin{array}{c}\text { Formação } \\
\text { Tamengo, Grupo } \\
\text { Corumbá }\end{array}$ & $\begin{array}{c}\text { Pedreira } \\
\text { Saladeiro, } \\
\text { Ladário, MS }\end{array}$ & Cloudina Iucianoi \\
\hline
\end{tabular}




\begin{tabular}{|c|c|c|c|}
\hline GP/L1E-49 & $\begin{array}{c}\text { Formação } \\
\text { Tamengo, Grupo } \\
\text { Corumbá }\end{array}$ & $\begin{array}{c}\text { Pedreira } \\
\text { Saladeiro, } \\
\text { Ladário, MS }\end{array}$ & Cloudina Iucianoi \\
\hline GP/L1E-50 & $\begin{array}{c}\text { Formação } \\
\text { Tamengo, Grupo } \\
\text { Corumbá }\end{array}$ & $\begin{array}{c}\text { Pedreira } \\
\text { Saladeiro, } \\
\text { Ladário, MS }\end{array}$ & Cloudina Iucianoi \\
\hline GP/L1E-51 & $\begin{array}{c}\text { Formação } \\
\text { Tamengo, Grupo } \\
\text { Corumbá }\end{array}$ & $\begin{array}{c}\text { Pedreira } \\
\text { Saladeiro, } \\
\text { Ladário, MS }\end{array}$ & Cloudina lucianoi \\
\hline GP/L1E-52 & $\begin{array}{c}\text { Formação } \\
\text { Tamengo, Grupo } \\
\text { Corumbá }\end{array}$ & $\begin{array}{c}\text { Pedreira } \\
\text { Saladeiro, } \\
\text { Ladário, MS }\end{array}$ & Cloudina Iucianoi \\
\hline GP/L1E-53 & $\begin{array}{c}\text { Formação } \\
\text { Tamengo, Grupo } \\
\text { Corumbá }\end{array}$ & $\begin{array}{c}\text { Pedreira } \\
\text { Saladeiro, } \\
\text { Ladário, MS }\end{array}$ & Cloudina Iucianoi \\
\hline GP/L1E-54 & $\begin{array}{c}\text { Formação } \\
\text { Tamengo, Grupo } \\
\text { Corumbá }\end{array}$ & $\begin{array}{c}\text { Pedreira } \\
\text { Saladeiro, } \\
\text { Ladário, MS }\end{array}$ & Cloudina Iucianoi \\
\hline GP/L1E-57 & $\begin{array}{c}\text { Formação } \\
\text { Tamengo, Grupo } \\
\text { Corumbá }\end{array}$ & $\begin{array}{c}\text { Pedreira } \\
\text { Saladeiro, } \\
\text { Ladário, MS }\end{array}$ & Cloudina Iucianoi \\
\hline GP/L1E-58 & $\begin{array}{c}\text { Formação } \\
\text { Tamengo, Grupo } \\
\text { Corumbá }\end{array}$ & $\begin{array}{c}\text { Pedreira } \\
\text { Saladeiro, } \\
\text { Ladário, MS }\end{array}$ & Cloudina Iucianoi \\
\hline GP/L1E-59 & $\begin{array}{c}\text { Formação } \\
\text { Tamengo, Grupo } \\
\text { Corumbá }\end{array}$ & $\begin{array}{c}\text { Pedreira } \\
\text { Saladeiro, } \\
\text { Ladário, MS }\end{array}$ & Cloudina Iucianoi \\
\hline GP/L1E-60 & $\begin{array}{c}\text { Formação } \\
\text { Tamengo, Grupo } \\
\text { Corumbá }\end{array}$ & $\begin{array}{c}\text { Pedreira } \\
\text { Saladeiro, } \\
\text { Ladário, MS }\end{array}$ & Cloudina Iucianoi \\
\hline GP/L1E-61 & $\begin{array}{c}\text { Formação } \\
\text { Tamengo, Grupo } \\
\text { Corumbá }\end{array}$ & $\begin{array}{c}\text { Pedreira } \\
\text { Saladeiro, } \\
\text { Ladário, MS }\end{array}$ & Cloudina Iucianoi \\
\hline GP/L1E-62 & $\begin{array}{c}\text { Formação } \\
\text { Tamengo, Grupo } \\
\text { Corumbá }\end{array}$ & $\begin{array}{c}\text { Pedreira } \\
\text { Saladeiro, } \\
\text { Ladário, MS }\end{array}$ & Cloudina Iucianoi \\
\hline GP/L1E-63 & $\begin{array}{c}\text { Formação } \\
\text { Tamengo, Grupo }\end{array}$ & $\begin{array}{l}\text { Pedreira } \\
\text { Saladeiro, }\end{array}$ & Cloudina Iucianoi \\
\hline
\end{tabular}




\begin{tabular}{|c|c|c|c|}
\hline & Corumbá & Ladário, MS & \\
\hline GP/L1E-64 & $\begin{array}{c}\text { Formação } \\
\text { Tamengo, Grupo } \\
\text { Corumbá }\end{array}$ & $\begin{array}{c}\text { Pedreira } \\
\text { Saladeiro, } \\
\text { Ladário, MS }\end{array}$ & Cloudina Iucianoi \\
\hline GP/L1E-65 & $\begin{array}{c}\text { Formação } \\
\text { Tamengo, Grupo } \\
\text { Corumbá }\end{array}$ & $\begin{array}{c}\text { Pedreira } \\
\text { Saladeiro, } \\
\text { Ladário, MS }\end{array}$ & Cloudina Iucianoi \\
\hline GP/L1E-66 & $\begin{array}{c}\text { Formação } \\
\text { Tamengo, Grupo } \\
\text { Corumbá }\end{array}$ & $\begin{array}{c}\text { Pedreira } \\
\text { Saladeiro, } \\
\text { Ladário, MS }\end{array}$ & Cloudina Iucianoi \\
\hline GP/L1E-67 & $\begin{array}{c}\text { Formação } \\
\text { Tamengo, Grupo } \\
\text { Corumbá }\end{array}$ & $\begin{array}{c}\text { Pedreira } \\
\text { Saladeiro, } \\
\text { Ladário, MS }\end{array}$ & Cloudina lucianoi \\
\hline GP/L1E-68 & $\begin{array}{c}\text { Formação } \\
\text { Tamengo, Grupo } \\
\text { Corumbá }\end{array}$ & $\begin{array}{c}\text { Pedreira } \\
\text { Saladeiro, } \\
\text { Ladário, MS }\end{array}$ & Cloudina Iucianoi \\
\hline GP/L1E-69 & $\begin{array}{c}\text { Formação } \\
\text { Tamengo, Grupo } \\
\text { Corumbá }\end{array}$ & $\begin{array}{c}\text { Pedreira } \\
\text { Saladeiro, } \\
\text { Ladário, MS }\end{array}$ & Cloudina lucianoi \\
\hline GP/L1E-70 & $\begin{array}{c}\text { Formação } \\
\text { Tamengo, Grupo } \\
\text { Corumbá }\end{array}$ & $\begin{array}{c}\text { Pedreira } \\
\text { Saladeiro, } \\
\text { Ladário, MS }\end{array}$ & Cloudina lucianoi \\
\hline GP/L1E-71 & $\begin{array}{c}\text { Formação } \\
\text { Tamengo, Grupo } \\
\text { Corumbá }\end{array}$ & $\begin{array}{c}\text { Pedreira } \\
\text { Saladeiro, } \\
\text { Ladário, MS }\end{array}$ & Cloudina lucianoi \\
\hline GP/L1E-72 & $\begin{array}{c}\text { Formação } \\
\text { Tamengo, Grupo } \\
\text { Corumbá }\end{array}$ & $\begin{array}{c}\text { Pedreira } \\
\text { Saladeiro, } \\
\text { Ladário, MS }\end{array}$ & Cloudina Iucianoi \\
\hline GP/L1E-102 & $\begin{array}{c}\text { Formação } \\
\text { Tamengo, Grupo } \\
\text { Corumbá }\end{array}$ & $\begin{array}{c}\text { Pedreira } \\
\text { Saladeiro, } \\
\text { Ladário, MS }\end{array}$ & Cloudina lucianoi \\
\hline GP/L1E-123 & $\begin{array}{c}\text { Formação } \\
\text { Tamengo, Grupo } \\
\text { Corumbá }\end{array}$ & $\begin{array}{c}\text { Pedreira } \\
\text { Saladeiro, } \\
\text { Ladário, MS }\end{array}$ & Cloudina lucianoi \\
\hline GP/L1E-124 & $\begin{array}{c}\text { Formação } \\
\text { Tamengo, Grupo } \\
\text { Corumbá }\end{array}$ & $\begin{array}{c}\text { Pedreira } \\
\text { Saladeiro, } \\
\text { Ladário, MS }\end{array}$ & Cloudina lucianoi \\
\hline
\end{tabular}




\begin{tabular}{|c|c|c|c|}
\hline GP/L1E-125 & $\begin{array}{c}\text { Formação } \\
\text { Tamengo, Grupo } \\
\text { Corumbá }\end{array}$ & $\begin{array}{l}\text { Pedreira } \\
\text { Saladeiro, } \\
\text { Ladário, MS }\end{array}$ & Cloudina lucianoi \\
\hline GP/L1E-126 & $\begin{array}{c}\text { Formação } \\
\text { Tamengo, Grupo } \\
\text { Corumbá }\end{array}$ & $\begin{array}{c}\text { Pedreira } \\
\text { Saladeiro, } \\
\text { Ladário, MS }\end{array}$ & Cloudina lucianoi \\
\hline GP/L1E-122 & $\begin{array}{c}\text { Formação } \\
\text { Tamengo, Grupo } \\
\text { Corumbá }\end{array}$ & $\begin{array}{l}\text { Pedreira } \\
\text { Saladeiro, } \\
\text { Ladário, MS }\end{array}$ & Cloudina lucianoi \\
\hline GP/L1E-12 & $\begin{array}{c}\text { Formação } \\
\text { Tamengo, Grupo } \\
\text { Corumbá }\end{array}$ & $\begin{array}{c}\text { Pedreira } \\
\text { Corcal, } \\
\text { Corumbá, MS }\end{array}$ & Cloudina lucianoi \\
\hline GP/L1E-13 & $\begin{array}{c}\text { Formação } \\
\text { Tamengo, Grupo } \\
\text { Corumbá }\end{array}$ & $\begin{array}{c}\text { Pedreira } \\
\text { Corcal, } \\
\text { Corumbá, MS }\end{array}$ & Cloudina lucianoi \\
\hline GP/L1E-14 & $\begin{array}{c}\text { Formação } \\
\text { Tamengo, Grupo } \\
\text { Corumbá }\end{array}$ & $\begin{array}{c}\text { Pedreira } \\
\text { Corcal, } \\
\text { Corumbá, MS }\end{array}$ & Cloudina lucianoi \\
\hline GP/L1E-15 & $\begin{array}{c}\text { Formação } \\
\text { Tamengo, Grupo } \\
\text { Corumbá }\end{array}$ & $\begin{array}{c}\text { Pedreira } \\
\text { Corcal, } \\
\text { Corumbá, MS }\end{array}$ & Cloudina Iucianoi \\
\hline GP/L1E-16 & $\begin{array}{c}\text { Formação } \\
\text { Tamengo, Grupo } \\
\text { Corumbá }\end{array}$ & $\begin{array}{c}\text { Pedreira } \\
\text { Corcal, } \\
\text { Corumbá, MS }\end{array}$ & Cloudina lucianoi \\
\hline GP/L1E-17 & $\begin{array}{c}\text { Formação } \\
\text { Tamengo, Grupo } \\
\text { Corumbá }\end{array}$ & $\begin{array}{c}\text { Pedreira } \\
\text { Corcal, } \\
\text { Corumbá, MS }\end{array}$ & Cloudina Iucianoi \\
\hline GP/L1E-18 & $\begin{array}{c}\text { Formação } \\
\text { Tamengo, Grupo } \\
\text { Corumbá }\end{array}$ & $\begin{array}{c}\text { Pedreira } \\
\text { Corcal, } \\
\text { Corumbá, MS }\end{array}$ & Cloudina lucianoi \\
\hline GP/L1E-19 & $\begin{array}{c}\text { Formação } \\
\text { Tamengo, Grupo } \\
\text { Corumbá }\end{array}$ & $\begin{array}{c}\text { Pedreira } \\
\text { Corcal, } \\
\text { Corumbá, MS }\end{array}$ & Cloudina lucianoi \\
\hline GP/L1E-20 & $\begin{array}{c}\text { Formação } \\
\text { Tamengo, Grupo } \\
\text { Corumbá }\end{array}$ & $\begin{array}{c}\text { Pedreira } \\
\text { Corcal, } \\
\text { Corumbá, MS }\end{array}$ & Cloudina lucianoi \\
\hline GP/L1E-73 & $\begin{array}{c}\text { Formação } \\
\text { Tamengo, Grupo }\end{array}$ & $\begin{array}{l}\text { Pedreira } \\
\text { Corcal, }\end{array}$ & Cloudina lucianoi \\
\hline
\end{tabular}




\begin{tabular}{|c|c|c|c|}
\hline & Corumbá & Corumbá, MS & \\
\hline GP/L1E-74 & $\begin{array}{c}\text { Formação } \\
\text { Tamengo, Grupo } \\
\text { Corumbá }\end{array}$ & $\begin{array}{c}\text { Pedreira } \\
\text { Corcal, } \\
\text { Corumbá, MS }\end{array}$ & Cloudina Iucianoi \\
\hline GP/L1E-75 & $\begin{array}{c}\text { Formação } \\
\text { Tamengo, Grupo } \\
\text { Corumbá }\end{array}$ & $\begin{array}{c}\text { Pedreira } \\
\text { Corcal, } \\
\text { Corumbá, MS }\end{array}$ & Cloudina Iucianoi \\
\hline GP/L1E-76 & $\begin{array}{c}\text { Formação } \\
\text { Tamengo, Grupo } \\
\text { Corumbá }\end{array}$ & $\begin{array}{c}\text { Pedreira } \\
\text { Corcal, } \\
\text { Corumbá, MS }\end{array}$ & Cloudina Iucianoi \\
\hline GP/L1E-77 & $\begin{array}{c}\text { Formação } \\
\text { Tamengo, Grupo } \\
\text { Corumbá }\end{array}$ & $\begin{array}{c}\text { Pedreira } \\
\text { Corcal, } \\
\text { Corumbá, MS }\end{array}$ & Cloudina lucianoi \\
\hline GP/L1E-78 & $\begin{array}{c}\text { Formação } \\
\text { Tamengo, Grupo } \\
\text { Corumbá }\end{array}$ & $\begin{array}{c}\text { Pedreira } \\
\text { Corcal, } \\
\text { Corumbá, MS }\end{array}$ & Cloudina Iucianoi \\
\hline GP/L1E-79 & $\begin{array}{c}\text { Formação } \\
\text { Tamengo, Grupo } \\
\text { Corumbá }\end{array}$ & $\begin{array}{c}\text { Pedreira } \\
\text { Corcal, } \\
\text { Corumbá, MS }\end{array}$ & Cloudina lucianoi \\
\hline GP/L1E-80 & $\begin{array}{c}\text { Formação } \\
\text { Tamengo, Grupo } \\
\text { Corumbá }\end{array}$ & $\begin{array}{c}\text { Pedreira } \\
\text { Corcal, } \\
\text { Corumbá, MS }\end{array}$ & Cloudina Iucianoi \\
\hline GP/L1E-81 & $\begin{array}{c}\text { Formação } \\
\text { Tamengo, Grupo } \\
\text { Corumbá }\end{array}$ & $\begin{array}{c}\text { Pedreira } \\
\text { Corcal, } \\
\text { Corumbá, MS }\end{array}$ & Cloudina lucianoi \\
\hline GP/L1E-82 & $\begin{array}{c}\text { Formação } \\
\text { Tamengo, Grupo } \\
\text { Corumbá }\end{array}$ & $\begin{array}{c}\text { Pedreira } \\
\text { Corcal, } \\
\text { Corumbá, MS }\end{array}$ & Cloudina lucianoi \\
\hline GP/L1E-83 & $\begin{array}{c}\text { Formação } \\
\text { Tamengo, Grupo } \\
\text { Corumbá }\end{array}$ & $\begin{array}{c}\text { Pedreira } \\
\text { Corcal, } \\
\text { Corumbá, MS }\end{array}$ & Cloudina lucianoi \\
\hline GP/L1E-84 & $\begin{array}{c}\text { Formação } \\
\text { Tamengo, Grupo } \\
\text { Corumbá }\end{array}$ & $\begin{array}{c}\text { Pedreira } \\
\text { Corcal, } \\
\text { Corumbá, MS }\end{array}$ & Cloudina lucianoi \\
\hline GP/L1E-85 & $\begin{array}{c}\text { Formação } \\
\text { Guaicurus, Grupo } \\
\text { Corumbá }\end{array}$ & $\begin{array}{c}\text { Pedreira } \\
\text { Corcal, } \\
\text { Corumbá, MS }\end{array}$ & Cloudina lucianoi \\
\hline
\end{tabular}




\begin{tabular}{|c|c|c|c|}
\hline GP/L1E-86 & $\begin{array}{c}\text { Formação } \\
\text { Tamengo, Grupo } \\
\text { Corumbá }\end{array}$ & $\begin{array}{c}\text { Pedreira } \\
\text { Corcal, } \\
\text { Corumbá, MS }\end{array}$ & Cloudina Iucianoi \\
\hline GP/L1E-87 & $\begin{array}{c}\text { Formação } \\
\text { Tamengo, Grupo } \\
\text { Corumbá }\end{array}$ & $\begin{array}{c}\text { Pedreira } \\
\text { Corcal, } \\
\text { Corumbá, MS }\end{array}$ & Cloudina lucianoi \\
\hline GP/L1E-4 & $\begin{array}{c}\text { Formação } \\
\text { Tamengo, Grupo } \\
\text { Corumbá }\end{array}$ & $\begin{array}{c}\text { Pedreira } \\
\text { Corcal, } \\
\text { Corumbá, MS }\end{array}$ & Cloudina lucianoi \\
\hline GP/L1E-10 & $\begin{array}{c}\text { Formação } \\
\text { Tamengo, Grupo } \\
\text { Corumbá }\end{array}$ & $\begin{array}{c}\text { Pedreira } \\
\text { Corcal, } \\
\text { Corumbá, MS }\end{array}$ & Cloudina lucianoi \\
\hline GP/L1E-11 & $\begin{array}{c}\text { Formação } \\
\text { Tamengo, Grupo } \\
\text { Corumbá }\end{array}$ & $\begin{array}{c}\text { Pedreira } \\
\text { Corcal, } \\
\text { Corumbá, MS }\end{array}$ & Cloudina Iucianoi \\
\hline GP/L1E-56 & $\begin{array}{c}\text { Formação } \\
\text { Tamengo, Grupo } \\
\text { Corumbá }\end{array}$ & $\begin{array}{c}\text { Pedreira } \\
\text { Corcal, } \\
\text { Corumbá, MS }\end{array}$ & Cloudina Iucianoi \\
\hline GP/L1E-103 & $\begin{array}{c}\text { Formação } \\
\text { Tamengo, Grupo } \\
\text { Corumbá }\end{array}$ & $\begin{array}{c}\text { Pedreira } \\
\text { Corcal, } \\
\text { Corumbá, MS }\end{array}$ & Cloudina Iucianoi \\
\hline GP/L1E-104 & $\begin{array}{c}\text { Formação } \\
\text { Tamengo, Grupo } \\
\text { Corumbá }\end{array}$ & $\begin{array}{c}\text { Pedreira } \\
\text { Corcal, } \\
\text { Corumbá, MS }\end{array}$ & Cloudina lucianoi \\
\hline GP/L1E-105 & $\begin{array}{c}\text { Formação } \\
\text { Tamengo, Grupo } \\
\text { Corumbá }\end{array}$ & $\begin{array}{c}\text { Pedreira } \\
\text { Corcal, } \\
\text { Corumbá, MS }\end{array}$ & Cloudina lucianoi \\
\hline GP/L1E-5 & $\begin{array}{c}\text { Formação } \\
\text { Tamengo, Grupo } \\
\text { Corumbá }\end{array}$ & $\begin{array}{c}\text { Pedreira } \\
\text { Laginha, } \\
\text { Corumbá, MS }\end{array}$ & Cloudina lucianoi \\
\hline GP/L1E-6 & $\begin{array}{c}\text { Formação } \\
\text { Tamengo, Grupo } \\
\text { Corumbá }\end{array}$ & $\begin{array}{c}\text { Pedreira } \\
\text { Laginha, } \\
\text { Corumbá, MS }\end{array}$ & Cloudina lucianoi \\
\hline GP/L1E-7 & $\begin{array}{c}\text { Formação } \\
\text { Tamengo, Grupo } \\
\text { Corumbá }\end{array}$ & $\begin{array}{c}\text { Pedreira } \\
\text { Laginha, } \\
\text { Corumbá, MS }\end{array}$ & Cloudina lucianoi \\
\hline GP/L1E-8 & $\begin{array}{c}\text { Formação } \\
\text { Tamengo, Grupo }\end{array}$ & $\begin{array}{l}\text { Pedreira } \\
\text { Laginha, }\end{array}$ & Cloudina lucianoi \\
\hline
\end{tabular}




\begin{tabular}{|c|c|c|c|}
\hline & Corumbá & Corumbá, MS & \\
\hline GP/L1E-9 & $\begin{array}{c}\text { Formação } \\
\text { Tamengo, Grupo } \\
\text { Corumbá }\end{array}$ & $\begin{array}{c}\text { Pedreira } \\
\text { Laginha, } \\
\text { Corumbá, MS }\end{array}$ & Cloudina lucianoi \\
\hline GP/L1E-88 & $\begin{array}{c}\text { Formação } \\
\text { Tamengo, Grupo } \\
\text { Corumbá }\end{array}$ & $\begin{array}{c}\text { Pedreira } \\
\text { Laginha, } \\
\text { Corumbá, MS }\end{array}$ & Cloudina lucianoi \\
\hline GP/L1E-89 & $\begin{array}{c}\text { Formação } \\
\text { Tamengo, Grupo } \\
\text { Corumbá }\end{array}$ & $\begin{array}{c}\text { Pedreira } \\
\text { Laginha, } \\
\text { Corumbá, MS }\end{array}$ & Cloudina lucianoi \\
\hline GP/L1E-90 & $\begin{array}{c}\text { Formação } \\
\text { Tamengo, Grupo } \\
\text { Corumbá }\end{array}$ & $\begin{array}{c}\text { Pedreira } \\
\text { Laginha, } \\
\text { Corumbá, MS }\end{array}$ & Cloudina lucianoi \\
\hline GP/L1E-91 & $\begin{array}{c}\text { Formação } \\
\text { Tamengo, Grupo } \\
\text { Corumbá }\end{array}$ & $\begin{array}{c}\text { Pedreira } \\
\text { Laginha, } \\
\text { Corumbá, MS }\end{array}$ & Cloudina lucianoi \\
\hline GP/L1E-92 & $\begin{array}{c}\text { Formação } \\
\text { Tamengo, Grupo } \\
\text { Corumbá }\end{array}$ & $\begin{array}{c}\text { Pedreira } \\
\text { Laginha, } \\
\text { Corumbá, MS }\end{array}$ & Cloudina lucianoi \\
\hline GP/L1E-93 & $\begin{array}{c}\text { Formação } \\
\text { Tamengo, Grupo } \\
\text { Corumbá }\end{array}$ & $\begin{array}{c}\text { Pedreira } \\
\text { Laginha, } \\
\text { Corumbá, MS }\end{array}$ & Cloudina Iucianoi \\
\hline GP/L1E-94 & $\begin{array}{c}\text { Formação } \\
\text { Tamengo, Grupo } \\
\text { Corumbá }\end{array}$ & $\begin{array}{c}\text { Pedreira } \\
\text { Laginha, } \\
\text { Corumbá, MS }\end{array}$ & Cloudina lucianoi \\
\hline GP/L1E-95 & $\begin{array}{c}\text { Formação } \\
\text { Tamengo, Grupo } \\
\text { Corumbá }\end{array}$ & $\begin{array}{c}\text { Pedreira } \\
\text { Laginha, } \\
\text { Corumbá, MS }\end{array}$ & Cloudina lucianoi \\
\hline GP/L1E-96 & $\begin{array}{c}\text { Formação } \\
\text { Tamengo, Grupo } \\
\text { Corumbá }\end{array}$ & $\begin{array}{c}\text { Pedreira } \\
\text { Laginha, } \\
\text { Corumbá, MS }\end{array}$ & Cloudina lucianoi \\
\hline GP/L1E-97 & $\begin{array}{c}\text { Formação } \\
\text { Tamengo, Grupo } \\
\text { Corumbá }\end{array}$ & $\begin{array}{c}\text { Pedreira } \\
\text { Laginha, } \\
\text { Corumbá, MS }\end{array}$ & Cloudina lucianoi \\
\hline GP/L1E-98 & $\begin{array}{c}\text { Formação } \\
\text { Tamengo, Grupo } \\
\text { Corumbá }\end{array}$ & $\begin{array}{c}\text { Pedreira } \\
\text { Laginha, } \\
\text { Corumbá, MS }\end{array}$ & Cloudina lucianoi \\
\hline
\end{tabular}




\begin{tabular}{|c|c|c|c|}
\hline GP/L1E-99 & $\begin{array}{c}\text { Formação } \\
\text { Tamengo, Grupo } \\
\text { Corumbá }\end{array}$ & $\begin{array}{c}\text { Pedreira } \\
\text { Laginha, } \\
\text { Corumbá, MS }\end{array}$ & Cloudina Iucianoi \\
\hline GP/L1E-100 & $\begin{array}{c}\text { Formação } \\
\text { Tamengo, Grupo } \\
\text { Corumbá }\end{array}$ & $\begin{array}{c}\text { Pedreira } \\
\text { Laginha, } \\
\text { Corumbá, MS }\end{array}$ & Cloudina Iucianoi \\
\hline GP/L1E-101 & $\begin{array}{c}\text { Formação } \\
\text { Tamengo, Grupo } \\
\text { Corumbá }\end{array}$ & $\begin{array}{c}\text { Pedreira } \\
\text { Laginha, } \\
\text { Corumbá, MS }\end{array}$ & Cloudina lucianoi \\
\hline GP/L1E-106 & $\begin{array}{c}\text { Formação } \\
\text { Tamengo, Grupo } \\
\text { Corumbá }\end{array}$ & $\begin{array}{c}\text { Pedreira } \\
\text { Laginha, } \\
\text { Corumbá, MS }\end{array}$ & Cloudina lucianoi \\
\hline GP/L1E-107 & $\begin{array}{c}\text { Formação } \\
\text { Tamengo, Grupo } \\
\text { Corumbá }\end{array}$ & $\begin{array}{c}\text { Pedreira } \\
\text { Laginha, } \\
\text { Corumbá, MS }\end{array}$ & Cloudina Iucianoi \\
\hline GP/L1E-120 & $\begin{array}{c}\text { Formação } \\
\text { Tamengo, Grupo } \\
\text { Corumbá }\end{array}$ & $\begin{array}{c}\text { Pedreira } \\
\text { Laginha, } \\
\text { Corumbá, MS }\end{array}$ & Cloudina lucianoi \\
\hline GP/L1E-121 & $\begin{array}{c}\text { Formação } \\
\text { Tamengo, Grupo } \\
\text { Corumbá }\end{array}$ & $\begin{array}{c}\text { Pedreira } \\
\text { Laginha, } \\
\text { Corumbá, MS }\end{array}$ & Cloudina Iucianoi \\
\hline GP/L1E-116 & $\begin{array}{c}\text { Formação } \\
\text { Tamengo, Grupo } \\
\text { Corumbá }\end{array}$ & $\begin{array}{c}\text { Pedreira } \\
\text { Laginha, } \\
\text { Corumbá, MS }\end{array}$ & Cloudina Iucianoi \\
\hline GP/L1E-117 & $\begin{array}{c}\text { Formação } \\
\text { Tamengo, Grupo } \\
\text { Corumbá }\end{array}$ & $\begin{array}{c}\text { Pedreira } \\
\text { Laginha, } \\
\text { Corumbá, MS }\end{array}$ & Cloudina lucianoi \\
\hline GP/L1E-108 & $\begin{array}{c}\text { Formação } \\
\text { Tamengo, Grupo } \\
\text { Corumbá }\end{array}$ & $\begin{array}{c}\text { Pedreira } \\
\text { Laginha, } \\
\text { Corumbá, MS }\end{array}$ & Cloudina lucianoi \\
\hline GP/L1E-109 & $\begin{array}{c}\text { Formação } \\
\text { Tamengo, Grupo } \\
\text { Corumbá }\end{array}$ & $\begin{array}{c}\text { Pedreira } \\
\text { Laginha, } \\
\text { Corumbá, MS }\end{array}$ & Cloudina lucianoi \\
\hline GP/L1E-110 & $\begin{array}{c}\text { Formação } \\
\text { Tamengo, Grupo } \\
\text { Corumbá }\end{array}$ & $\begin{array}{c}\text { Pedreira } \\
\text { Laginha, } \\
\text { Corumbá, MS }\end{array}$ & Cloudina lucianoi \\
\hline GP/L1E-111 & $\begin{array}{c}\text { Formação } \\
\text { Tamengo, Grupo }\end{array}$ & $\begin{array}{l}\text { Pedreira } \\
\text { Laginha, }\end{array}$ & Cloudina lucianoi \\
\hline
\end{tabular}




\begin{tabular}{|c|c|c|c|}
\hline & Corumbá & Corumbá, MS & \\
\hline GP/L1E-112 & $\begin{array}{c}\text { Formação } \\
\text { Tamengo, Grupo } \\
\text { Corumbá }\end{array}$ & $\begin{array}{c}\text { Pedreira } \\
\text { Laginha, } \\
\text { Corumbá, MS }\end{array}$ & Cloudina Iucianoi \\
\hline GP/L1E-113 & $\begin{array}{c}\text { Formação } \\
\text { Tamengo, Grupo } \\
\text { Corumbá }\end{array}$ & $\begin{array}{c}\text { Pedreira } \\
\text { Laginha, } \\
\text { Corumbá, MS }\end{array}$ & Cloudina Iucianoi \\
\hline GP/L1E-114 & $\begin{array}{c}\text { Formação } \\
\text { Tamengo, Grupo } \\
\text { Corumbá }\end{array}$ & $\begin{array}{c}\text { Pedreira } \\
\text { Laginha, } \\
\text { Corumbá, MS }\end{array}$ & Cloudina Iucianoi \\
\hline GP/L1E-115 & $\begin{array}{c}\text { Formação } \\
\text { Tamengo, Grupo } \\
\text { Corumbá }\end{array}$ & $\begin{array}{c}\text { Pedreira } \\
\text { Laginha, } \\
\text { Corumbá, MS }\end{array}$ & Cloudina lucianoi \\
\hline GP/L1E-118 & $\begin{array}{c}\text { Formação } \\
\text { Tamengo, Grupo } \\
\text { Corumbá }\end{array}$ & $\begin{array}{c}\text { Pedreira } \\
\text { Laginha, } \\
\text { Corumbá, MS }\end{array}$ & Cloudina Iucianoi \\
\hline GP/L1E-119 & $\begin{array}{c}\text { Formação } \\
\text { Tamengo, Grupo } \\
\text { Corumbá }\end{array}$ & $\begin{array}{c}\text { Pedreira } \\
\text { Laginha, } \\
\text { Corumbá, MS }\end{array}$ & Cloudina Iucianoi \\
\hline GP/L1E-25 & $\begin{array}{c}\text { Formação } \\
\text { Tamengo, Grupo } \\
\text { Corumbá }\end{array}$ & $\begin{array}{c}\text { Pedreira } \\
\text { Laginha, } \\
\text { Corumbá, MS }\end{array}$ & Cloudina Iucianoi \\
\hline GP/L1E-26 & $\begin{array}{c}\text { Formação } \\
\text { Tamengo, Grupo } \\
\text { Corumbá }\end{array}$ & $\begin{array}{c}\text { Pedreira } \\
\text { Laginha, } \\
\text { Corumbá, MS }\end{array}$ & Cloudina lucianoi \\
\hline GP/L1E-27 & $\begin{array}{c}\text { Formação } \\
\text { Tamengo, Grupo } \\
\text { Corumbá }\end{array}$ & $\begin{array}{c}\text { Pedreira } \\
\text { Laginha, } \\
\text { Corumbá, MS }\end{array}$ & Cloudina Iucianoi \\
\hline GP/L1E-28 & $\begin{array}{c}\text { Formação } \\
\text { Tamengo, Grupo } \\
\text { Corumbá }\end{array}$ & $\begin{array}{c}\text { Pedreira } \\
\text { Laginha, } \\
\text { Corumbá, MS }\end{array}$ & Cloudina lucianoi \\
\hline GP/L1E-29 & $\begin{array}{c}\text { Formação } \\
\text { Tamengo, Grupo } \\
\text { Corumbá }\end{array}$ & $\begin{array}{c}\text { Pedreira } \\
\text { Laginha, } \\
\text { Corumbá, MS }\end{array}$ & Cloudina lucianoi \\
\hline GP/L1E-30 & $\begin{array}{c}\text { Formação } \\
\text { Tamengo, Grupo } \\
\text { Corumbá }\end{array}$ & $\begin{array}{c}\text { Pedreira } \\
\text { Laginha, } \\
\text { Corumbá, MS }\end{array}$ & Cloudina Iucianoi \\
\hline
\end{tabular}




\begin{tabular}{|c|c|c|c|}
\hline GP/L1E-31 & $\begin{array}{c}\text { Formação } \\
\text { Tamengo, Grupo } \\
\text { Corumbá }\end{array}$ & $\begin{array}{c}\text { Pedreira } \\
\text { Laginha, } \\
\text { Corumbá, MS }\end{array}$ & Cloudina Iucianoi \\
\hline GP/L1E-32 & $\begin{array}{c}\text { Formação } \\
\text { Tamengo, Grupo } \\
\text { Corumbá }\end{array}$ & $\begin{array}{c}\text { Pedreira } \\
\text { Laginha, } \\
\text { Corumbá, MS }\end{array}$ & Cloudina lucianoi \\
\hline GP/L1E-42 & $\begin{array}{c}\text { Formação } \\
\text { Tamengo, Grupo } \\
\text { Corumbá }\end{array}$ & $\begin{array}{l}\text { Arredores do } \\
\text { Parque } \\
\text { Marina } \\
\text { Gattaz, } \\
\text { Corumbá, MS }\end{array}$ & $\begin{array}{c}\text { Cloudina } \\
\text { latilabrum nov. } \\
\text { sp. }\end{array}$ \\
\hline GP/L1E-43 & $\begin{array}{c}\text { Formação } \\
\text { Tamengo, Grupo } \\
\text { Corumbá }\end{array}$ & $\begin{array}{l}\text { Arredores do } \\
\text { Parque } \\
\text { Marina } \\
\text { Gattaz, } \\
\text { Corumbá, MS }\end{array}$ & $\begin{array}{c}\text { Cloudina } \\
\text { latilabrum nov. } \\
\text { sp. }\end{array}$ \\
\hline
\end{tabular}

